Portland State University

PDXScholar

Summer 7-23-2014

\title{
Beyond the McNair Program: A Comparative Study of McNair Scholars' Understandings of the Impacts of Program Participation on their Graduate School Experiences
}

Cristina Restad

Portland State University

Follow this and additional works at: https://pdxscholar.library.pdx.edu/open_access_etds

Part of the Education Commons, and the Sociology Commons Let us know how access to this document benefits you.

\section{Recommended Citation}

Restad, Cristina, "Beyond the McNair Program: A Comparative Study of McNair Scholars' Understandings of the Impacts of Program Participation on their Graduate School Experiences" (2014). Dissertations and Theses. Paper 1900.

https://doi.org/10.15760/etd.1899

This Thesis is brought to you for free and open access. It has been accepted for inclusion in Dissertations and Theses by an authorized administrator of PDXScholar. Please contact us if we can make this document more accessible: pdxscholar@pdx.edu. 
Beyond the McNair Program: A Comparative Study of McNair Scholars'

Understandings of the Impacts of Program Participation on their Graduate School

Experiences

by

Cristina Restad

A thesis submitted in partial fulfillment of the requirements for the degree of

Master of Science

in Sociology

Thesis Committee:

Peter Collier, Chair

David Morgan

Toeutu Faaleava

Portland State University 2014 
(C) 2014 Cristina Restad 


\begin{abstract}
The Ronald E. McNair Scholars Program is a U.S. Department of Education TRIO Program, funded at 152 institutions across the United States and Puerto Rico. In 2013, total funding reached over $\$ 35$ million—of which, Portland State University received approximately $\$ 211,000$ (US Department of Education, 2013). The program's goal is to introduce first-generation, low-income, under-represented group college students to effective strategies for succeeding in doctoral programs so they may become professors and create a more supportive environment for future non-traditional students. One way to explore program effectiveness beyond completion of the McNair Program is to ask the McNair Scholars themselves about program impact. This comparative interview study explores McNair graduates' understandings of issues they face in adjusting to graduate school and how participation in the McNair Program prepared them to address these issues. Typically, McNair program evaluations emphasize the collection and analysis of quantitative data - e.g. graduate school enrollment and degree attainment. However, little qualitative research has been conducted on graduate's perceptions of the impact of program participation on their graduate school experiences. This study, which uses Bourdieu's Theory of Social Reproduction, along with the sociology-based ideas of roleas-resource, role mastery, and expertise development, explores students' perceptions of the McNair Program's effectiveness in regards to helping them understand the "graduate student" role and use that role to succeed in graduate school and beyond.
\end{abstract}




\section{DEDICATION}

To my grandparents, Jean and George Yilek, who had faith in me no matter where I was headed. I cannot express how much it is because of your unwavering love and support

that I'm still here. Grandma, I wish you could have seen this. I love you both very much. 


\section{ACKNOWLEDGEMENTS}

There are so many people who have supported me; far too many to list here. My greatest thanks go to Dr. Pete Collier, who is the main reason this project ever made it off the ground and the only reason I ever considered attempting it. His dedication to students and willingness to help goes beyond anything I've ever witnessed and I owe him more than I could ever express or repay. "Love, Peace, and Soul!" In addition, I would like to thank Dr. David Morgan for his insights and encouragement, but especially for letting me blow off steam playing with wind-up toys. He is brilliant and the students at PSU are lucky to have him.

Thanks so much to the PSU McNair Program for allowing me to conduct this study and for always being available to me. Thank you to Director Faaleava, whose enthusiasm and dedication to an objective and thorough study I greatly respect and appreciate. Special thanks also to Associate Director, Dr. Jolina Kwong-Caputo, who demonstrated so much patience with all of my requests! I couldn't have done this without her support and assistance. Also, thanks to past and present McNair graduate assistants Jodi Swartfager, Kristy Hauver, Shilo George, Jenny Robe, and everyone who has worked in that office. They are doing wonderful work up there and I hope they know how much they're changing people's lives.

I must acknowledge the PSU Sociology Department. The faculty members here are so intelligent, thoughtful, and warm to their students. Thank you to Dr. Bob Liebman and Dr. Daniel Sullivan for their support and for encouraging me to step back and look at the project with fresh eyes. Thanks to Dr. Randy Blazak and Dr. Amy Lubitow for 
always having a few minutes to catch up with me. Thanks to Dr. Burdsall and Matt Town for way too many late night chats and all of their valuable advice. Thanks also to Bahar Jaberi and Kris Lucht-Adams, they keep this train running and they put a smile on my face on so many days when I really didn't want to! Thanks also to the members of the Sociology Club and the undergraduate students at PSU, who always reminded me why I love this work in the first place. Special thanks to Kyla Tompkins, Nathan Rochester, Emily Wiant, Chris Guy, and Jack Madson. Some of them thought I was motivating and advising them, but they were inspiring me every day!

I feel very lucky to know every member of my cohort here and a few other students as well. I truly believe that I would not have finished this without them and I hope they know that. Jeff Shelton has been the most amazing school-husband I could ever ask for. Dylan Waite never tired of hearing me talk about this project, or at least he didn't let it show! Thanks to James Foutch; sometimes it felt like it was he and I against the world-he is an awesome partner-in-crime. Bryan Zinschlag, who I really wish was my little brother, was a constant source of support and positivity. Thanks to Robin Clough and Sonja Taylor, who were never too busy to stop and chat—sometimes those chats were the only thing keeping me sane. Heidi Esbensen never let us go too long without letting our hair down and we all needed that so much. Christa Zinke is doing great things for students; I couldn't have asked for a better partner on the UNST project. Schaylee Esparza, Amanda Mercier, and Jen Loomis are so passionate and they are all doing amazing work; I want to thank each of them for always giving me their two cents and always listening to mine! 
I want to thank all of my friends and family, who just happen to be the greatest people in the world. I really appreciate Jeff DeMott, Joel Kaufmann, and Kendy Abrams, who each helped me to understand this project in a deeper way and to realize what it all meant. Thanks also to Jeremy Oliphant, Heather Williams, Julia Rhamey, Chrystal Fortugno, Diane Ziel, Harper Morgan-Werner, and Michael Munkvold, who always asked how things were going and often kept me from getting in my own way. 


\section{TABLE OF CONTENTS}

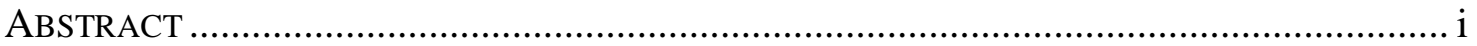

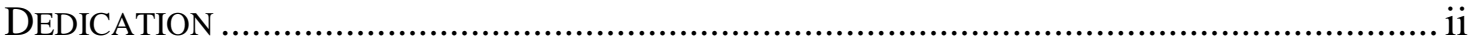

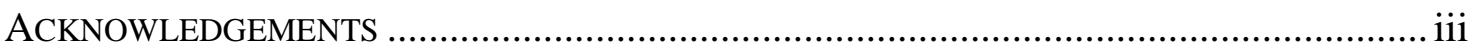

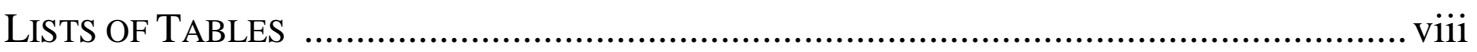

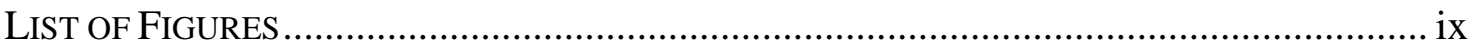

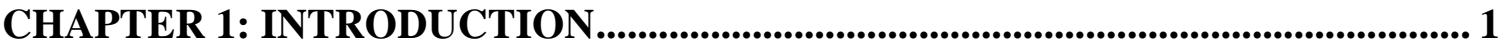

CHAPTER 2: LITERATURE REVIEW ..................................................................... 5

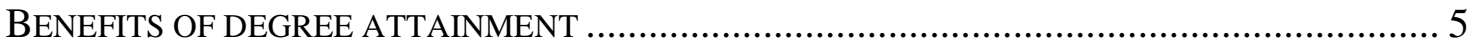

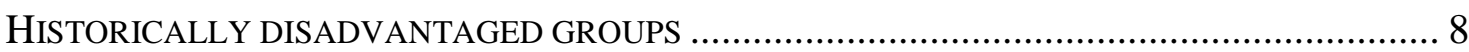

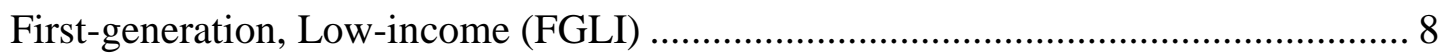

Underrepresented groups................................................................................... 10

First-generation, Low-income, Underrepresented group (FLU) ................................ 14

POTENTIAL INTERVENTIONS FOR FLU STUDENT SUCCESS .............................................. 14

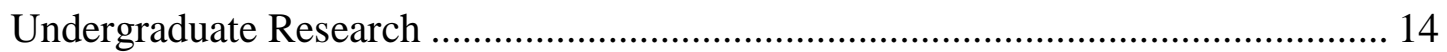

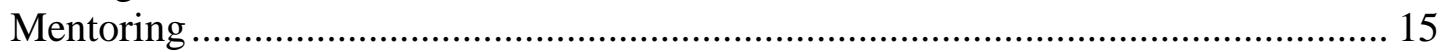

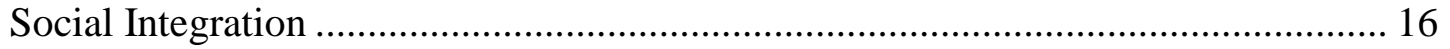

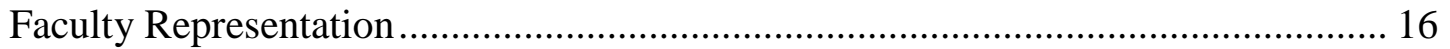

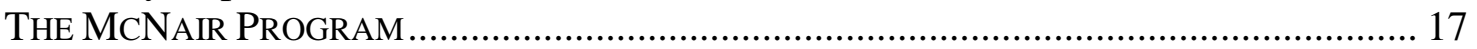

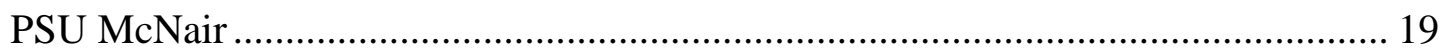

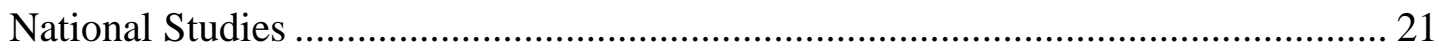

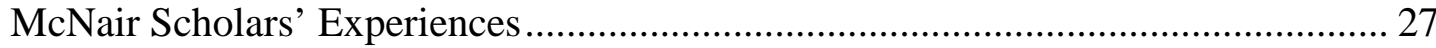

CHAPTER 3: THEORETICAL FRAMES ........................................................................ 31

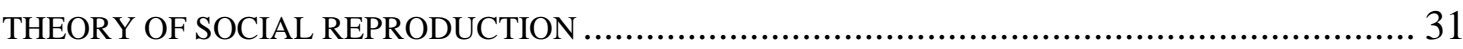

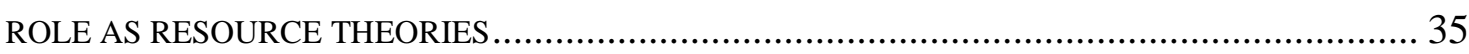

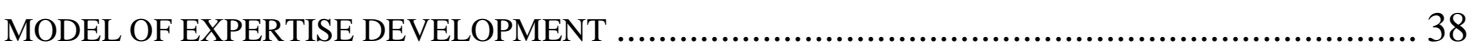

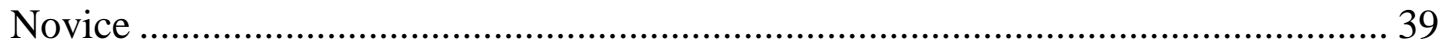

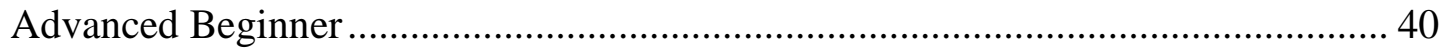

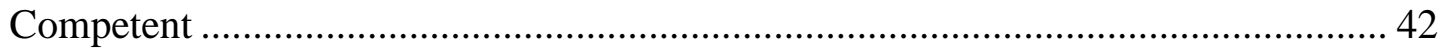

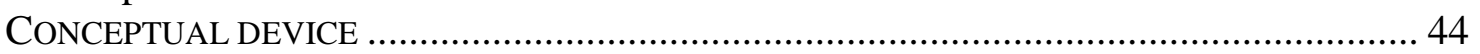

CHAPTER 4: METHODOLOGY .................................................................................. 49

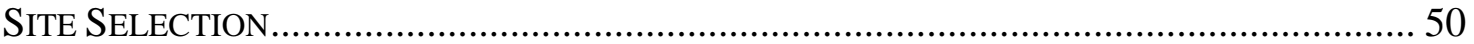

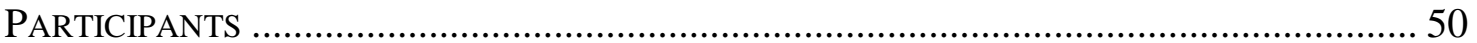

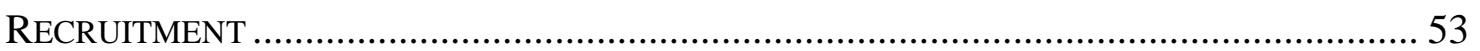

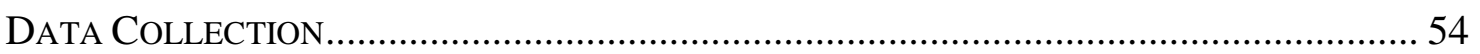

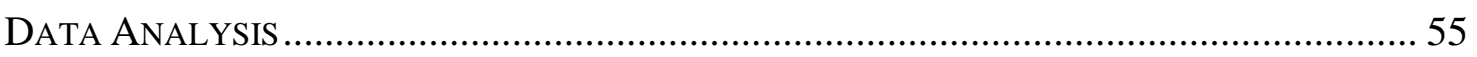

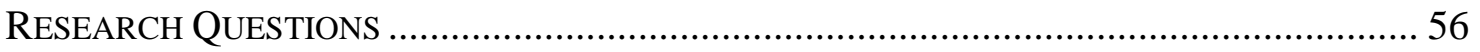

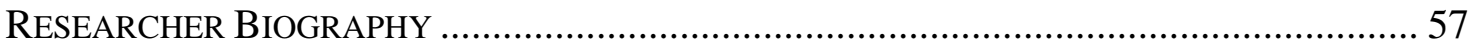

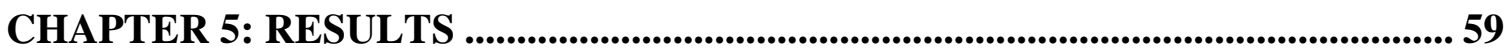

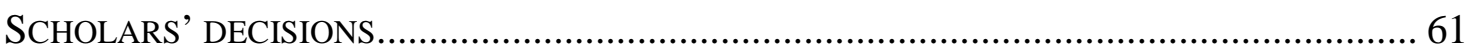




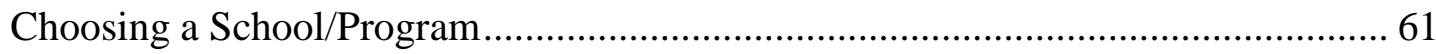

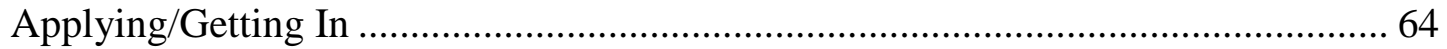

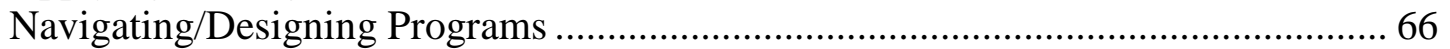

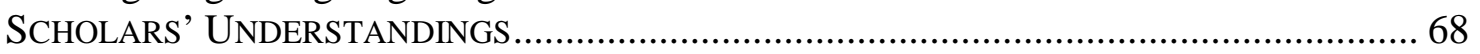

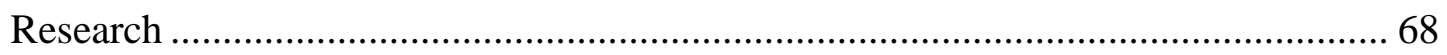

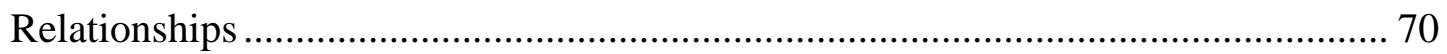

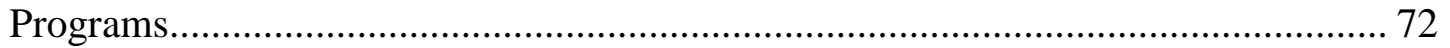

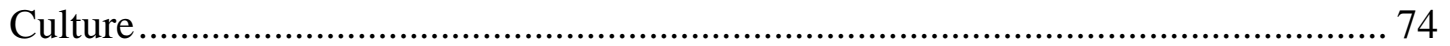

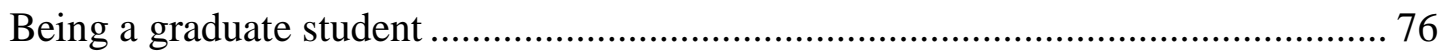

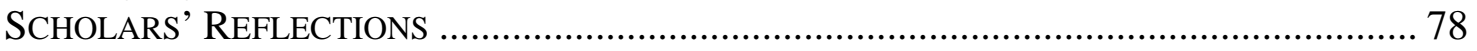

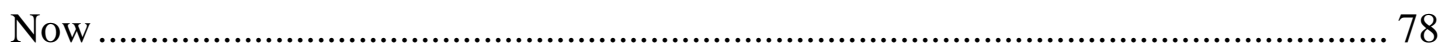

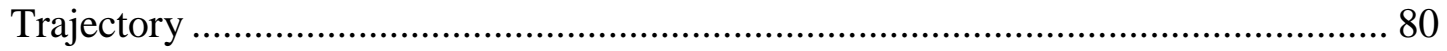

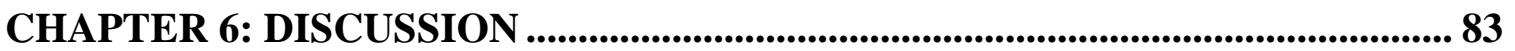

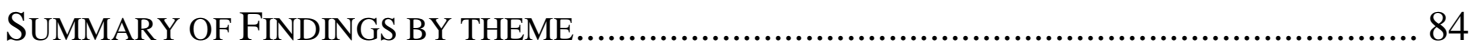

PART ONE: ROLE EXPERTISE AT DIFFERENT POINTS IN TIME ....................................... 89

PART TWO: SCHOLARS' INACCURATE EXPECTATIONS ................................................ 98

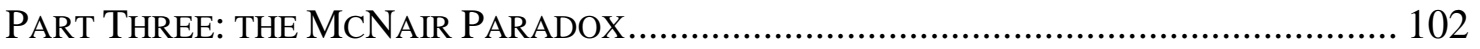

CHAPTER 7: CONCLUSIONS ......................................................................... 107

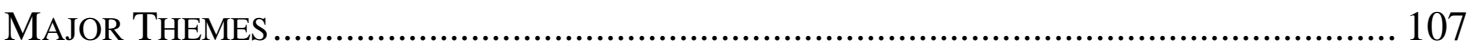

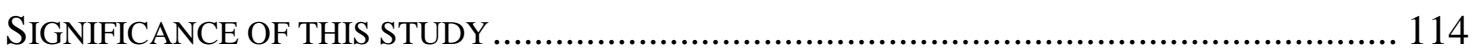

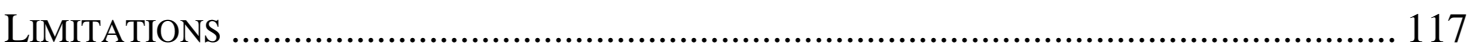

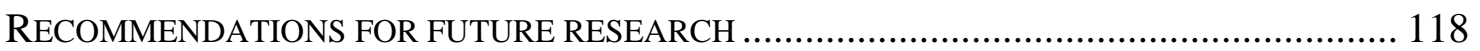

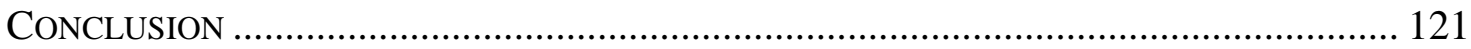

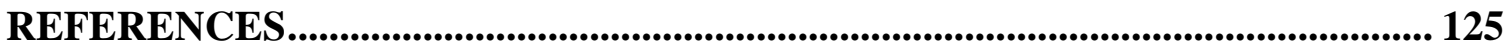

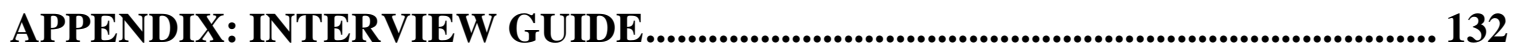




\section{LIST OF TABLES}

TABLE 1: PERCENTAGE DISTRIBUTION OF 1992/1993 B.A. RECIPIENT GRADUATE DEGREE ATTAINMENT AND ENROLLMENT STATUS 10 YEARS LATER, BY RACE 12

TABLE 2: PERCENTAGE OF 1992/19993 B.A. RECIPIENT GRADUATE ACCEPTANCE AND ENROLLMENT AFTER APPLICATION 10 YEARS LATER, BY RACE ..................................... 13

TABLE 3: PARTICIPANT CHARACTERISTICS ............................................................... 52

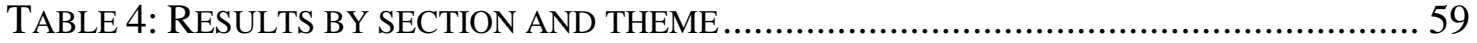




\section{LIST OF FIGURES}

Figure 1: McNair Graduate SchoOl PiPELINE ..................................................... 22

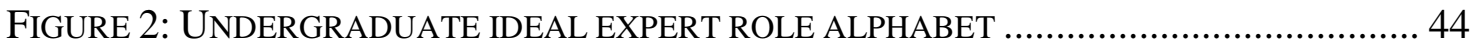

FIGURE 3: UNDERGRADUATE PRE-MCNAIR RolE ALPHABET ..................................... 52

FIGURE 4: UNDERGRADUATE POST-MCNAIR ROLE ALPHABET ..................................... 59

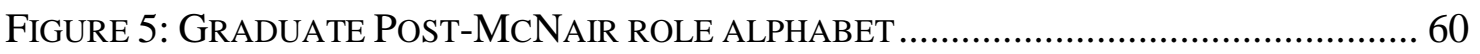

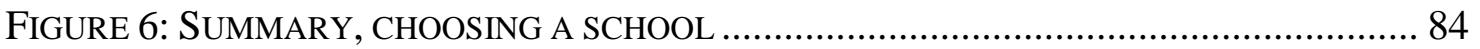

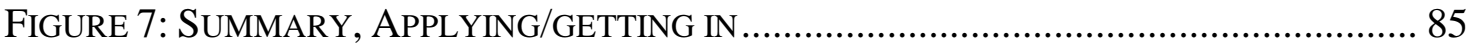

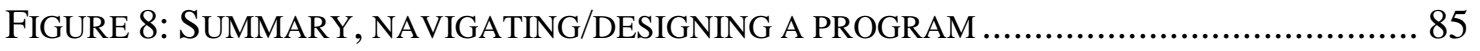

FIGURE 9: SUMMARY, UNDERSTANDING RESEARCH ................................................. 86

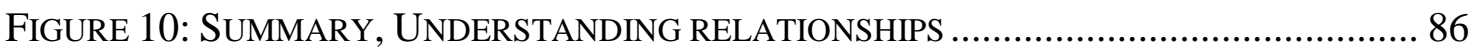

FIGURE 11: SUMMARY, UNDERSTANDING PROGRAMS ................................................ 87

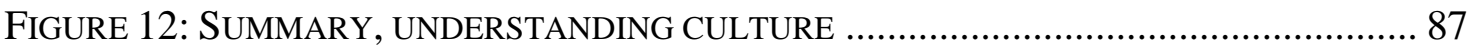

FIGURE 13: SUMMARY, UNDERSTANDING BEING A GRADUATE STUDENT ...................... 88

FIGURE 14: SUMMARY, REFLECTIONS NOW ............................................................. 88

FIGURE 15: SUMMARY, REFLECTIONS TRAJECTORY …….......................................... 89

FIGURE 16: UNDERGRADUATE POST-MCNAIR ROLE ALPHABET .................................... 90

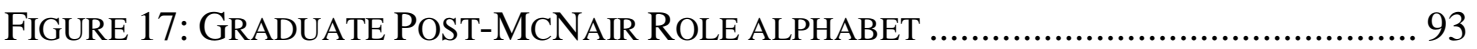

FIGURE 18: GRADUATE FIRST-YEAR ROLE ALPHABET ................................................ 93

FIGURE 19: GRADUATE SECOND/THIRD-YEAR ROLE ALPHABET .................................. 95 


\section{Introduction}

College degree attainment is strongly correlated with important economic and social outcomes such as economic success, employment, health, family stability, social connections, and social mobility (Hout, 2012). For example, bachelor's degree holders earn a 56\% higher median income and advanced degree holders a 98\% higher median income, than do those with only high school diplomas (NCES, 2013). While the total number of degree holders in the U.S has increased over the last 60 years, these increases are not equal across demographic groups. The type and length of college education received is strongly correlated with socioeconomic background (Touche, 2011). Firstgeneration, low-income, and certain minority group students are "historically disadvantaged" in college. These students are less likely than their traditional peers to pursue and receive bachelor's degrees and even less likely to pursue and receive advanced degrees (NCES, 2007).

The Ronald E. McNair Post Baccalaureate Achievement Program ("The McNair Program" or "The Program") is a graduate school preparation program for historically disadvantaged students. The McNair Program is a U.S. Department of Education TRIO Program funded at approximately 152 institutions across the United States and Puerto Rico. In 2013, total funding for the Program reached over \$35 million (US Department of Education, 2013). The program introduces juniors and seniors who are first-generation and low-income, and/or members of under-represented groups to academic research and to effective strategies for getting into and graduating from Ph.D. programs (PSU McNair Program, 2013). 
The goal of the McNair Program is to provide disadvantaged college students with effective preparation for doctoral study to ultimately pursue an academic career. Underlying the McNair Program is the belief that by expanding the number of Ph.D. recipients from these backgrounds, university faculties will become more diversified, and that greater diversity in the professoriate will contribute to non-traditional students' future educational attainment by creating a more supportive academic environment (Federal TRIO Programs, 2005).

The purpose of this comparative interview study is to explore how former Portland State University McNair Scholars understand the ways that participation in the program impacted their graduate school experiences. A qualitative study of this nature is the only way to fully explore participants' unique understanding of the ways in which McNair Program participation impacted their graduate school experiences. This approach is best suited to capture the voices of McNair Program alumni, representatives of a population whose voices are often omitted or distorted in academic research (Perry, Moore, Edwards, Acosta, \& Frey, 2009).

'Participation in the McNair Scholar Program' is understood to mean having been accepted and actively participating in and completing a three-term program at PSU designed to prepare students for graduate study. 'Graduate school experiences' are understood to refer to academic as well as social experiences during active participation in any advanced degree program (e.g. challenges faced, program expectations, and feelings about the program).

This study aims to answer the following questions: 
1. How do former PSU McNair Scholars who are first-year graduate students understand the ways that program participation impacted their graduate school experiences?

2. How do former PSU McNair Scholars who are second- and third-year graduate students understand the ways that program participation impacted their graduate school experiences?

3. How are the experiences of these two groups of students similar to each other?

4. How are the experiences of these two groups of students different from each other?

This thesis is organized as follows. Chapter two will review the relevant literature on two topics relevant to this study: understanding McNair Scholars and their location in higher education, and past research on the effects of the McNair Program on those students. Chapter three will present the theoretical frameworks used in this study. Chapter four will focus on the methodology used in this study, including research design, participants and recruitment, data collection, and analysis. Chapter five will present the findings of this study, organized by theme under each research question. Chapter six will discuss the findings in relation to the theoretical framework used for the study and how these findings may help us make sense of the McNair Paradox. Finally, chapter seven will review key findings, discuss the implications of this research, acknowledge the limitations of this study and provide suggestions for future research.

This chapter introduced the research topic and placed this study into a relevant social context. In addition, this chapter presented the research questions for this study and 
the organizational structure of this thesis. The next chapter will explore the literature relevant to this study. 


\section{Literature Review}

This chapter will review the relevant literature relevant to this study. This literature is presented in two parts: understanding McNair Scholars, including their unique positions in higher education and understanding the McNair Program, including program description and past research on the program. The first section will first address the value of a college degree. Then first-generation, low-income, and underrepresented group students will be defined and challenges of each group will be addressed. The first section of the literature review will conclude by introducing potential approaches to increase degree attainment among these three groups of students. The second section will describe the McNair Program, review national data on the McNair Program, and introduce studies that explore McNair Scholars' experiences in different ways. The second section of the literature review will conclude by introducing the "McNair Paradox."

\section{Benefits of Degree Attainment}

College degrees yield substantial economic value in income, occupational status, insurance coverage, and more. Graduate degrees return even more value. Full-time workers who hold bachelor's degrees earn median annual wages of $\$ 46,900$, while those with high school diplomas earn $\$ 29,960$. Workers who hold master's degrees or higher earn median wages $(\$ 59,620)$ that are about twice the amount of workers with high school degrees (NCES, 2013). People with more education have more desirable jobs and report higher job satisfaction (Perna, 2005). Occupational status increases even more for advanced degree holders (Hout, 2012). Individuals of working age (25 to 64 years old) with a bachelor's degree or higher are less than half as likely to be unemployed than those with a high school diploma (4.1\% compared to 9.2\%) (NCES, 2013). Economic 
benefits of higher education extend beyond income and occupation. Bachelor's degree holders have a greater likelihood of having health insurance coverage and lower likelihood of being on public assistance than non-degree completers (Perna, 2005).

Degree attainment is positively related to quality of life factors beyond economic benefits. A college education is related to relative increases in health, happiness, and longevity (Ross \& Mirowsky, 1999). For example, the percentage of high school graduates who report smoking cigarettes declines as the level of degree attainment increases, which has individual health benefits as well as the social benefit of reduced costs of providing health care to smokers (Perna, 2005: 49) Other non-economic benefits include greater civic involvement, which encompasses higher rates of voting and volunteering (Perna, 2005).

These benefits extend intergenerationally. College-educated mothers have higher educational expectations for their children, are more likely to have books and computers available for their children in the home, and are more involved in their children's' schooling than are mothers who did not attend college, even after controlling for mothers' family class background, race and ethnicity, and age (Attawell \& Lavin, 2007). These practices are all associated with better education outcomes for children, separate from higher incomes of college-educated parents (p. 120).

Attawell \& Lavin (2007) determined that non-traditional students, especially students who had poor academic preparation, are older, have heavy employment responsibilities, and who are parents, take longer to graduate college than many studies 
allow ${ }^{1}$. Time intervals are generally four to six years and misclassify students who do not obtain bachelor's degrees as drop-outs. The influence of social background on adult children's economic well-being is strongest among those with lower levels of schooling, but it fully disappears among bachelor degree holders. In other words, attainment of a bachelor's degree "closes the gap" between lower SES and higher SES students. (Hout, 2012).

In a study of intergenerational mobility, Torche (2011) found that, while the mobility gap between students from privileged families and historically disadvantaged students nearly closes at attainment of a bachelor's degree, it re-emerges as students pursue advanced degrees. Disadvantaged students are able to 'catch up' with their traditional peers in terms of social class, occupational status, individual earnings, and total family income at the bachelor's degree level, but when they enroll in advanced degrees, these differences are once again apparent. These differences can be attributed mainly to selectivity of graduate programs attended, as well as income levels of fields chosen (Torche, 2011). This means that choices students make in selecting areas of study and institutions for graduate work while they are undergraduates are important to their post-graduate degree attainment outcomes.

\footnotetext{
${ }^{1}$ In their book Passing The Torch (2007), Attawell \& Lavin describe their study of mothers from disadvantaged backgrounds. They followed students admitted under the City University of New York's (CUNY) open admissions policy between 1970 and 1972 and their children over a 30 year period. They compared this data to the National Longitudinal Study, Census data, and the Department of Education National Educational Longitudinal Study data. They found that graduation rates were considerably higher than many estimates that allow only four to six years from enrollment to graduation (the longest period was in one NCES study that allowed 12 years): $71 \%$ of the CUNY cohort earned a degree; about $15 \%$ of those earned an associate's degree, about 30\% earned a bachelor's degree and 26\% completed a Master's degree. About 29\% completed their degrees over 10 years after first enrollment and 10\% completed them 20 or more years after enrollment.
} 


\section{Historically Disadvantaged Students}

The McNair Program seeks to address three dimensions of student “disadvantage": first-generation status, low-income status, and underrepresented group status. First-generation and low-income (referred to as FGLI) students are often considered a single group because they are so closely associated in both the McNair Program requirements and in studies of the Program. Sometimes first-generation, lowincome, and underrepresented group (referred to as FLU) students are also treated as a single category. While some studies of the McNair Program discuss FLU students as an aggregate group (e.g. Beal, 2007; Conrad \& Canetto, 2009; Esler,1998; Exstrom, 2003; Grimmet, et al, 1999; Hallock, 2003; Leichnitz, 2007; Willison \& Gibson, 2011), many studies of the McNair Program distinguish between FGLI and underrepresented group students (e.g. Acker-Ball, 2007; Bryson, 2005; Carrera, 2002; Greene, 2007; Ishiyama, 2007; Ishiyama \& Hopkins, 2002; Lam, et al., 2003; McCoy, Wilkinson, \& Jackson, 2008; Norfles \& Mortenson, 2002; Seburn, Chan, \& Christenson, 2005; Vance, 1993; Williams, 2004).

\section{First-Generation Low-Income}

The McNair Program relies on definitions from the Higher Education Act of 1965 in order to establish program eligibility. A first-generation student is defined to be “either: 1) a student both of whose parents did not complete a baccalaureate degree or 2) if a student resided with and received support from only one parent, a student whose only such parent did not complete a baccalaureate degree" (Higher Education Act, 1965). A low-income student is defined as “one whose family's taxable income for the preceding 
year did not exceed 150 percent of the federal poverty level as established by the US Census Bureau” (Higher Education Act of 1965).

The subjects in this study participated in the McNair Program during the funding cycle from 2007 to 2012 . In $2007,150 \%$ of the poverty level was $\$ 15,315$ for a single person (US Department of Health and Human Services, 2007). In 2012, 150\% of the federal poverty level was $\$ 16,755$ (US Department of Health and Human Services, 2012).

First-generation and low-income students are less likely than their traditional peers to pursue advanced degrees. A student's enrollment in a doctoral or any other type of graduate program is profoundly influenced by her or his parents' education, even after attainment of a bachelor's degree (NCES, 2007). After earning a four-year degree, students whose parents received advanced degrees are three times more likely to enroll in a doctoral degree program than those students whose parents received high school diplomas or equivalent (NCES, 2007: 12). Family income has been shown to impact college enrollment, even after controlling for academic ability (Thayer, 2000). For example, Akerheilm, Berger, Hooker, \& Wise (1998) found that students who scored in the top third on standardized tests in high school who were also low income were five times more likely to skip college than their higher income peers.

Collier and Morgan (2007) identified some of the obstacles first-generation college students face in achieving positive educational outcomes. First-generation students often have less awareness of "how to do the college student role" than traditional students due to lack of background information about higher education. This information is traditionally provided by family members who have more experience with higher 
education (Collier \& Morgan, 2007: 430). This suggests that first-generation, low-income students are uniquely situated in graduate education and face different challenges than do their traditional peers.

\section{Underrepresented Groups}

The McNair program also relies on the Higher Education Act of 1965 of for its definition of an underrepresented group student. "The student must be a member of a group traditionally underrepresented in US higher education: Black (non-Hispanic), Hispanic/Latino, Native American, Alaska Native, Native Hawaiian, or Pacific Islander." (Higher Education Act of 1965, as amended).

Underrepresented group students' college enrollment and degree attainment rates have risen dramatically since 1989, even though challenges to affirmative action and increased public criticism of the consideration of race and ethnicity in college admission criteria have also increased during that time period (Parker, 2003). However, the percentage of white students earning doctoral degrees is disproportionate when compared with US racial demographics. While underrepresented groups make up about $29 \%$ of the US population (2010 US Census), they only make up 14\% of those students who received doctoral and professional degrees in 2010 (NCES, 2011).

It should be noted here that Asian Americans are not considered underrepresented in higher education. In 1997, they made up $4 \%$ of the US population and $6 \%$ of enrolled college students, and these numbers have only increased (Hune, 2002); however, these rates can be misleading. While certain groups of Asian Americans, such as ChineseAmerican students, are overrepresented among college students, other groups, such as Hmong-American students, have dismal college participation rates. There are differences 
in attainment by geographic location. In the western region of the US, where Asian groups are concentrated, their educational attainment is less than that of whites. There are also differences in gender. Asian-American women attend college at a much lower rate than Asian-American men, though their degree attainment rates are higher (Hune, 2002).

Hispanic and black students are more likely than white students to expect an advanced degree after obtaining a bachelor's degree. Black and Hispanic students are more likely than white and Asian/Pacific Islander students to enroll in a graduate program (see table \#1). However, while black and Hispanic students are more likely than whites to apply to a graduate program after attainment of a bachelor's degree, they are less likely to obtain a degree (Nevill \& Chen, 2007: 34). Black and Hispanic students take longer to enroll in graduate programs, on average, than do white and Asian/Pacific Islander students after attainment of a bachelor's degree (Neville \& Chen, 2007: 45). This is important because completion rates drop as time to enrollment increases (Nevill \& Chen, 2007: 61). 
Table \#1: Among 1992-93 bachelor's degree recipients who had enrolled in a graduate degree program by 2003 , percentage distribution of attainment and enrollment status in 2003 , by race*

\begin{tabular}{|c|c|c|c|c|c|c|c|c|c|}
\hline & Attained & & & & Enrolled & & & & $\begin{array}{l}\text { No } \\
\text { Degree, } \\
\text { Not } \\
\text { enrolle } \\
\text { d }\end{array}$ \\
\hline & Total & $\begin{array}{l}\text { Maste } \\
\mathrm{r}\end{array}$ & $\begin{array}{l}\text { First } \\
\text { Prof. }\end{array}$ & $\begin{array}{l}\mathrm{Ph} . \\
\mathrm{D}\end{array}$ & Total & $\begin{array}{l}\text { Maste } \\
\mathrm{r}\end{array}$ & $\begin{array}{l}\text { First } \\
\text { Prof } \\
.\end{array}$ & $\begin{array}{l}\mathrm{Ph} . \\
\mathrm{D}\end{array}$ & \\
\hline $\begin{array}{l}\text { White-Non- } \\
\text { Hispanic }\end{array}$ & 62.6 & 48.8 & 9.3 & 4.5 & 13.7 & 9.9 & 1.1 & 2.7 & 23.1 \\
\hline $\begin{array}{l}\text { Black, Non- } \\
\text { Hispanic }\end{array}$ & 53.8 & 42.1 & 6.6 & 5.1 & 24.7 & 15.7 & 3.8 & 5.2 & 21.5 \\
\hline Hispanic & 55.9 & 39.2 & 8.3 & 8.4 & 19.3 & 16.3 & 1 & 2 & 24.8 \\
\hline $\begin{array}{l}\text { Asian/Pacific } \\
\text { Islander }\end{array}$ & 64.8 & 35.2 & 26.4 & 3.2 & 12.8 & 8.4 & 2.5 & 2 & 22.4 \\
\hline
\end{tabular}

SOURCE: U.S. Department of Education, National Center for Education Statistics, 1993/03

Baccalaureate and Beyond Longitudinal Study (B\&B: 93/03) as presented in McCormick, Nunez, Shah, \& Choy, 1999.

*Included in the totals but not shown separately are data for American Indian/Alaska Native respondents and those who identified themselves with another race not shown. Race categories exclude Hispanic origin unless specified.

Table \#2 shows that black students are accepted at a lower rate to graduate programs than are white, Asian/Pacific Islander, and Hispanic students who apply, even though a higher proportion of black students apply (McCormick, Nunez, Shah, \& Choy 1999: 46). Hispanic students are also accepted at lower rates than white and Asian/Pacific Islander students. Hispanic students appear to be leaving graduate programs more often than other groups. This group shows the highest percentage of students who enrolled in graduate programs but who did not earn a degree and are no longer enrolled (see table \#1). American Indian and Alaskan Native students are sometimes entirely excluded from NCES data because numbers are so few that estimates are not reliable; these student rates are sometimes included in totals but not presented as a distinct category, along with students who identify as two or more races or races other than those included (McCormick et al, 1999: 14; Nevill \& Chen, 2007). 
Table \# 2: Percentages of 1992-93 bachelor's degree recipients who applied for admission to a graduate or first-professional program, were accepted if applied, and enrolled if accepted, by student race/ethnicity: 199397

\begin{tabular}{|l|c|c|c|}
\hline & Applied & Accepted & Enrolled if Accepted \\
\hline American Indian/Alaskan Native & 35.4 & - & - \\
\hline Asian/Pacific Islander & 48.7 & 90.5 & 64 \\
\hline Black, non-Hispanic & 50.1 & 75.2 & 72.7 \\
\hline Hispanic & 41.2 & 81.8 & 82.4 \\
\hline White, non-Hispanic & 39.4 & 88.1 & 77.1 \\
\hline
\end{tabular}

- Too few cases for a reliable estimate.

Source: U.S. Department of Education, National Center for Education Statistics, 1993 Baccalaureate and Beyond Longitudinal Study, Second Follow-up (B\&B:93/97) as presented in McCormick, Nunez, Shah, \& Choy, 1999.

Rendon (1994) explains that curriculum, activities, and organizations in colleges and universities often favor traditional, white students. Curriculum is often Euro-centered and does not acknowledge academic contributions of non-whites and women. There is a culture of competition versus collaboration, and teaching often involves the professor as the sole authority who lectures to students who passively listen. Finally, assessment is often focused on learning outcomes as opposed to the learning process (Rendon, 1994: p. $34)$.

This kind of environment leaves non-traditional college students, specifically those students from underrepresented groups, feeling alienated and intimidated. These students are forced to adapt to a new culture. They must unlearn past behaviors and learn new attitudes, beliefs, and values that are often very removed from their own (Rendon, 1994: p. 42). However, these students must also maintain and nurture connections to their cultural heritage in order to be successful in college (Giuffrida, 2007). 
First-generation, Low-Income, Underrepresented group

The challenges listed above for each group are compounded for students who belong to all three disadvantaged groups. First-generation students are more likely to be female, older, Hispanic or black, and to be from families in the lowest income quartile regardless of race (U.S. Department of Education 2011). These three dimensions of disadvantage often interact with one another in different ways for college students (Thayer, 2000). First-generation students have negative educational outcomes compared with their traditional peers even when controlling for factors often associated with firstgeneration status, such as socio-economic status, attendance status and institution type (US Department of Education, 1998). However, middle income, first-generation students find the college transition less challenging than do minority first-generation and FGLI students (Richardson and Skinner, 1992). Finally, FLU students face compounded challenges regarding college enrollment and degree attainment compared with any other individual group (Rendon, 2005).

\section{Potential Interventions for FLU student success}

Given the unique challenges that FLU students face in higher education, it is important to understand how to facilitate their future success. There are aspects of the undergraduate experience that are particularly important for FLU student success. Studies

suggest that some of the most important aspects include: opportunities for undergraduate research; mentorship; social connections; and faculty representation.

\section{Undergraduate research}

Research suggests that positive student outcomes are associated with studentfaculty interactions, particularly interactions connected with conducting undergraduate 
research (Laanan, 2007; Engstrom \& Tinto, 2008). Undergraduate research experiences have been identified as especially useful for enhancing the retention, persistence, and graduate enrollment of underrepresented minority students (Pascarella \& Terenzini, 2005). The research process mimics the professional socialization of graduate students and faculty in many ways for students who must acclimate to this new atmosphere (Pascarella \& Terenzini, 2005).

Undergraduate research programs have been shown to positively impact a number of educational outcomes. First, undergraduate research is useful for helping students understand the research process, as well as increasing research and problem-solving skills (Kardash, 2000; Loppatto, 2004). Second, undergraduate research experience is useful for clarifying and influencing student career goals, including the possibility of a faculty career (Hathaway, Nagda \& Gregerman, 2002; Loppatto, 2004). Third, this type of research experience enhances the likelihood of students being recruited for, admitted to, transitioning into and being successful in graduate school (Grimmett et al., 1998; Nandozie, Ishiyama, \& Chon, 2001). Finally, students report that undergraduate research experiences makes them feel more connected to their discipline and that they are part of a learning community (Hakim, 1998; Loppatto, 2004)

\section{Mentoring}

Mentoring is associated with a variety of positive college student outcomes at all degree levels. In fact, few studies have failed to find some level of positive outcomes associated with college student mentoring (Crisp, 2009). Several studies have identified a positive relationship between mentoring and undergraduate student persistence and 
academic performance (Campbell \& Campbell, 1997; Carrera, 2002). Mentoring also impacts students' perceptions of the benefits of their research (Ishiyama, 2007).

Graduate students experiencing high levels of schoolwork-associated stress and anxiety find mentoring particularly helpful. For example, Hadjioannou Shelton, Fu, \& Dhanarattigannon (2007) found that doctoral students reported that mentoring allowed them to participate in academic discourse, obtain skills to navigate through the program, improve their academic writing, and receive emotional support as well as provide them with professional/academic socialization needed to alleviate the stress and anxiety that accompanies doctoral work.

\section{Social integration/connection}

FLU students required a supportive academic environment. Developing a sense of belonging is important for student success (Bradbury \& Mather, 2009). Research indicates that academic persistence is related to the amount of social support students perceive (Dixon Rayle et al., 2006; Laanan, 2007). This is especially true for firstgeneration students, many of whom, compared to their peers, report feeling uncomfortable and alone in college (Kodama, 2002). Tinto's (1975) Model of Student Persistence established that both academic and social integration are crucial components of student success. This may be particularly challenging for black and Latino students, who must maintain connections both on and off-campus in order to be successful (Fischer, 2007).

\section{Faculty Representation}

Diversity among faculty members at academic institutions is strongly correlated with positive educational outcomes for students and creating a supportive atmosphere for 
FLU students. A longitudinal survey study by Sylvia Hurtado (2005) of over 4,000 students at 10 campuses found that there was a significant relationship between a diverse faculty and student body and student growth with regards to multiple positive educational outcomes. Umbach (2006), in a survey study of over 13,000 faculty members at 134 institutions, found that a more diverse faculty benefits undergraduate students in two ways. First, faculty members of color employ a broader array of pedagogical techniques and interact with students more often than do white faculty members (pp. 332-333). Second, greater faculty diversity results in an increased use of effective educational practices, such as higher order cognitive and diversity related activities (pp. 334-335).

\section{The McNair Program}

The Ronald E. McNair Post Baccalaureate Achievement Program (McNair Program) is named in honor of the second African American in space who perished in the Space Shuttle Challenger explosion in 1986. The McNair Scholars Program, a U.S. Department of Education TRIO Program, is funded at 152 institutions across the United States and Puerto Rico. In 2013, total funding reached over $\$ 35$ million—of which Portland State University received approximately $\$ 211,000$ (US Department of Education, 2013). The program accepts first-generation and low-income, or underrepresented group undergraduate students who have demonstrated academic potential.

Undergraduate students are prepared for applying and transitioning to graduate programs through program elements such as involvement in research and other scholarly activities, summer internships, tutoring, academic counseling, and activities designed to assist students in securing financial aid. Additional optional program elements include 
educational and counseling services designed to increase student financial and economic literacy, mentoring programs with faculty members, and exposure to cultural events and programs not generally available to disadvantaged students (US Department of Education, 2013).

Though not explicitly stated in the McNair program's legislation, the goal of the program is to prepare historically disadvantaged students for graduate study and to steer them toward teaching and higher education career paths (Council for Opportunity in Higher Education, 2014). Based on that goal and the stated goals in the program legislation "to increase the attainment of Ph.D. degrees by students from underrepresented segments of society" (Department of Education, 2014), it is clear the Program is attempting to change the ways that FLU students experience higher education.

Potential interventions for increasing the achievement of underrepresented students include opportunities for research, mentoring, social integration, and faculty representativeness. The underlying goals of the McNair Program suggest an assumption by the Program that facilitating an increase in professors from diverse backgrounds will create a more supportive environment for FLU students and will help future students to be more successful in higher education. The McNair program seems to be attempting to create a reproductive process: The program provides interventions (e.g. mentoring, research, and integration) for McNair Scholars to succeed, in the hope that scholars will become professors (increasing faculty representativeness) and will then provide similar opportunities and create a supportive atmosphere for future FLU students. 


\section{PSU McNair}

The McNair Program at PSU consists of a three-term seminar and a summer research internship, supervised by a faculty mentor. The summer research experience is supplemented by a stipend of $\$ 2,800$, provided to students in installments over the summer. This stipend is important for the students to conduct their research, as many cannot afford to take time away from work and outside responsibilities to do undergraduate research on their own. The McNair Program also provides limited funds for students to purchase materials and to travel to professional meetings to present the results of their research.

The first term seminars focus on students locating an appropriate mentor and research topic, exploring a basic understanding of research and research methods, and establishing a community of support and cohort-bonding in the face of "the impostor syndrome'. This phenomenon refers to the inability to internalize one's accomplishments which results in the feeling that one is not qualified or capable of the opportunities they have received (Young, 2011). Students are provided an interdisciplinary book about conducting academic research.

The second term focuses on practical skills for admission into and success in a graduate program. Specific program elements include help in locating an appropriate program, developing an educational plan, acquiring funding and other resources, building a successful application and succeeding once accepted into a program. There are multiple components of building a successful application including writing an engaging and appropriate statement of purpose and curriculum vita, obtaining letters of recommendation, GRE and other standard exams, campus-visits and interviews, and 
other aspects of the application process. Students' exposure to academic culture continues with opportunities to attend conferences and other academic events. In addition, guest presentations by faculty members and McNair Program alumni discuss non-traditional educational paths and strategies for succeeding in graduate programs. Students are provided a waiver for testing fees for common exams such as GREs, as well as a reference book for studying for these exams.

The final term focuses on the research project. While some students conduct research throughout their McNair Program experience, many are limited to conducting research in the summer term while they are receiving the research stipend and/or are able to travel. It is recommended that students meet with their faculty mentors weekly and seminars revolve around discussing research and challenges in the process and encouraging students from different disciplines to share their experiences with one another. The McNair Program ends with a Research Symposium where students have the opportunity to present their research. A final paper is submitted either for publication in the PSU McNair Online Journal or to some other publication approved by the student's mentor. Students receive certificates of completion as well as a waiver letter for graduate application fees, accepted by many institutions across the US and Puerto Rico.

It should be noted here that McNair Programs vary by both length and rigor depending on institution and funding. The PSU McNair Program is particularly rigorous relative to other programs. In 2001, Nnadozie, Ishiyama, and Chon examined the relationship between level of rigor of research experiences in the McNair Program and student success in graduate school. The findings suggest that three elements to researchpreparation, presentation, and publication—are often missing from programs. McNair 
Programs required students to complete aspects of research preparation to varying degrees: $51 \%$ submission of research design, $62 \%$ submission of research proposal, $68 \%$ research papers. Presentations were less common: Less than 50\% of McNair Programs reported participants presenting at local, regional, or national conferences. Least common were publication requirements: about $31 \%$ of $\mathrm{McNair}$ Programs required students to submit papers for publication and only $15 \%$ required students to publish their research papers in a scholarly journal (Nnadozie, Ishiyama, \& Chon, 2001: p. 150, table 4). In

this study, McNair Program Directors rated the McNair Program more highly in regard to effectiveness in McNair Sscholars' admission to graduate programs than in effectiveness of the research component (p. 151). Overall, rigor of research was positively associated with graduate school success.

\section{National Studies}

Literature on the McNair Program is sparse. The US Department of Education and the Pell Institute have published the three most comprehensive studies on the McNair Program over the past 12 years. These studies provide a profile of the programs nationally as well as a range of participant outcomes

In 2008, McCoy, Wilkinson and Jackson published "Education and Employment Outcomes of the Ronald E. McNair Post baccalaureate Achievement Program Alumni”. This study explored the extent that McNair Program participants earned bachelor, master, doctoral, and professional degrees. It also determined the extent to which McNair Scholars pursued careers in higher education, specifically the extent that alumni obtained positions of tenure at research institutions. 
Data was collected from Annual Performance Reports (APRs) submitted to the DOE by McNair Program Directors as a condition of funding, combined with additional survey data obtained via an automated telephone survey. Data from participants enrolled in the McNair Program between 1989 and 2000 were collected in 2004. Though extensive tracing efforts were made, the response rate for the survey was $39 \%$ of program participants $(\mathrm{N}=8,929)$. The study claimed that length of follow-up involved (10 years) allowed an appropriate amount of time for students from earlier cohorts to complete Ph.D.'s- there are no other national studies (listed below) which allowed for more than five years after completion of the McNair Program. However, as an author of this study notes, "reliance on self-reported data from a survey of participants—biased by the fact that results were obtained only for respondents that could be located... requires results be interpreted with caution." (Email correspondence with Russell Jackson, 2013). It is likely that attrition from graduate programs is greatly underestimated, since those students who were not retained were more difficult to locate.

Key findings of the study were presented as a pipeline from McNair Program participation through attainment of a bachelor's degree and advanced degrees. This pipeline can be seen here:

Figure 1: Pipeline of Doctoral or First Professional Degree Attainment of Early Cohort Participants (198993) by 2004_per Typical 100 McNair Program Participants at Least 10 Years after Program Participation.

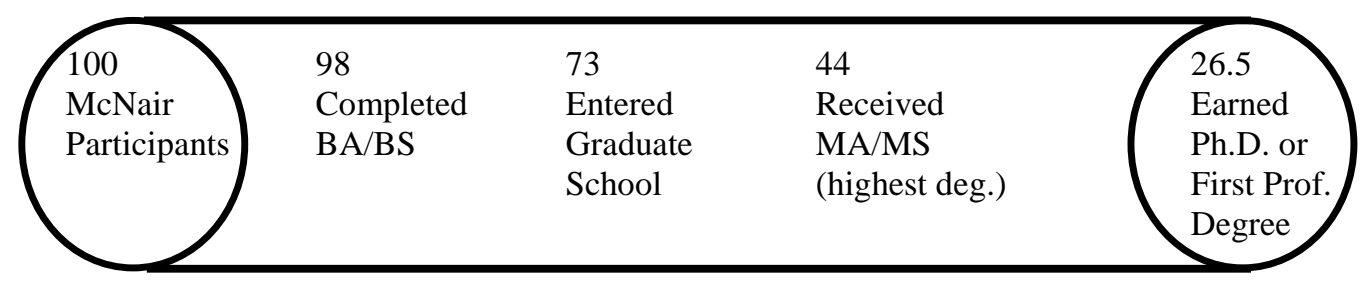


The authors note that whites and Asians, who are not considered underrepresented group students, were overrepresented in Ph.D. attainment. However, they also note that underrepresented group students who are not first-generation and low-income are overrepresented in professional degree attainment compared to their first-generation lowincome peers. According to race by Ph.D. attainment, Caucasian participants made of 43\% of McNair Scholars who earned Ph.D.'s, while they made up only $19 \%$ of total McNair Program participants. Alternatively, African Americans accounted for 25\% of McNair Scholars who earned Ph.D.'s, while they made up 44\% of total McNair Program participants. Finally, Hispanics accounted for $19 \%$ of the Ph.D.'s, and made up $25 \%$ of total McNair Program participants. Most McNair Scholars earned Ph.D.'s in life sciences (26\%), social sciences (24\%) and physical sciences (14.6\%) (McCoy, et al, 2008: 19).

Although some students may have returned to graduate programs later, it is clear that many students halted their degree attainment at the Master's level (44\%), rather than acquiring a Ph.D. or professional degree (26.5\%). At the time of this study in 2004, more total McNair alumni held professional degrees (802) than held Ph.D.'s (541).

Professional degrees include disciplines such as medicine, pharmacy, law, education, etc. Given that the overall goal of the program is to increase diversity among campus faculty, and that students indicated a desire to earn a Ph.D. upon entrance to the program, it is puzzling that McNair Scholars are not pursuing these degrees. This study sheds light on changes in identity and goals as students experience graduate school.

A second national study of the McNair Program was conducted in 2005 by Seburn, Chan, and Kirshstein entitled "A Profile of the Ronald E. McNair Post baccalaureate Achievement Program: 1997-1998 through 2001-2002”. The researchers 
compared McNair Program participants with a sample of students with similar backgrounds from "Baccalaureate and Beyond: a longitudinal study" (2007), a national study by the National Center for Educational Statistics.

Up to five years after program participation, $40 \%$ of McNair alumni who earned bachelor's degrees were accepted into graduate programs and 98\% of those students enrolled in a graduate program. Overall, $16 \%$ of these students earned Master's degrees and about $4 \%$ earned a doctoral or professional degree. Compared with national averages, McNair alumni entered graduate school at a higher rate than students who did not participate; however, persistence in graduate school was lower for McNair scholars than it was for their non-participant peers.

Both McNair participants and students from similar backgrounds who did not participate in McNair Programs reported financial difficulty and lack of social support as the most common reasons for withdrawal from graduate programs. Given that the McNair Program is designed to intervene with these challenges for FLU students to succeed in graduate programs, it is important to understand these issues from students' perspectives. This study explores in more detail the roadblocks for McNair scholars in graduate school and provides insight for more effective intervention strategies that the program can implement in the future. Again, there is also insight into the ways that McNair Scholars' goals and identities change as they experience the transition from undergraduate to graduate programs after participation in the McNair Program.

In 2002, Norfles and Mortenson authored another national study for the Pell Institute. Like Seburn, et al (2005), the authors conducted a comparative study—this time to explore the ways that McNair Program alumni financed their first year of graduate 
school. The study examined alumni who had earned a bachelor's degree in 1998 and received financial aid for the school year 1998-1999. These data were compared with graduate students of similar backgrounds in the National Postsecondary Students Aid Study, 1995-96 (NPSAS). Data were obtained through the Council of Graduate Schools/Council for Opportunity in Education Joint McNair Committee database, which allows program directors to enter alumni information that can then be used by graduate school deans across the country to recruit McNair Program participants into graduate programs.

Survey data was collected via mail on a randomly selected sample from the database, consisting of 462 surveys. The survey collected demographic, educational, and financial aid information on alumni who were presumed to have immediately enrolled in a graduate program after graduation (considering that the graduation date was 1998 and students received financial aid for school year 98-99). The response rate for the survey was $55 \%$ and data were compared to NPSAS data on graduate student financial aid.

There were some important differences among McNair alumni compared to a demographically similar national sample. McNair Scholars were more likely to receive grants or scholarships, attend graduate school at non-doctoral degree-granting institutions, and enter a master's program. These findings suggest that, while the program plays an important part in facilitating students' enrollment in graduate programs and financing these programs, there is still some challenge in students' attainment of a Ph.D. that is not being addressed through program intervention.

Further qualitative research was recommended to determine reasons that students were more likely to pursue master's degrees at institutions that do not grant doctoral 
degrees. Again, given that the goal of the program is to increase diversity among Ph.D. recipients and that students indicated at their entrance to the McNair Program that their intention was to earn a Ph.D., it is important to understand the decision making processes of these students and challenges they might be facing in pursuing Ph.D.'s. The current study explores the experiences and decisions of McNair alumni and provides information for McNair and programs like it about what happens to Scholars after program completion and graduate school enrollment.

In summary, there are several concerns raised by national studies of McNair Programs:

1. Most studies are quantitative; they provide no insight into the experiences of McNair Scholars in graduate programs.

2. Response rates are low and there is a selection bias in students who completed graduate programs compared to those who did not.

3. McNair alumni persistence in graduate programs is low.

4. Programs may be more successful in facilitating admission into graduate programs rather than success in programs after enrollment.

5. The goal of the program to increase diversity among doctoral degree holders is not being met; even students who are successful in attaining financial aid are enrolling in and completing master's degree programs and attending non-doctoral degree granting institutions.

Students need not only to be admitted but to succeed in graduate school to meet the goals of the program. Considering that studies have shown McNair Scholars leaving graduate programs at a higher rate than their peers (see Seburn et al, 2005), and that 
students are less likely to enroll in Ph.D. programs rather than master's programs, even with financial aid (see Norfles and Mortenson, 2002), it is important to understand how their experiences in the McNair Program have prepared them for graduate study past enrollment. This is especially true since different programs require different levels of rigor in the research projects of their participants. If a background in research from McNair Program participation affects the experiences of McNair Scholars in graduate programs, information on that background must be included. The current study explores the ways that conducting research in the program impacted students through their first three years of graduate study.

\section{McNair Scholars' Experiences}

Research on the experiences of undergraduate McNair Program participants is limited. Many of the studies listed are Ph.D. dissertations that have not been published in scholarly journals or books at this time. These studies fall into three major categories:

non-McNair Program experiences of Program participants, McNair Program experiences that impact students' development, and McNair Scholars' perceptions of the Program.

The first group of studies focuses on McNair Scholars' personal experiences and influences outside of program participation in regard to personal, academic, and professional development and socialization. These studies use program participation as an indicator of first-generation, low-income, and underrepresented group status to distinguish them from traditional college students, but do not specifically address Program participation. The literature on non-McNair experiences of Program participants is limited to four studies. These studies are related to the academic, social, and family influences of participants during college (Exstrom, 2003); challenges and success stories 
in the lives of Program participants (Bryson, 2005); Program participant educational aspirations (Acker-Ball, 2007) and participant motivation for major and vocational choice (Conrad \& Canetto, 2009).

The second group of studies focuses on the influence of the McNair Program in regard to personal, academic, and professional development of participants. This category includes nine studies that can be further categorized into three sub-themes: academic socialization, program influences on student success in undergraduate studies and graduate program enrollment, and student satisfaction of the McNair program.

Studies that focus on socialization do so from the perspective of McNair Scholars themselves. Beal (2007) focused on McNair Scholars' development of a scholarly identity. Carrera (2002) explored the influence of mentoring on academic goals, achievement, and career development. Hallock (2003) focused on anticipatory socialization into the professoriate. Vance (1993) examined participant changes in confidence and graduate degree aspirations. Finally, Williams (2004) explored academic, research, and social self-efficacy among participants.

Some studies that focus on the impact of McNair Program participation focus on undergraduate student success. These include program elements as predictors of undergraduate success (Lam, et al, 2003) and the influence of mentoring and support on retention and success of participants (Leichnitz, 2006). Other studies of McNair Program impact focus on graduate enrollment and include retention and graduate school enrollment of participants (Ishiyama \& Hopkins, 2003), and graduate school preparation, knowledge, and likelihood of enrollment (Esler, 1998), 
The final group of studies focuses on student perceptions and satisfaction. Greene (2007) explored participant perceptions of and recommendations regarding strengths and weaknesses of the program. Grimmet et al (1999) were interested in participant expectations of and satisfaction with program components. Ishiyama (2007) focused on student perceptions of the benefits of mentored research. Finally, Willison and Gibson (2011) examined graduate student confidence in the preparation for graduate school and specific aspects they felt the McNair Program had prepared them for in graduate school (Willison \& Gibson, 2011). Overall, McNair scholars are satisfied with the Program and feel prepared for graduate school.

The findings about McNair Scholars' positive experiences in the McNair Program and enrolling in graduate programs, combined with national data that brings to light low graduate school persistence and failure to enroll in Ph.D. programs seems to confirm something identified earlier as the McNair Paradox. Students are satisfied with participating in the McNair Program and the McNair Program is successful in getting scholars into graduate programs, but the McNair Program does not seem to be meeting federal outcome goals.

There is little insight into the McNair Paradox in the literature or any other explanations as to why students who enroll in a Program that explicitly attempts to prepare them for doctoral study are not earning Ph.D.'s at expected rates. Beal (2007) noted that students reported their overall goals at program-end were not to earn Ph.D.'s, but to give back to their communities and to work directly with people and apply research findings to real-world problems. She identified the issue as being one of cultural mismatch due to McNair Scholars' poor academic background prior to program 
participation, problems dealing with the rigors of research, and the perceived oppressive nature of the academy. As McNair Sscholars adopted the identity of scholar, they found that they could not relate with the missions of their universities. She recommended that the McNair Program's “definition of scholar must be extended further to encompass scholars who seek to work in non-academic environments" (p. 643). The current study contributes to the ongoing discussion about whether there really is a "McNair Paradox". This research explores McNair Scholars' experiences through the first three years of graduate study and illuminates the ways that McNair Scholars understanding the impact of the program and their academic futures are different at different points in time.

This chapter reviewed relevant literature on McNair Scholars and the impact of McNair Program participation. Additionally, the "McNair Paradox" was introduced and suggestions were provided regarding the ways that this study may help explore this seeming paradox from the perspectives of McNair Scholars themselves. The next chapter will explore the theoretical framework employed in this study. 


\section{Theoretical Frames}

There are three theoretical perspectives employed in this study. This chapter will first discuss Bourdieu's $(1973,1977,1984)$ theory of Social Reproduction and concepts of cultural capital and habitus (Lareau \& Horvat, 1999; Dumais, 2002; Collier \& Morgan, 2007). Second, chapter three will explain role-as-resource theory (Turner, 1978; Baker and Faulkner 1991; Callero 1994; Collier 2001). Third, this chapter will describe the Dreyfus Model of Skill Acquisition (Dreyfus \& Dreyfus, 1980; Benner 2004), more specifically the first three stages in the model. Next, a combined approach, drawing from all three theoretical perspectives, will be used to explain the impact of the McNair Program on student participants. Finally, a visual representation of this combination of theories will be presented. This combination of theories can help us understand both how the Program attempts to provide Scholars with resources that prepare them for graduate school, as well as the impact of program experiences on students' success and their knowledge of how to be successful in graduate school at different points in time.

\section{Theory of Social Reproduction}

Bourdieu's theory of Social Reproduction proposes that culture of the dominant class is transmitted through the family and rewarded by the educational system. Bourdieu's theory can by summarized as a formula: (capital $\mathrm{x}$ habitus) + field $=$ practice (Calhoun, 1993:83). This research focuses mainly on the concepts of cultural capital and habitus.

One aspect of Social Reproduction theory is the concept of habitus. Dumais explains that "habitus, or one's view of the world and one's place in it, is an important consideration in trying to understand how students navigate their way through the educational system" (2002, p. 45). In a given social setting such as higher education, 
habitus simultaneously generates a range of possible lines of action and limits and differentiates as "acceptable" a sub-set of viable actions from the larger universe of "everything that could possibly occur in that setting." Whether or not the individual takes action, she unwittingly contributes to the reproduction of her class status.

Navigating college is one of the most important aspects of college students' success. This is even more important for graduate students, since they must determine how to be successful in coursework, individual research, and professional development. Collier, Morgan, \& Fellows describe how habitus, or this view of the world and oneself within it, is socialized and internalized as disposition rather than conscious logic. "Bourdieu contends that much of an individual's choices of alternative paths of action in social situations are a result of that person's 'general disposition' or habitus, rather than on a conscious computation of possible benefits and costs." (2007, p. 7). This suggests that FLU students, due to their own and their families' lack of experience in higher education, may hold inaccurate views as to what is involved with graduate studies in specific disciplines or the range of possible occupational opportunities available to individuals with specific credentials. It also means that these students have limited abilities to make effective computation of possible benefits and costs when surveying choices of alternative paths of action. FLU students' habitus may limit their views of what they can achieve both in graduate school and subsequent employment. In addition, habitus serves like a camera lens that colors their abilities to gauge the chances of success for each of these possibilities.

Cultural capital describes intellectual assets that promote social mobility. Initially cultural capital is transferred intergenerationally from parent to child. Cultural capital 
partially consists of displaying preferences or mannerisms that legitimate an individual as part of an elite social class (Horvat, 2001). Cultural capital is "spent" by an individual in accordance with her habitus. Possessing capital is not a resource if the students do not view themselves as legitimate consumers of what can be "bought" with it. Cultural capital in education can be understood as ways of acting and understanding that are consistent with dominant culture (Dumais, 2002). Regardless of their family educational backgrounds, once students enter higher education they acquire additional cultural capital by learning "how to succeed in college". To learn how to succeed in college, students must act in ways that their professors recognize as legitimate and appropriate.

The concept of cultural capital helps explain why FLU students are less likely to enroll and succeed in graduate programs than their traditional peers. For FLU students, there has been little to no transmission of cultural capital from parent to child that can be "spent" in higher education. This cultural capital could take several forms. One form might be taken-for-granted implicit skills and knowledge, such as appropriate ways of interacting with professors and other authority figures. Another form of cultural capital could involve explicit advice like which classes to take or how to navigate college and financial systems. Parents who have no experience with higher education would not be able to provide this cultural capital to their children, who then begin college at a disadvantage compared to their traditional peers.

FLU students acquire less cultural capital than do their traditional peers to be successful in college. They also provide less of this capital to their own children. However, disadvantaged students who attend college may be providing more of capital to their own children, essentially breaking the social reproduction cycle. Attawell \& Lavin 
(2007) term the phrase "lagged acquisition of cultural capital" to explain the way that experiences in higher education for the upwardly mobile college graduate affect their children. The graduate perceives the importance of cultural capital in college after exposure to their middle and upper class peers and organizes it for their own children, even if those activities don't fit the tastes the parents were raised with themselves. Parents deliberately expose their children to more elite culture to cultivate the kids beyond their parents' levels. This could include taking their children to a museum or theater or paying for them to take dance or music lessons (p. 82).

Field can be understood as social context. Fields have unique systems of value and practice. Bourdieu contends that field is a social space that includes the "rules of the game", and that there is a constant struggle by elites to occupy desired positions in the field as well as to control the rules that govern that space (Horvat, 2001: p. 212). This study focuses on two intersecting fields, graduate school within higher education and associated occupations, including but not limited to the professoriate. The value of capital is dependent on the specific field of interaction (Horvat, 2001). For example, knowledge of how to interact with professors is more valuable to a student than to a mechanic; conversely, knowledge of how to interact with auto part vendors is more valuable to a mechanic than to a student. These relative values are based within each field (higher education and the auto industry).

Practice is action that resulting from the interaction between capital and habitus, within a particular field of interaction. Individuals engage in practices or actions that, given their habitus and capital, maximize their potential outcomes in specific fields. "Practice is the action taken given the everyday sense-making over time in which 
individuals engage." (Horvat, 2001: p. 214) McDonough, Ventresca, and Outcalt (1999)

contend that practice is action aimed at securing resources, such as educational credentials or occupational positions.

This is where the McNair Program attempts to intervene with FLU students. Many of these students lack the cultural capital necessary to succeed in graduate school. One part of this study investigates the ways that the McNair Program imports cultural capital to students who generally enter college with less than their traditional peers (Collier \& Morgan, 2007) and how this capital impacts those students' experiences in graduate school. In addition, because habitus is internalized from childhood as disposition, it may be more difficult and may take more time to change FLU students' respective habitus, as opposed to immediate changes to capital. If changes in habitus occur due to acquisition of cultural capital provided by the McNair Program, habitus is likely changing more slowly than changes in students' respective levels of cultural capital. Therefore this study also examines whether participating in the McNair Program brought about changes to FLU students' habitus, and how those changes might affect the ways these students navigate graduate school.

\section{Role-as-Resource Theory}

Roles are "bundles of norms and expectations" (Callero, 1994: p. 229) that can be used as resources for multiple purposes. Callero (1994: 238-240) identifies four general categories of role usage: to define self and others; in thinking, as a means to achieve other ends; and as a guide for action. This study focuses on roles as a guide for actions. Callero's idea of "role as a guide for action" compliments Bourdieu's concept of practice. Role knowledge, in the form of understanding how to enact the college student role and 
awareness of what is possible to accomplish within higher education, is a resource that individuals employ to realize valued goals (Callero, 1994). Role knowledge can interact with students' habitus in two ways. First, habitus influences what the student thinks is possible to do with the college student role. Second, increased role knowledge can produce adjustments in habitus as the student tries to more accurately calculate the chances of success of possible goal-directed actions, such as applying for graduate school or specific jobs.

Increased role knowledge is also described as role mastery. Ralph Turner (1978) defines role mastery as a process of deepening understanding and greater facility with a particular role. According to Turner, people first understand a role through imitating examples they have seen of others enacting that a role- they are "role playing" (Turner, 1994). When people are role playing, they perform conventional existing versions of the roles they have seen. Over time, the individual may begin to "claim" this role as part of her social identity. In addition to claiming the role, the person adapts that role to fill particular needs. In other words, the person begins to use her understanding of this role as a resource-a process Turner (1994) calls “role making”. In Callero's terms, this new understanding of the role is a resource for both thinking and action. The individual has new ways of problem solving that were not previously available to her. In addition, she utilizes these problem-solving resources to achieve valued interactional goals, such as successfully completing an undergraduate degree and successfully applying to graduate school.

Students who begin college with a greater mastery of the college student role possess an important resource for recognizing what is expected of them and for 
responding accordingly (Collier \& Morgan, 2007). Role knowledge is one form of cultural capital for college students. Students who have been exposed to fewer existing versions of the role of the going-to-graduate school student role have relatively lower levels of cultural capital. In other words, they are role playing with limited knowledge of the role. Traditional students, who come from families where their parents are already familiar with what it takes to succeed at college, can more quickly begin working on their role-making, freeing up their cognitive energies to focus on other important things needed to succeed at college.

Differentiated Role Mastery (Collier, 2001) is a more sophisticated approach to role mastery that describes a second form of greater role knowledge, i.e. knowing that alternative versions of the same role exist at any given time. An individual who knows that multiple versions of a role exist, that different versions of the same role are "favored" in different contexts, and who knows when and how to enact each version appropriately, has a tremendous advantage compared to someone who is only aware of a single version of the same role. Differentiated Role Mastery becomes a resource when students understand that enacting different versions of the college student role will benefit them in different situations (Collier, 2001). For example, students who know that professors have different expectations at different types of institutions (e.g. community college vs. university), and can understand how to meet those different sets of expectations, have an advantage compared to students who attempt to meet the different professors' expectations in the same way at both types of institutions.

The concepts of role as resource and developing role mastery are helpful in explaining how the McNair Program helps students from families that are not familiar 
with higher education complete their undergraduate degrees in ways that better equip them to be admitted to graduate school. The McNair Program also helps students to understand the role of graduate student, and appropriately respond to graduate school expectations. The McNair Program provides students with examples of what it means to be a successful "undergraduate student," a "scholar," a "graduate student," and eventually a "professor" or "professional." McNair Scholars have had limited exposure to these roles. McNair attempts to equip students with knowledge of these roles and provides experience enacting these roles to help students to succeed at the graduate level and beyond.

\section{Model of Expertise Development}

Callero's Role as Resource theory demonstrates how role knowledge -or, in Bourdieu's terms, "cultural capital" -can serve as a resource for taking action and accomplishing valued goals, like completing a Bachelor's degree or being admitted to graduate school. Differentiated Role Mastery explains how, as a result of shared knowledge from the McNair program, McNair Scholars can learn that there are many ways to enact the college student role and that some are more effective for getting into graduate school than others. While Turner identifies two levels of fundamental role mastery, he does not explain the steps an individual goes through in moving from roleplaying to role-making. A recent model of expertise development can help explain how the McNair Program helps students acquire a depth of knowledge about specific versions of successful graduate student role through program activities. Hubert and Stuart Dreyfus (1980; 2005) developed a five-stage model of expertise development to explain how adults learn new skills by instruction. Benner (2004) then extended this understanding to 
more complex settings to study skill acquisition of nurses in actual clinical situations. The current research employs this model to examine how McNair Scholars acquire the depth of role knowledge, or cultural capital, they need to successfully complete in graduate school.

There are five stages in the in the Dreyfus and Dreyfus model: novice, advanced beginner, competent, proficient, and expert. This discussion will only focus on the first three stages of this model that are relevant in describing McNair Scholars transition to and role enactment in graduate school. This subsection will provide a brief description of each of the first three stages, followed by an example of the development of McNair Scholars before and after program participation.

\section{Novice}

The novice has no background in the domain. Students must be given clear descriptions and tasks must be broken down into easily recognizable features. Rules and guidelines for action must not require any experience for recognition. The novice is rulegoverned and inflexible. These students are also fully engaged and eager to learn (Benner, 2004). This means that they must be provided with a set of context-free rules to be used in every situation, since they cannot distinguish nuances because they have no experience. These strict rules are used in every situation. Novices are not able to predict success of outcomes because they have no prior experience doing so.

Dreyfus and Dreyfus (2005) provide the example of learning to drive a manualtransmission car. An instructor may provide a student with rules such as shifting from first to second gear when the speedometer shows $10 \mathrm{mph}$. This will not always be the 
appropriate action, but at this point the student must first gain experience to understand when it is not.

As they complete their undergraduate degrees in the McNair program, Scholars internalize a standard of how to be a successful undergraduate student that is much more exhaustive than they previously were aware of. They take pride in conducting their own research, presenting at conferences, and even publishing the research project reports. At the same time they are also aware that most other undergraduates are not working this hard. The McNair program reinforces this by sharing the message that Scholars are working at levels comparable with graduate students. However, when McNair Scholars start graduate school they are novices; they have no experience being graduate students. This means that they will seek out and follow context-free rules. A McNair Scholar may follow the rule "better students always work harder" when she starts graduate school, since hard work and a rigorous research project were required in the McNair program and presented as graduate standard. Since the Scholar has no experience in graduate school, this is a context-free rule and can be understood regardless of any characteristics of the graduate program or faculty. Following this simple context-free rule may become a problem for the McNair Scholar without more nuanced meaning or caveats regarding possible exceptions to the rule.

\section{Advanced Beginner}

In the Dreyfus model, the advanced beginner gains more experience in the context over time. The advanced beginner has generally been successful using context-free rules, but understands that a wide range of factors can significantly influence outcomes of action. The student now combines context-free rules with situational awareness to 
develop instructional maxims. The advanced beginner is still following guidelines for action, but these guidelines require some experience to be fully understood (Dreyfus \& Dreyfus, 2005). Students pay close attention to the actions of their colleagues and peers and seek out credible sources of information to guide their own actions (Benner, 2004). This type of learning still requires following instructions and teaching at this level often still requires providing examples, but these instructions and examples would not be understood by a novice with no experience.

Dreyfus and Dreyfus (2005) continue the example of driving a car by explaining that a driver begins to learn the maxim to shift up when it sounds like the motor is racing, and to shift down when it sounds like the motor is dragging or sputtering. This maxim requires some experience with the sound of the motor and the prior experiences of shifting. However, it does not take into account all factors that could affect shifting.

Former McNair Scholars may become advanced beginners by the end of their first year of graduate school and are increasing their knowledge of the graduate student role. The PSU McNair Program tries to prepare Scholars for dealing with a new set of issues through an assignment called the "education plan" that requires undergraduate Scholars to plot their first year in graduate school and how they plan to navigate the challenges of graduate school. The Program also brings in alumni to discuss the challenges they have faced in graduate school. The Program is attempting to provide maxims of action for Scholars to employ after enrollment. This model would also predict that Scholars would begin to connect with their peers and faculty to better understand the expectations of their graduate programs. 


\section{Competent}

As experiences build up, the advanced beginner begins to see that situational aspects more often impact outcomes, and becomes aware of more of these aspects. It should be noted that the complexity of past experiences will influence how fast someone gains competence; The more factors they have seen impact outcomes, the faster they realize how many factors have this kind of impact. The student begins to realize that there are a vast number of factors that contribute to possible outcomes. To deal with so many possibilities, the student begins to construct contingency plans for action- "if A happens then do B" but "if X happens then do Z". This plan helps the student to identify which factors are the most important and which can be ignored (Dreyfus and Dreyfus, 2005). As students learn to decipher the most important aspects of a situation, decision-making becomes easier. Future-planning often increases at this point, because the student is able to forecast and predict outcomes for future events (Benner, 2004).

Competence often develops unevenly depending on experience and quality of teaching available. At the novice and advanced beginner levels, a student could rationalize making a mistake by thinking that it was due to inadequate instruction or insufficient rules. At the competent stage, since the outcomes depend on the plan developed and the choices made by the student, she will take responsibility for those choices made. This may sometimes lead to failure and confusion, but it may also lead to success and elation (Dreyfus and Dreyfus, 2005).

Dreyfus and Dreyfus (2005), continuing with the driving metaphor, provide a scenario in which the driver, leaving a freeway off- ramp, has learned to pay attention to the speed of the car in this situation versus shifting gears. Taking into account speed and 
other factors such as road conditions and other drivers, the driver may decide the car is going too fast. At that point the driver must decide whether to let up on the accelerator, remove her foot or downshift, or to brake. The driver is relieved if the car makes it through the turn and flustered if the car begins to skid.

Scholars who complete the McNair program develop competence with regards to all or almost all of the elements that make up the undergraduate-student-aspiring-to-be-agraduate student version of the college student role. Their McNair program experiences make them aware that they actually have a relatively higher level of role expertise than many of their peers. They have experiences dealing with different professors (and extended exposure to working with their project mentor), conducting and writing about a research project from beginning to end at the undergraduate level, and selecting and applying to graduate programs and for funding. They then transition to graduate school, and have to learn a new version of the "successful college student" role as a graduate student.

The expertise development process starts all over again in graduate school. By the end of their second or third year of graduate school, former McNair Scholars may have developed competence with some areas of the graduate student role. After several years of graduate school, they are much more capable of understanding how other factors may affect their academic plan for completing graduate school: "If I get funding for this project, then I will continue working with this faculty member," or "If I can use my networks to apply for this job, then I will have enough time to attend classes part time." Expertise development can help us understand the ways that Scholars take the 'lessons' they learn in McNair, to first become more expert undergraduate students 
aspiring to graduate school. In addition, McNair provides Scholars with advice on how to proceed in graduate school. Former McNair Scholars incorporate their McNair acquired knowledge with their experiences in graduate school, to develop a depth of knowledge about the role of graduate student and possible occupational positions in the field of higher education, including professor or other academic professionals.

\section{Combining Cultural Capital, Role-as-Resource, Role Mastery and Expertise}

Development: a conceptual device to understand how McNair Scholars learn to be successful college students.

\begin{tabular}{|l|l|l|l|l|l|l|l|l|l|l|l|l|l|l|l|l|l|l|l|l|l|l|l|l|l|}
\hline Figure 2: Undergraduate Role: Ideal Expert \\
\hline a & b & c & d & e & f & g & h & i & j & k & l & m & n & o & p & & r & s & t & & v & w & x & y & z \\
\hline $\mathrm{x}$ & $\mathrm{x}$ & $\mathrm{x}$ & $\mathrm{x}$ & $\mathrm{x}$ & $\mathrm{x}$ & $\mathrm{x}$ & $\mathrm{x}$ & $\mathrm{x}$ & $\mathrm{x}$ & $\mathrm{x}$ & $\mathrm{x}$ & $\mathrm{x}$ & $\mathrm{x}$ & $\mathrm{x}$ & $\mathrm{x}$ & $\mathrm{x}$ & $\mathrm{x}$ & $\mathrm{x}$ & $\mathrm{x}$ & $\mathrm{x}$ & $\mathrm{x}$ & $\mathrm{x}$ & $\mathrm{x}$ & $\mathrm{x}$ & $\mathrm{x}$ \\
\hline $\mathrm{x}$ & $\mathrm{x}$ & $\mathrm{x}$ & $\mathrm{x}$ & $\mathrm{x}$ & $\mathrm{x}$ & $\mathrm{x}$ & $\mathrm{x}$ & $\mathrm{x}$ & $\mathrm{x}$ & $\mathrm{x}$ & $\mathrm{x}$ & $\mathrm{x}$ & $\mathrm{x}$ & $\mathrm{x}$ & $\mathrm{x}$ & $\mathrm{x}$ & $\mathrm{x}$ & $\mathrm{x}$ & $\mathrm{x}$ & $\mathrm{x}$ & $\mathrm{x}$ & $\mathrm{x}$ & $\mathrm{x}$ & $\mathrm{x}$ & $\mathrm{x}$ \\
\hline $\mathrm{x}$ & $\mathrm{x}$ & $\mathrm{x}$ & $\mathrm{x}$ & $\mathrm{x}$ & $\mathrm{x}$ & $\mathrm{x}$ & $\mathrm{x}$ & $\mathrm{x}$ & $\mathrm{x}$ & $\mathrm{x}$ & $\mathrm{x}$ & $\mathrm{x}$ & $\mathrm{x}$ & $\mathrm{x}$ & $\mathrm{x}$ & $\mathrm{x}$ & $\mathrm{x}$ & $\mathrm{x}$ & $\mathrm{x}$ & $\mathrm{x}$ & $\mathrm{x}$ & $\mathrm{x}$ & $\mathrm{x}$ & $\mathrm{x}$ & $\mathrm{x}$ \\
\hline
\end{tabular}

I will use different versions of the alphabet to illustrate how McNair Scholars

learn to be successful undergraduate and graduate students (see figure 2). This lower-case alphabet represents all of the important steps a student must master in order to successfully complete an undergraduate degree. This alphabet is in a temporal sequence_- "a" may be applying to university, while " $\mathrm{z}$ " might be graduating. Through the middle letters, there may be aspects like study habits and time management skills, interacting with professors and other students, navigating the university bureaucracy and financial aid systems, and so on. For students interested in graduate school, the end of the alphabet might represent some aspects of preparing for that, such as putting together an 
application, taking appropriate classes, taking the GRE, volunteering or doing other extracurricular activities, and so on. The x's below each letter represent experience within each task. The more experience a student has with each aspect of the role of student, the farther along they would be in the Dreyfus Model of Expertise Development for that step. McNair Scholars: Pre-McNair

\section{Figure 3: Undergraduate Role: Pre-McNair}

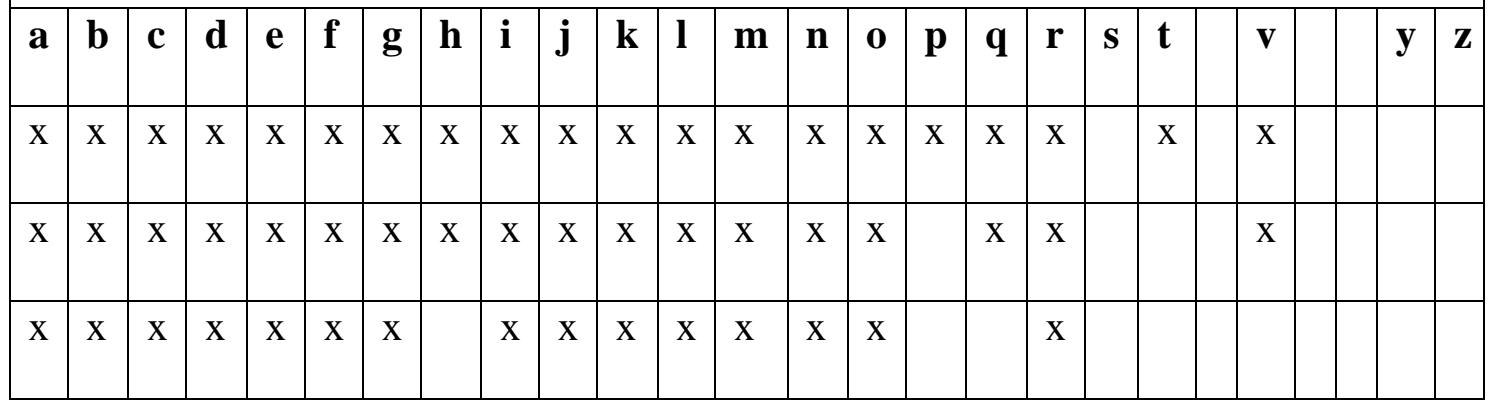

When students begin the McNair program as juniors or early term seniors, they may not be aware of all the separate steps needed to be a successful undergraduate. However, considering that students are only eligible for the program if they have "demonstrated strong academic potential", we can assume that they know quite a bit about the role of undergraduate student. The McNair program helps undergraduate Scholars learn all of the steps in the alphabet, and provides experiences that increase the depth of the Scholar's knowledge for specific steps near the end of the alphabet sequence (see figure 3).

From this representation it is clear that they may be missing a few letters, as they cannot know what they don't know. In addition, they have less expertise with regards to the last steps because they have had fewer experiences toward the end of the alphabet 
than at the beginning. They have a breadth and a depth of knowledge about being an undergraduate, but are likely missing some awareness and experience about the end of their undergraduate experience and ways of preparing for graduate school.

McNair Scholars: Post-McNair

\section{Figure 4: Undergraduate Role: Post-McNair}

\begin{tabular}{|c|c|c|c|c|c|c|c|c|c|c|c|c|c|c|c|c|c|c|c|c|c|c|c|c|c|}
\hline $\mathbf{a}$ & b & c & d & $\mathbf{e}$ & f & $\mathbf{g}$ & h & $\mathbf{i}$ & $\mathbf{j}$ & $\mathbf{k}$ & l & $\mathbf{m}$ & $\mathbf{n}$ & $\mathbf{0}$ & p & $\mathbf{q}$ & $\mathbf{r}$ & $\mathbf{S}$ & $\mathbf{t}$ & $\mathbf{u}$ & $\mathbf{v}$ & $\mathbf{W}$ & $\mathbf{x}$ & $\mathbf{y}$ & $\mathbf{Z}$ \\
\hline $\mathrm{X}$ & X & $X$ & $X$ & X & X & $X$ & X & X & X & X & X & $\mathrm{X}$ & X & X & $\mathrm{X}$ & $\mathrm{X}$ & $\mathrm{X}$ & $\mathrm{X}$ & $X$ & $\mathrm{X}$ & $\mathrm{X}$ & $\mathrm{X}$ & $\mathrm{X}$ & $\mathrm{X}$ & $X$ \\
\hline $\mathrm{X}$ & X & $X$ & X & X & X & $X$ & X & X & X & X & X & $X$ & X & $\mathrm{X}$ & $X$ & $X$ & $\mathrm{X}$ & $\mathrm{X}$ & $X$ & $X$ & $\mathrm{X}$ & $X$ & $\mathrm{X}$ & X & \\
\hline$X$ & $\mathrm{X}$ & $X$ & X & $X$ & $\mathrm{X}$ & $\mathrm{X}$ & & $X$ & $X$ & $X$ & $X$ & $\mathrm{X}$ & $X$ & $\mathrm{X}$ & & $\mathrm{X}$ & $\mathbf{X}$ & $\mathrm{X}$ & $\mathrm{X}$ & $\mathrm{X}$ & & $\mathrm{X}$ & $\mathrm{X}$ & & \\
\hline
\end{tabular}

After participating in the McNair Program, we can assume that students have extensive knowledge about the undergraduate student role, because the Program has imported this cultural capital to them. They also have a depth of knowledge through their experiences at the undergraduate level. While there might be the occasional gap in this knowledge, these students have become experts in awareness of the role of undergraduate and how to enact it effectively, and they have built up experience doing so (see Figure 4). 
Figure 5: Graduate Student Role: Post-McNair, pre-grad school

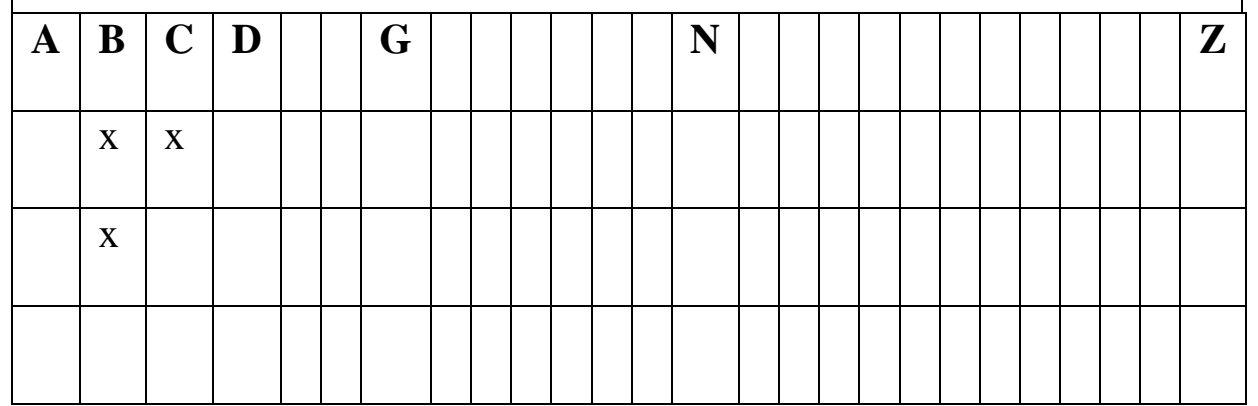

At this point, students are also working on Differentiated Role Mastery. Students are made aware that there are two roles of student: undergraduate and graduate. McNair helps students understand and become experts in the undergraduate student role and introduces them to the role of graduate student (see figure 5). Again, this upper-case alphabet represents a students' breadth of knowledge — all the things they would need to know to be a successful graduate student. We can think of capital "A" as being accepted into a program and (considering the goals of the McNair Program) capital " $\mathrm{Z}$ " as getting a Ph.D. While students still have a lot to learn about the role of graduate student, McNair has made them aware that there is a different role and has introduced them to certain aspects like getting in, and provided experiences like working with faculty and conducting research.

This chapter has described the three theories combined that will be useful in this study. Combining these three theories can help us understand the impact of the McNair Program, as well as that of graduate school experiences, on FLU students. The McNair Program imports cultural capital to these students in the form of increased role knowledge. Basically, McNair participation helps Scholars achieve greater role mastery 
of the undergraduate student role. This increase in cultural capital may also impact their habitus. Changes in Scholars' levels of cultural capital and habitus may subsequently affect students' view of what they could achieve in the field of higher education. Changes in what Scholars now believe is possible to achieve in the field will in turn impact their actions, or practice.

Student awareness of what is possible and how to act appropriately in different settings can be understood through role-as-resource theories. Students with greater role mastery possess an important resource that can help them succeed in graduate school. Expertise development can explain students' development over time in undergraduate and then graduate school—before and after McNair Program participation. This combination of student knowledge of how to be successful and experience in doing so is visually represented here as an alphabet representing breadth and x's representing depth of experience. This representation will be revisited in the discussion of students' understanding of the impact of the McNair Program at different points in time in chapter six. The next chapter of this thesis will explain the methodology used in this study, including the research design, site selection, participants, data collection and analysis. 


\section{Methods}

In this chapter, decisions and rationale for the research method and design are discussed. Strategies regarding sampling, data collection, and data analysis are described. Finally, a researcher biography is presented.

This study uses a comparative interview design to explore first-year graduate students' understandings of the impact of participating in the McNair Program on their graduate school experiences, and to explore second and third year graduate students' understandings of the impact of participating in the McNair Program on their graduate school experiences. An interview design is appropriate for this study because it is effective for capturing the lived experiences of individuals. Michael Patton explains that "depth interviewing probes beneath the surface, soliciting detail and providing a holistic understanding of the interviewee's point of view" (1987, p. 108). Interviews "capture the deep meaning of experience in the participants' own words (Marshall \& Rossman, 2011, p. 93).

A comparative design is appropriate for this study because it may shed light on variation in McNair Scholars' understandings at different points in time. As former McNair Scholars progress through graduate school, role as resource theory predicts that their understandings of the role of graduate student, and effective ways of enacting that role, become more sophisticated. For this reason, and because many graduate programs vary from year to year, it is important to differentiate between the ways that first-year and the ways that second- and third-year graduate students understand the impacts of program participation on their graduate school experiences. A comparative in-depth interview design is the most ideal way to acquire this information. 


\section{Site Selection}

While the purpose and research questions for this study are not site-specific, they are population-specific. The focus is on currently enrolled graduate students who participated in the PSU McNair Program during a single funding cycle (2007-2012). This does not mean that these students are attending graduate school at Portland State University. Former scholars of the PSU McNair Program are enrolled in graduate programs all over the world. Because the study is population-specific, it could not be conducted on McNair Scholars from a different program/school. This study could be easily adapted to focus on Scholars from other programs.

\section{Participants}

The participants in this study are students who participated in the Portland State University McNair Scholars Program between 2007 and 2012 who have completed at least one year of graduate study at the time of the interview, regardless of when they completed the program. In order to be eligible for the McNair Program, students must be either first-generation college students and low-income, or from an underrepresented minority group. All students in the McNair Program were required to attend PSU fulltime, hold a cumulative GPA of 3.0 or higher, and be US citizens or permanent residents.

The population is constrained by the year that scholars participated in the program (2007-2012) because these years fall within a single funding cycle. The program content and expectations of the Department of Education vary by funding cycle. In order to explore the ways that McNair Scholars understand the impacts of the program on their 
graduate experiences, it is important that they all participated within the same funding cycle because the program design was consistent during this time. Because this is a comparative study, it is even more important to control for other variations-such as differences in the design of the program by funding cycle. 
Ten students have been interviewed. Six had completed one year of their graduate programs, four had completed two or three years. Participant characteristics are presented in table 3 below:

Table \#3: Participant Characteristics

\begin{tabular}{|c|c|c|c|c|c|c|c|}
\hline Pseudonym & Gender & Age & Degree type & Discipline & Year & FLU & State \\
\hline Jennifer & $\bar{F}$ & 32 & Master's & Social Science & $1^{\mathrm{st}}$ & $\overline{F L}$ & In \\
\hline Kathy & $\mathrm{F}$ & 24 & $\begin{array}{l}\text { Ph.D. [combined- } \\
\text { two institutions] }\end{array}$ & Natural Science & $1^{\text {st }}$ & FL & Out \\
\hline Amanda & $\mathrm{F}$ & 27 & $\begin{array}{l}\text { [Dual] } \\
\text { Master's/Ph.D. }\end{array}$ & Social Science & $1^{\text {st }}$ & FL & In \\
\hline Rachel & $\mathrm{F}$ & 28 & $\begin{array}{l}\text { [Professional] } \\
\text { Master's }\end{array}$ & Humanities & $1^{\text {st }}$ & FLU & Out \\
\hline Mary & $\mathrm{F}$ & 37 & $\begin{array}{l}\text { [Professional] } \\
\text { Master's }\end{array}$ & Social Science & $1^{\mathrm{st}}$ & FLU & In \\
\hline Charlie & $\mathrm{F}$ & 31 & $\begin{array}{l}\text { [Dual] Master's } \\
\text { /Ph.D. }\end{array}$ & $\begin{array}{l}\text { Social Science/ } \\
\text { Natural Science }\end{array}$ & $1^{\mathrm{st}}$ & FL & In \\
\hline Aaron & M & 28 & [Dual] Master's & Social Science & $2^{\text {nd }}$ & FL & Out \\
\hline Lydia & $\mathrm{F}$ & 26 & Master's & Social Science & $2^{\text {nd }}$ & FL & Out \\
\hline Vincent & M & 30 & [Professional] & Social Science & $3^{\text {rd }}$ & FL & In \\
\hline Ichobod & $\mathrm{F}$ & 44 & [Dual] Master's & Social Science & $3^{\text {rd }}$ & FLU & In \\
\hline
\end{tabular}

\section{Recruitment}


The following is a description of how the researcher gained access to participants of the McNair Program. In the spring of 2012, an email was sent directly from the McNair office to eligible students, with an announcement that students may soon receive an email from the principal investigator with an invitation to participate in a research project that explores the impact of McNair program participation. The second email from the principal investigator was sent successfully to 92 students, describing study participation as involving an approximately one-hour tape-recorded interview, and also provided investigator contact information, and a copy of the informed consent form for potential participants to review before they contact the researcher and agree to participate (see Appendix).

This process was repeated again in the spring of 2013; 103 emails were sent successfully to eligible students. These email invitations to participate were resent three times over the summer of 2013. Finally, McNair Scholars (who expressed an interest in this study) were asked to contact other students who met the criteria for inclusion to the study and to invite them to contact the researcher for possible inclusion in the study. Students made these contacts via email, Facebook, and text messaging.

Once a participant agreed to be part of the study and scheduled an interview time, she was asked to review the attached informed consent document, and email the researcher indicating she had reviewed the document and was still willing to participate in the study. Individuals who scheduled an in-person interview were provided with a hard copy of the informed consent to review and sign immediately before beginning the interview as well as a copy of this signed form. Participants completing the interview via 
Skype or phone were asked to confirm, for a second time, that each had read the consent document and was still willing to participate.

\section{Data Collection}

Data was collected using semi-structured interviews. The interview instrument contains 12 questions, with an occasional probe or clarifying question (see appendix \#). Students were asked about their current experiences and strategies, as well as to reflect on their experiences in the McNair Program and how this influenced their graduate experiences. Based on four pilot interviews conducted in 2012, this instrument adequately answers each of the research questions. No major changes were made to the instrument guide, and all 10 interviews are included in this analysis.

Recruitment for interviews began during the spring of 2012. At this time, 10 interviews (six first year and four second or third year) interviews have been conducted. All interviews were tape-recorded with consent and are varied in length from 45 to 90 minutes. The interviews were informal and open-ended, and carried out in a conversational style. Memoranda were written while conducting interviews, listening to taped interviews, typing transcripts, and reflecting upon a particular interview.

Since the pilot study focused on first-year graduate students only, questions were added to explore second- and third-year experiences compared to the first year. Second/third-year students were asked the same questions as first-year students, as well as questions about the subsequent years in the program and how their experiences might have changed over time. This means that second- and third-year students were able to reflect on their current as well as their first-year experiences. For example, second/thirdyear students were asked to reflect on the issues they faced during their first year and 
strategies they had employed or wished they had employed upon reflection. They were then asked the same about their second and third years. Students were also asked whether their expectations of their graduate programs and of themselves as students had changed over this time. See Appendix \# for the full interview guide.

\section{Data Analysis}

Coding the data from this study used a scheme of numbers and letters to designate major categories and subcategories. Memoranda were written by the researcher while conducting interviews, listening to digitally recorded interviews, typing verbatim transcripts, and reflecting upon a particular interview. Ongoing data analysis took place throughout the study. Initial code categories were based on the pilot study. Initial code categories included "Issues Faced in the First Year of Graduate School", "McNair Preparation for Graduate School", "Feelings about graduate school" and "Feelings about the McNair Program”. Codes were added by the researcher with regard to second/third year experiences and all interviews were recoded. These code categories included "Issues faced in the second/third year of graduate school", "second/third year strategies", "Understanding what a good graduate student is", "and McNair preparation for second/third year". These and other categories allow an exploration of the ways Scholars understand the impact of the McNair program through the first, and second or third year of graduate school.

Thematic content analysis (Simons, Lathlean, \& Squire, 2008) was used to identify themes and patterns in the data. Themes were analyzed within groups, first-year students and second/third-year students, and then compared between groups. This method of analyzing allowed for identification of similarities and differences. 


\section{Research Questions}

This study aims to answer the following questions:

1. How do former PSU McNair Scholars who are first-year graduate students understand the ways that program participation impacted their graduate school experiences?

2. How do former PSU McNair Scholars who are second- and third-year graduate students understand the ways that program participation impacted their graduate school experiences?

3. How are the experiences of these two groups of students similar?

4. How are the experiences of these two groups of students different?

Question \#1 allows for exploration of how former PSU Scholars who have completed the first year of graduate school understand the ways participation in the program impacted their graduate school experiences. Interview guide questions to address this research question explored students experiences during the first year of their graduate programs, such as issues they faced, strategies they employed for success, and the ways they thought McNair participation had prepared them for challenges they had faced and experiences they had during their first year of graduate school. Question \#2 allows for exploration of how former PSU Scholars who have completed two or three years of graduate school understand the ways participation in the program impacted their graduate school experiences during the first year as well as the second and third year. Second- and third-year Scholars were asked the same questions as first-year Scholars. In addition, they were asked about challenges and experiences during their second and third years of graduate school, and the ways they felt McNair participation had prepared them 
for these experiences. Scholars were also asked how their feelings about graduate school and the McNair Program, and their expectations about graduate school, had changed.

Question \#3 relates to the comparative aspect of the study by exploring what is common between first- and second/third-year students' understanding of the impact of participation in the program on their graduate school experiences. Question \#4 relates to the comparative aspect of the study by exploring what is different between first- and second/third-year students' understandings of the impact of participation in the program on their graduate school experiences. Codes were tagged with "F" or " $\mathrm{S}$ " to indicate first or second year response to each question.

\section{Researcher Biography}

The researcher is a first-generation, low-income, white female from Portland, Oregon. It should be noted that the researcher qualified for the McNair Program, participated in the Program, and is currently a graduate student. This former PSU McNair Scholar had a positive experience and produced a final paper in the program. This is only one type of experience in the program and may have influenced data collection (interviews) and analysis (interpretation). Former Scholars may have felt some loyalty to a fellow Scholar and therefore were more likely to participate in the study. Scholars may also have felt more at ease discussing their experiences in the McNair Program and in their current graduate programs since they were interviewed by a current graduate student who participated in the McNair Program.

This researcher also has developed relationships with administrators and assistants in the PSU McNair program. The Program Director is on the Committee for this thesis and the Associate Director was the point of access to the population. The 
Committee Chair for this thesis project is a current McNair Program mentor and was the McNair mentor on the pilot study for this project. It should be noted that the Director of the PSU McNair Program has encouraged that the research design, data collection and analysis be conducted independently of any influence by the Program; Autonomous research is the priority for this project. While there are still opportunities for bias, the similarities between researcher and participants in demographics as well as power differentials may alleviate much of this potential bias.

Approval from the Portland State University Institutional Review for the pilot project was granted in 2012. A continuation for the project was granted in the spring of 2013. Informed consent was collected and confidentiality maintained wherever possible. Specifically, identities of participants who made potentially negative comments about the program were protected by avoiding program or project specific references beyond general categories (Master's/Ph.D. program, physical science, social science, humanities and in/out-of-state). Participants were offered a review of the interview transcripts. No participants requested copies of transcripts; however, every participant requested a copy of the published work. 


\section{Results}

Table 4 outlines the layout of the results chapter, followed by a more detailed description:

\begin{tabular}{|l|l|}
\hline Table 4: Results by section and theme & \\
\hline Scholars' Decisions & Choosing a School \\
\hline & Applying and Getting in \\
\hline Scholars' Understandings & Designing/Navigating a Program \\
\hline & Research \\
\hline & Relationships \\
\hline & Programs \\
\hline & Culture \\
\hline Scholars' Reflections & Being a graduate student \\
\hline & Now \\
\hline
\end{tabular}

Chapter five presents the results of analyses of interview data about McNair

Scholars' understandings of the impact of program participation on their graduate school experiences. The results are organized into three major sections. The first section, "Decisions," explores scholars' accounts of how program participation influenced their choices of graduate schools and specific programs. The second section, “Understandings," explores Scholars' current knowledge of different aspects of being graduate students through either the first or second / third years of their programs. The final section, "Reflections," explores Scholars' thoughts about current experiences in 
their graduate programs. The "Reflections" section also includes scholars' projections of their future trajectories in their graduate programs and potential post-graduate school occupational positions.

The "Decisions" section contains three themes. The first theme, choosing a school, examines Scholars' decisions about choosing a school. The second, applying and getting in, focuses on Scholars' experiences getting into graduate school. The third, designing/navigating a program, explores Scholars' decisions about whether to try navigating an existing program or designing a new custom or dual program. The second section, "Understandings," contains five themes. The first theme, research, explores Scholars' understandings of research, including the McNair research project, graduate research methods coursework, and their own graduate research. The second theme, relationships, focuses on Scholars' understanding of relationships, including relationships with McNair mentors, with faculty members in graduate school, with peers, and others. The third theme, programs, has to do with Scholars' understandings of their graduate programs and includes understanding academic rigor, workload, their own study habits, their own personal challenges while in their programs, and their work/life balance during their programs. The fourth theme, culture, explores Scholars' understandings of the culture in their graduate programs, which often involved class differences. The fifth theme, being a graduate student, highlights challenges scholars faced and the strategies they had for dealing with those challenges. The final section, "Reflections," contains two themes. The first theme, now, has to do with Scholars' reflections about what they're doing now, and the second, trajectories, presents Scholars' projections of their possible trajectories moving forward beyond graduate school. 
Each theme will be broken into four parts based on the original four research questions. Initially, first-year Scholars' experiences will be presented (RQ\#1), followed by a description of second/third-year Scholars' experiences (RQ\#2). Next, similarities among all Scholars' experiences with regards to the theme will be identified (RQ\#3), followed by discussion of differences between first-year and second/third-year Scholars' experiences with that same theme (RQ\#4). Scholars will be identified by their year of graduate school and the design of their program (e.g. dual-Master's).

\section{Scholars' Decisions}

\section{Choosing a School/Program}

Scholars at the end of their first year of graduate school described the McNair Program as one of the major influences on their choice of school and program. Other identified influences on school/program choice included being place-bound and financially restricted. Scholars specifically mentioned the McNair Program "education plan" assignment as being particularly helpful as they considered their decisions. The McNair Program "education plan" assignment required Scholars to research potential graduate schools and map out what each term for at least the initial two years of graduate school would look like in the students' chosen program. Scholars felt the McNair Program had a major impact of their school/program choice decisions because they would not have known how to research and apply for graduate programs without their experiences in the program. 
One Scholar referred to the education plan specifically:

"It's understanding and pulling all of those different pieces together...there were not a lot of details about like 'here is how you come up with an education plan' you know it's just like 'okay we just want you to map this out... Just figure it out, you're smart.'” (First-year, Master's)

Scholars at the end of their second and third years of graduate school did not discuss at much length how participating in the McNair program initially impacted their choices of schools or programs. Instead, these students demonstrated the impact of the McNair program in the ways they talked about what their research interests had been at the time of their McNair projects and how those interests had changed. These Scholars reflected backward on their interests, the impact their McNair research projects had on those interests, and eventually on their choice of schools and programs. A second-year Scholar remembered:

"When I was in McNair I did a study and I got exposed to the literature a little bit and then when I was deciding where I wanted to go to grad school, I narrowed the topics I wanted to potentially study based on [the literature] and then I kinda tried to find the best-fit grad schools. [My current program] was kind of always my first choice." (Second-year, Professional Master's)

What was similar in both groups' responses relating to this theme was that each group felt that the program had increased their confidence in the school choice process. Both groups of Scholars brought up McNair seminars that focused specifically on "impostor syndrome" ${ }^{\text {. }}$ Scholars mentioned that these discussions helped them to both recognize the "imposter" feeling when they had it as well as to know that they were not

\footnotetext{
${ }^{2}$ As described in the literature review, the impostor syndrome refers to the inability to internalize one's accomplishments which results in the feeling that one is not qualified or capable of the opportunities they have received.
} 
alone in feeling this way. One first-year Scholar reflected on how McNair participation increased her confidence about going to graduate school:

I think [McNair has] given me the confidence to just reach out and try for those things. And just realize that it's okay if you don't get it but you're never going to get it if you don't try to get it... I think there was a fear before like "oh well I would never qualify for that sort of thing" but how are you going to know that unless you try for it? (First-year, Master's)

A third-year Scholar specifically remembered the McNair discussions about the impostor syndrome:

“...it helped to normalize it... to be in a group of people who not only copped to having the imposter syndrome but also who I knew were not imposters was like "oh, really?" Seeing people I thought of as successful were in the same [McNair] program as me." (Third-year, Dual Master's)

The major difference between the groups was that the first-year Scholars focused on specific assignments when discussing the way the McNair program impacted their school choices. Second/third year Scholars spoke of the program's impact of program choice decisions in more roundabout ways. The Scholars noted the ways that conducting their McNair research projects impacted their research interests, which in turn impacted their choices of school and programs. A third-year Scholar discussed her increased interest in theory after being exposed to new theorists as part of her McNair project: " $I$ had this preconceived notion about theory and McNair helped me see the importance of it." This first-year Scholar explained the value she found in keeping the assignments after completing the McNair program: 
You might be able to stumble on it yourself but it's so nice to go through a program... where they show you the ins and outs and the secrets... [The assignments said] if you're searching for a grad program, here's the ways you can do that, here's the things you need to be really concerned about. If you go to visit a campus, here's a list of things you should be asking. There was a lot of detail, a lot of information, yet I had access to that information over and over again. (First-year, Professional Master's)

Applying and Getting In

First-year Scholars discussed how participating in the McNair program as undergraduates increased their confidence when it came to applying to graduate programs. The new confidence also made Scholars more willing to apply for other academic opportunities such as scholarships, presenting at conferences, and submitting journal manuscripts. Scholars explained that completing the McNair Program application was particularly helpful for understanding the details of the subsequent graduate school application process. First-year Scholars also discussed how the experience gained from their McNair projects helped them feel competitive during the graduate school application process. A first-year Master's student described how McNair participation increased her confidence in applying to graduate programs:

It's like training wheels for the application process. I mean the first thing that you do is you apply to the McNair program. You have to get your letters of recommendation, you have to get your stuff...just going through it, it's this kind of safe spot to try. (First-year, Master's)

Continuing the pattern found in the school choice theme, second/third-year Scholars spoke more about their experiences since enrollment than how McNair participation impacted the graduate programs application process. None of the second/third-year Scholars discussed the impact of the McNair Program on their competitiveness with regards to being accepted to their graduate programs, even 
when directly asked about the ways they thought program participation impacted getting into their programs. Second/third-year Scholars focused on the application process. This third-year Scholar remembered, "One of the assignments was go get an application for school and fill it out, have each other look at it...it's not that hard. But if you've never actually filled one out, it is kind of daunting." (Third year Professional Degree).

One similarity in both groups' responses was recognition of how helpful the McNair application process, and seminar information about graduate school applications, were for their efforts in applying to their different programs. One Scholar disclosed that she didn't have anyone else to turn to in order to get this information about applications:

"People who come from backgrounds where other people have gone to college...they know what it takes to get into grad school...so I think what McNair did was say 'Okay y'all this is how it works. You gotta write a personal statement. There's no secret here. This is what a good personal statement looks like, this is what a not so good personal statement looks like. This is the process."” (Third-year, Dual Master's)

However, there were some differences in how Scholars from each group talked about specific program impacts on the admission process. First-year Scholars emphasized how participating in the program helped them feel competitive with other applicants, while second/third-year Scholars did not. All first-year Scholars said they believed that, had they not participated in the McNair Program, they would not have been accepted to their graduate programs. First-year scholars identified two different positive effects: On one hand, many felt that without their McNair experiences, they would not have had the confidence and know-how to apply; on the other, Scholars mentioned that 
McNair participation gave them research and experiences that graduate schools were looking for in applicants. A first-year Scholar pointed out this competitive edge:

"The biggest part [of McNair] is that it allowed me to work with someone, an advisor, to conduct a project. And that's really what the people who interviewed me in all the graduate programs were looking for, for someone who was able to do that." (First-year, Combined Ph.D.)

\section{Navigating/Designing a Program}

First-year Scholars discussed the ways that they made program-choice decisions. Three out of six first-year Scholars were in a custom dual or combined program, one was in an existing dual Master's Program, another in a custom dual Master's/Ph.D. program, and a third in a combined Ph.D. Program at two different institutions. Two of the three remaining first-year Scholars were in professional Master's Programs, while the final Scholar was in a Master's Program.

When asked why they had chosen dual or custom programs, these Scholars generally talked about wanting a challenge. One first-year Scholar stated, "I guess you could say ... I thought it would be a challenge” (First Year-dual Master's/Ph.D.). Firstyear scholars also spoke about their interests in certain kinds of research and social justice interests, specifically in being able to influence policy that affects marginalized groups disproportionately.

Second/third-year Scholars also discussed the ways they had made decisions about their programs. One second-year Scholar had completed two years of a dual Master's program and another had completed two years of a Master's program. One third-year Scholar had just completed the third year of a professional degree program and another had just completed the final year of an existing three-year dual Master's program. 
When asked why they had chosen dual programs, second/third-year Scholars' responses were both similar and different from the first-year's responses. One Scholar noted, "[My dual program] was interesting and I think like a lot of McNair scholars, I wanted a challenge.” (Third Year Scholar, dual Master's). Another second/third-year Scholar shared a different reason for his program choice, explaining that the dual program certification was necessary for the kind of work he sought. "I'm working in [field of study] and I'll probably continue in either working at think tanks or doing [one part of the dual program] policy for [the other topic of the dual program] companies" (Secondyear dual Master's).

There were more similarities than differences in this theme. All of first-year and most of the second/third-year Scholars reported that they were very busy balancing schoolwork and other responsibilities. All of the Scholars either received departmental funding and worked in their programs, or worked jobs outside of school. Many first-year scholars noted with some pride that they were "working their asses off" in order to succeed in graduate school. Both groups of Scholars connected their program choice decisions to "wanting a challenge," and many stated they believed that other McNair Scholars made program choice decisions for the same reason.

An interesting difference was that first year Scholars seem to tie their program design choice decisions to their research interests and passion about social justice, while second/third year Scholars described their program design decisions as reflecting what they thought would help them in their subsequent job searches. In the choosing a school theme, second/third-year scholars reflected on their initial decisions based on their 
research interests they had developed in McNair, but in this theme these scholars reflect that the design of their programs will help them in their future occupations.

\section{Scholars' Understandings}

\section{Understanding Research}

First-year Scholars went into great detail about the ways that their experiences conducting McNair projects either shaped or, in some cases, discouraged their interests in research and in studying specific topics. Interestingly, first-year Scholars recalled their projects as either complete successes or complete failures, and this perception seems to have a major impact on their interests. All the first-year Scholars recollected that the McNair project was often their only opportunity to do research. In addition, Scholars noted that their research experiences and discussions of research in McNair seminars were particularly helpful for succeeding in graduate-level research methods courses. One first year Scholar stated she thought that she had an advantage over her peers in a methods class because of her McNair experiences.

"I think that because I had done qualitative analysis in the McNair program before this class, I had a little bit of an edge on some of the other students that I was working with because I had just had a little bit of exposure, at least with the terms." (First-year, Master's)

Interestingly, second/third-year Scholars did not see their McNair projects in such "black" and "white" terms. Second/Third-year Scholars realized that even a "failed" project was good experience for subsequent graduate-level research. These Scholars often felt that their McNair projects had been "too grand" or "not feasible" and wished that they had scaled them back in order to achieve better outcomes. These students also thought back about how their experiences in the McNair Program, combined with their 
experiences in the first year or two of graduate school, helped them to realize what they

did not want to study. That was the case for this Scholar:

I kind of had an inclination through my undergrad of doing [my McNair research topic] so once I got to grad school it confirmed, 'no I don't want to do this ever again'. I feel like if I was an undergrad that didn't really know anything, once I got to [that topic] in grad, I probably would have stayed like "yeah I gotta keep going on this stuff, I know it's hard right now but later on it will pay off" but for me it was more like 'No, no - I need to stay away from this crap." (Third-year, Professional)

The McNair research project and seminars had a major impact on both groups of Scholars. These project helped Scholars shape their interests both in different kinds of methodology as well as different research topics. Scholars also felt that the experiences they gained in the project and in McNair methods seminars helped prepare them for graduate classes. One third-year student realized, "I came out of McNair with a different level of research experience and a different perspective on the importance of theory. That helped in the first year definitely because I took several theory classes."

The biggest difference between the two groups was that second/third-year Scholars expressed more nuanced recognition of the value of their McNair research projects. First-year Scholars had a difficult time seeing any value in a project they deemed to be "failed", as this first-year Scholar lamented:

“My project was just not, it just wasn't well thought out, it wasn't well organized, like my data collection was just kind of shoddy. And I just didn't really get the positive value from doing research that a lot of students get. (First-year, Master's)

While second/third-year Scholars now were aware of the flaws in their projects and felt they had reached too far, they did not see this experience as a total failure. These Scholars noted that they could now see how even failed 
McNair projects lay the foundations for success in future projects. For example, one third-year Scholar who had tried a mixed methods approach with a McNair project she never finished discussed how that work impacted her current graduate project:

"I actually did a mixed method evaluation so it's like what I would have hoped to do in McNair, I did successfully there... And I just kind of stuck my toe in the water with McNair but then I had that background and I had the background of actually having done research, of actually doing qualitative research on a really difficult issue." (Third-year, Dual Master's)

\section{Understanding Relationships}

First-year Scholars focused on their relationships with their former McNair mentors, McNair staff, and their peers. They discussed how having conflict with their McNair mentors prepared them for "working with academics". First-year Scholars mentioned how McNair seminars where faculty and McNair alumni talked about the realities of graduate school were particularly helpful for preparing them for the feelings of being alienated from their peers and faculty once they began their graduate programs. Similar to their "black" and "white" understandings of the McNair research projects, first year Scholars also had a difficult time seeing any value in a negative mentor experience. Many expressed that they felt isolated because of this experience, like this first year Master's student who, when asked if she had gotten any value out of the mentor relationship, reported, "Yeah, not really. But I know that some of the other people in my cohort had great relationships with their mentors and still do, I think it was just my personal situation.” (First-year Master's). 
Second/third-year Scholars focused on their relationships with current faculty members. These Scholars focused very little on their relationships with their McNair mentors, unless they were still in the same programs or still had frequent contact with them. This is an important distinction. When Scholars maintained regular contact with their McNair mentors, this relationship was still seen as very valuable especially the Scholars still working with their mentors at the graduate level. Second/third-year Scholars contended that relationships with faculty were about much more than interacting in classes. They mentioned reciprocity and networking as important aspects of these relationships. Interestingly, second/third-year scholars reported that they had little contact with their cohorts and had not found effective strategies in dealing with this. One third-year scholar expected to have even more friends in graduate school than he had in undergraduate: "I thought I'd have a bigger group of friends and I realized it shrunk even more. Instead of "there's only 140 students, I should have a big group of friends" it turned out not to be that way."(Third year professional)

One important similarity was that both groups of Scholars felt isolated from their peers. In some cases these Scholars attributed this isolation to differences in class and finances, but just as often about their lack of cohort due to their custom and dual programs. For example, this Scholar communicated her feelings of limbo:

"[My peers] all left this year with some really close friendships and I kinda left with none. Because my program is very different. My first year I'm with all Ph.D. students, my second year I drop down to being with [Master's] students. So my cohort changes. I'm not even with them next year, which is another reason I felt really disconnected. I'm in limbo." First-year, Dual Master's/Ph.D.) 
An importance difference between the two groups of Scholars' responses had to do with relationships with graduate program faculty members. First-year Scholars' reflections about current faculty members were limited. When they did bring up these relationships, there was a focus on conflict. In contrast, second/third-year Scholars focused on reciprocity and networking with faculty members. These more experienced Scholars felt it was important to make the most of these relationships and that interaction with faculty in classes wasn't enough. This second-year Scholar connects this facultystudent relationship directly to his job prospects:

“...stacking up classes is not going to just accumulate and make you a smarter stronger job candidate, you actually have to build up and out... You have to think about networks really thoughtfully so you have to think about who's doing what and how are they related to where you're going to need to be." (Second-year Dual Master's)

\section{Understanding Programs}

One very interesting finding is that, on a general level, first-year scholars expressed how their graduate programs were easier than they expected, and not as challenging as the McNair Program had been. One Scholar declared that her professional Master's program was "not as academic" as the McNair Program had led her to expect.

Most second/third-year scholars also reported that their programs were generally not as academically challenging as they had expected when they first started graduate school. However, these scholars had determined that there were other things to prioritize, such as connecting with faculty and gaining internship experience. These scholars also discussed understanding the opportunities that were available to work with faculty members outside of the classroom. This 
second-year dual master's scholar discussed the difference between connecting

with instructors in class versus working for professors on research:

"I don't think that [professors] who take you under their wing in their classroom ever pay off very much. It's all people you work for and to whom you provide some benefit, reciprocity, but especially paying attention to the role that the student plays, you actually have to do something for the professor that advances their career" (Second-year, Dual Master's)

Both first-year and second/third-year Scholars in custom-designed programs spoke of the particular challenges they experienced in trying to navigate them, especially administrative issues. Administrative issues, for dual-enrolled students, included a range of issues all related to a lack of established program procedures. One dual-enrolled student expressed frustration about her inability to register for courses and, as a result, needing to contact the program administrators every term. These administrators would tell the Scholar, “We forgot about you.” In addition, both groups of Scholars mentioned how McNair prepared them for the heavy reading load they experienced in graduate school, as well as helping them learn how to "just get things done".

The major difference in Scholars' understanding of their programs was the level of frustration that first-year Scholars felt about their programs being less rigorous than they had anticipated. One first-year Professional Master's Scholar explained that she was disappointed that her instructors didn't have Ph.Ds. and that it was "a challenge to try to overcome my perceptions of who I thought an instructor should be”. Another Scholar expressed disappointment in her program: 
I wanted a challenge... I thought it would be a challenge and I'm bored. All year I had a huge course load and I had internships and I was just absolutely not challenged at all. According to my cohort it was very difficult so I'm just weird. My personal life was more challenging than my academic life. (First-year, Dual Master's/Ph.D.)

Conversely, when second/third-year Scholars talked about the programs not being as challenging as they expected, they didn't express any frustration. They felt good about finally recognizing the appropriate amount of work to do in order to succeed in their courses and talked of using that "extra" energy to prepare for gaining work experience and networking. A second-year Master's Scholar described the difference between her graduate program and her undergraduate experience at Portland State University:

"At PSU I was doing really well and all my teachers liked me and it was exciting and fun and I was constantly learning things and I was being challenged! But then I went to my Master's program and, like the first semester was okay but, like I took a statistics class and it was basically the same class as I took as an undergrad. And I don't really care. And my classes in my program were okay. I've been working full time for a while now." (Second-year, Master's)

\section{Understanding Culture}

First-year Scholars who did not stay on at Portland State described the challenge of adjusting to a new culture, a new city, a new lab, or a new department. For some Scholars, "understanding culture" had to do with dealing with new faculty and different teaching practices. However, for many Scholars, "understanding culture" focused more on class differences between Scholars and their peers. First-year Scholars spoke specifically about having to take out student loans and working their way through school. They felt isolated from their peers and had not developed effective strategies for dealing with this. When asked how they dealt with this challenge, they explained that they "just got used to it”. This first-year Scholar pointed out: 
"Some of the cultural differences were mostly class differences. Because I come from lower class, lower middle class, and then I'm going to school with all these people who don't think twice about paying a fifty thousand dollar tuition a year you know, they're not even taking out loans, some of them." (First-year, Professional Master's)

Second-year Scholars also reflected on the impact of differences in class on their success in graduate school. They spoke specifically about "secret codes" and "secret languages" that elites use, and how this was a difficult thing for them to adjust to. This third year Professional Scholar was frustrated by these differences between himself and a classmate whose parents worked in the same field they were studying:

"There's a certain language that, unless you know the [field] it would just go right over your head. Their stuff just sounds good, even though it doesn't make any sense. It's stupid to me. It's a semantic point." (Thirdyear, Professional)

Both groups of Scholars spoke at length about finances, working, and dealing with loan debt. They also expressed frustration that their affluent peers didn't need to worry about those things. Both groups of Scholars felt these more affluent students had important practical advantages, both in understanding the culture of the academy and in stress levels. This second- year professional Master's Scholar recalls:

"[My peers'] stress level is completely different because people would jet set off on the weekends and I wouldn't have money to get enough food. People typically aren't concerned about debt. They're able to entertain internships and fellowships that are unpaid but prestigious which was something I couldn't even think about doing" (Second-year, Dual Master's)

There were several interesting differences in the two groups' responses. Only one first- year Scholar discussed anything about "secret languages" or "secret codes" that 
elite students use, even though multiple second/third-year Scholars did ${ }^{3}$. In addition, first-year Scholars expressed a lot of frustration, but had few strategies for dealing with their affluent peers. Another difference is that first-year Scholars pointed out class difference between themselves and their peers but did not connect their awareness of this issue to the McNair program. On the other hand, second/third-year Scholars reflected on the ways that McNair had prepared them to be in school with elite students. This thirdyear Scholar explained:

"I don't know exactly the demographics [in my program] but it tends to be a more elite group in terms of class background and definitely racial background. So I'm glad I had a chance to kind of start to really look at that while I was in McNair." (Third-year, Dual Master's)

\section{Understanding being a graduate student}

When first-year Scholars brought up issues like having to learn new study skills and time management and then were asked how they planned to deal with these issues, most hadn't come up with any effective strategies for this. They often said things like "I'll do better next year", with no particular strategy for how they were going to accomplish this goal. First-year scholars explained that the McNair Program had taught them that graduate students must do everything right and be perfect. For example, one first-year Master's student stated:

"My current program is really, really competitive and I think that the preparation that the McNair gave to us and just that exposure of like, this is what it takes to be a grad student. You have to work hard, you have to make it perfect, you have to do it right." (Firstyear-Master's)

\footnotetext{
${ }^{3}$ The topic of "secret codes" and "secret languages" was not in the instrument or brought up by the researcher, but emerged during three of the four second/third year interviews, and one first year.
} 
Second/third-year scholars reflected about exhausting themselves the first year or two. They described literally making themselves sick before learning to prioritize and accept that they couldn't read every article or book in its entirety or complete every assignment at a 100\% level. One third-year professional program Scholar described how he learned over her time in graduate school to sometimes only give assignments $80 \%$ effort in order to also be able to focus on resting. This third-year dual Master's Scholar recalled her schedule and illnesses:

"I [tend to] overschedule myself and so I get exhausted and like last year... I was TAing, I was advising, I was doing my classes, I was doing my practicum and I was also on [a committee] and I was on three faculty search committees and I had five back to back infections.” (Third-year, Dual Master's)

All of the scholars reported that they faced a range of personal challenges, including illnesses, breakups, family issues, and moving. For both groups of Scholars, understanding themselves as graduate students really came down to how they dealt with specific graduate school issues. In addition to dealing with academic challenges, scholars had not anticipated facing so many personal challenges and couldn't see any way to handle these challenges besides simply avoiding them. When this first-year scholar asked how she might have handled this challenge differently, she stated simply that she would not have moved:

"I think that the full weight and magnitude of what I had gotten myself into kind of hit me like three weeks ago. ... I had just... purchased a house, we were planning on moving, and you know I had finals coming up. And I was taking on a particular class last term that was, I felt like I was like way in over my head. (First-year, Master's)

There were some clear differences in the ways that scholars faced personal and academic challenges. Second/third-year scholars generally expressed a higher level of 
confidence in their abilities as graduate students and a number of effective strategies for dealing with the challenges they had faced. They also spoke specifically about prioritizing and realizing when to just let things go, which is something first-year scholars did not mention. Second/third-year Scholars spoke of an additional benefit of their McNair participation: the motivation provided by McNair that encouraged them to stick to their programs and complete their degrees. One third-year professional Scholar stated:

There definitely was some of that motivation and confidence from (McNair), like I definitely wanted to finish so I could say that I finished. I can tell McNair that I'm done because I know they get funding when someone concludes a terminal degree. (Third-year, Professional)

\section{Scholars' Reflections}

Now

First-year Scholars were generally happy with their programs and with themselves as students. One first-year scholar explained the ways that she thinks the McNair Program impacted the work she is doing now:

"I feel positive...because of all the things that it gave me as far as being ready for grad school. I just feel like it was a really useful preparatory experience. There's much less self-doubt when I go in, I'm not going to say... "I don't even know where to start". I could probably figure out where to start. And that's usually enough to help get a foot in the door. "(First-year, Dual Master's/Ph.D.)

In general, two areas that seemed to be causing Scholars the most frustration were that their programs were not what they had anticipated, and that they did not feel connected to their departments or to their peers. This disconnect was often attributed to social class or lack of cohort, but at times Scholars felt racial discrimination as well. One first-year professional Master's Scholar, who stayed enrolled in her program, went in-depth about 
an incident in a class when she was asked to do an activity based on an article she had read:

"...so in that article they were referencing another journal article that had the actual activity in it so I went back to this other article that wasn't a requirement because you know, McNair! You gotta check stuff out! ... and they discussed exercises and activities that you could do in a business environment to help people connect to place and to the environment. One of them was called a 'mini vision quest' and I was just so upset and that you know this year's been really stressful anyways and I just started crying. I was like 'Im done, I'm done with these people. I'm done with this program. I'm going in tomorrow and I'm going to tell them I'm done. I know I'm a year in but this is so frustrating. "'(First-year, Professional Master's)

All of the second/third-year Scholars had recently graduated or were about to graduate at the time of the interviews. There was an interesting division of Scholars' experiences with their graduate programs. Two of the four second/third year Scholars were happy with their programs. These Scholars spoke specifically about having gained valuable work experience in graduate school as well as networking with professors. When this second-year scholar was asked about how he felt about graduate school, he responded, "I feel good. I mean I would say that I got a lot out of it. I got more out of it than a lot of my peers so I would say by those metrics I feel fairly successful."

The other two Scholars had not been able to find work after graduation and expressed some disappointment. They explained that they did not foresee finding the work they had anticipated in their fields even though they completed their degrees, because they did not know to seek out internship experiences and build extensive network connections while in school. To be clear, these scholars saw occupations available to them, just not the ones they had originally anticipated. Upon reflection, they wished that they had researched their programs more than they had before enrollment. 
One third-year professional degree student who had just graduated thought back about graduate school and what he wished he had known beforehand. It should be noted here that this Scholar listed many positions he was qualified for, but did not feel he was "in the tier of people good enough to get those jobs" that he had looked forward to at the start because he had not known to do an internship his first year:

“I felt like I didn't do enough in [my program]. My first year was really hard to figure stuff out. Academically it was hard enough but also socially and environmental-wise, figuring out the ins and outs and the unsaid rules that I feel like a lot of other people had a better jump on. I was just figuring all this crap out on my own. I had no experience... A lot of people I knew that first summer took extra credits so that way during the next few years they could get a job and work and stuff like that. I guess it's my own fault but still it sucked." (Third-year, professional)

One similarity was that both groups of Scholars discussed their interests in social justice, in general, and their desire to "pay it forward" to students like themselves, specifically. A few Scholars sought out the McNair Program at their schools and offered to help them. A third year Scholar reflected about the impact of McNair through her on other students:

"Not only did McNair have an impact on me but I'm also a big believer in paying it forward and I feel like the skills McNair gave me I've been able to transmit to other students. I work as an academic advisor and as a teacher and I'm always like 'There is no secret code. You come to my office; I will give it to you. Don't let these people keep you out." (Thirdyear, Dual Master's)

\section{Trajectory}

All first-year Scholars mentioned that they were hopeful about the next year of graduate school and they anticipated that they would have better experiences then. They were often looking forward to more practical experiences like working, conducting research, and doing internships or assistantships during the second year. Most first-year 
Scholars hadn't developed effective strategies for dealing with the challenges of their first year and were also looking forward to doing this; however, some Scholars did have plans to modify their study habits. One Scholar noted that during the first year, she had done much of her homework on her couch, and she didn't feel that this was a good strategy for effective studying. Her revised strategy for the upcoming year was to set aside a more formal space to study and to "shut the world out and just get it done".

It was very interesting that none of the second/third-year Scholars were enrolled in $\mathrm{Ph} . \mathrm{D}$. programs and none of them expressed any desire to pursue a Ph.D. in the future. However, these Scholars were still interested in helping other students succeed in higher education. All of the Scholars were interested in public policy and discussed the ways they could use their Master's and Professional degrees to pursue careers in affecting and changing these policies and serving their communities. When asked about the reasons they may not want to pursue Ph.D.'s, Scholars cited dismal reports about the condition of the professoriate and the job market as well as the impact that pursuing a tenured position at a university might have on their personal lives. This second-year Scholar described this reasoning:

"I saw a mismatch between my personal life goals and the ability for me to be successful in the university system. So when I was in the McNair program I definitely thought about getting a Ph.D., becoming a professor, and thought that that would be pretty awesome. I liked that idea. And then I kind of refined it and was like 'Oh, well maybe I can teach part time at a community college or adjunct' and just accept the fact that I won't get the benefits of being a tenured professor and that just started to sound crummier and crummier." (Second-year, Master's)

When discussing life trajectories, there was little in common with both groups of Scholars. First-year Scholars were focused on strategies for succeeding 
in the next year of graduate school, while second/third-year Scholars were focused on their careers moving forward. The same second-year Master's Scholar who changed her mind about becoming a professor described her plans moving forward:

"I want to open up a community resource center... I wanted to teach and that was always from like when I was very little was wanting to be a teacher and it kept growing where I was like 'I want to teach elementary school' and then it was like 'I want to teach high school' and then it was like 'I want to teach college' and now it's like 'I want to teach the community'”' (Second-year, Master's) 


\section{Discussion}

This chapter will initially revisit the research questions that guided this study. Then similarities and differences between first and second/third year Scholars' responses for each theme will be reviewed. Next, a three-part discussion will be presented, using the combination of theories introduced in chapter three to examine the ways that Scholars understand the impact of the McNair Program on their graduate school experiences at different points in time. In the first part of this theoretically-informed discussion, variations in Scholars' understanding of the graduate student role at different points in time will be considered using the conceptual device of the alphabet introduced in chapter three to understand these differences in role knowledge. In the second part, an argument will be presented that more and different knowledge, possibly through continued mentorship of Scholars, is essential for the success of first-year Scholars. In the third part of this theoretically informed discussion, the "McNair Paradox" introduced in the literature review will be revisited, and changes in Scholars' habitus will be used to understand this situation. Finally, the chapter will be summarized and the concluding chapter will be introduced.

This study aimed to answer the following questions:

1. How do former PSU McNair Scholars who are first-year graduate students understand the ways that program participation impacted their graduate school experiences?

2. How do former PSU McNair Scholars who are second- and third-year graduate students understand the ways that program participation impacted their graduate school experiences? 
3. How are the experiences of these two groups of students similar?

4. How are the experiences of these two groups of students different?

Several themes emerged from the data gathered in interviews with first-, second-, and third-year graduate students who participated in the PSU McNair Program between 2007 and 2012. Tables highlighting similarities and differences between these groups' responses with regards to each of the themes discussed in chapter 5 are presented below (figures 6-15).

Summary of Findings by theme

Figure 6: Choosing a School

Similarities

McNair increased confidence to go to graduate school. McNair discussion of "impostor syndrome" was particularly helpful.

Differences

First Year Scholars

Discussed the ways specific McNair assignments impacted how they researched schools and ultimately made their choices.
Second/Third Year Scholars

Discussed the ways exposure to literature and research in McNair impacted their schoolchoice decisions, and how their interests have changed since enrollment. 


\section{Figure 7: Applying/Getting in}

\section{Similarities}

- McNair increased knowledge of applying for admission as well as other opportunities and resources.

- McNair application process was particularly helpful since it was similar to applying to graduate school.

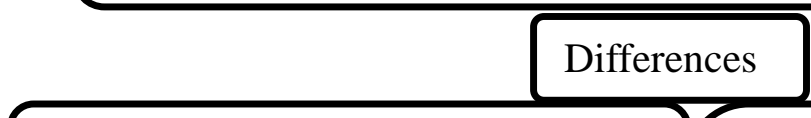

First Year Scholars

- Focused on 'competitive edge' gained from McNair.

Second/Third Year Scholars

- Focused on the ways that advice about applications from staff and students in McNair impacted their choices, as well as how their interests have changed since enrollment.

\section{Figure 8: Navigating/Designing Programs}

\section{Similarities}

- Many enrolled in combined, dual, and/or custom programs.

- Wanted a challenge and believed other McNair Scholars did too.

\section{Differences}

\section{First Year Scholars}

- Tied program choice to research interests and passion for social justice.
Second/Third Year Scholars

- Tied program choice to what would be useful in postcollege job market. 
Figure 9: Understanding Research

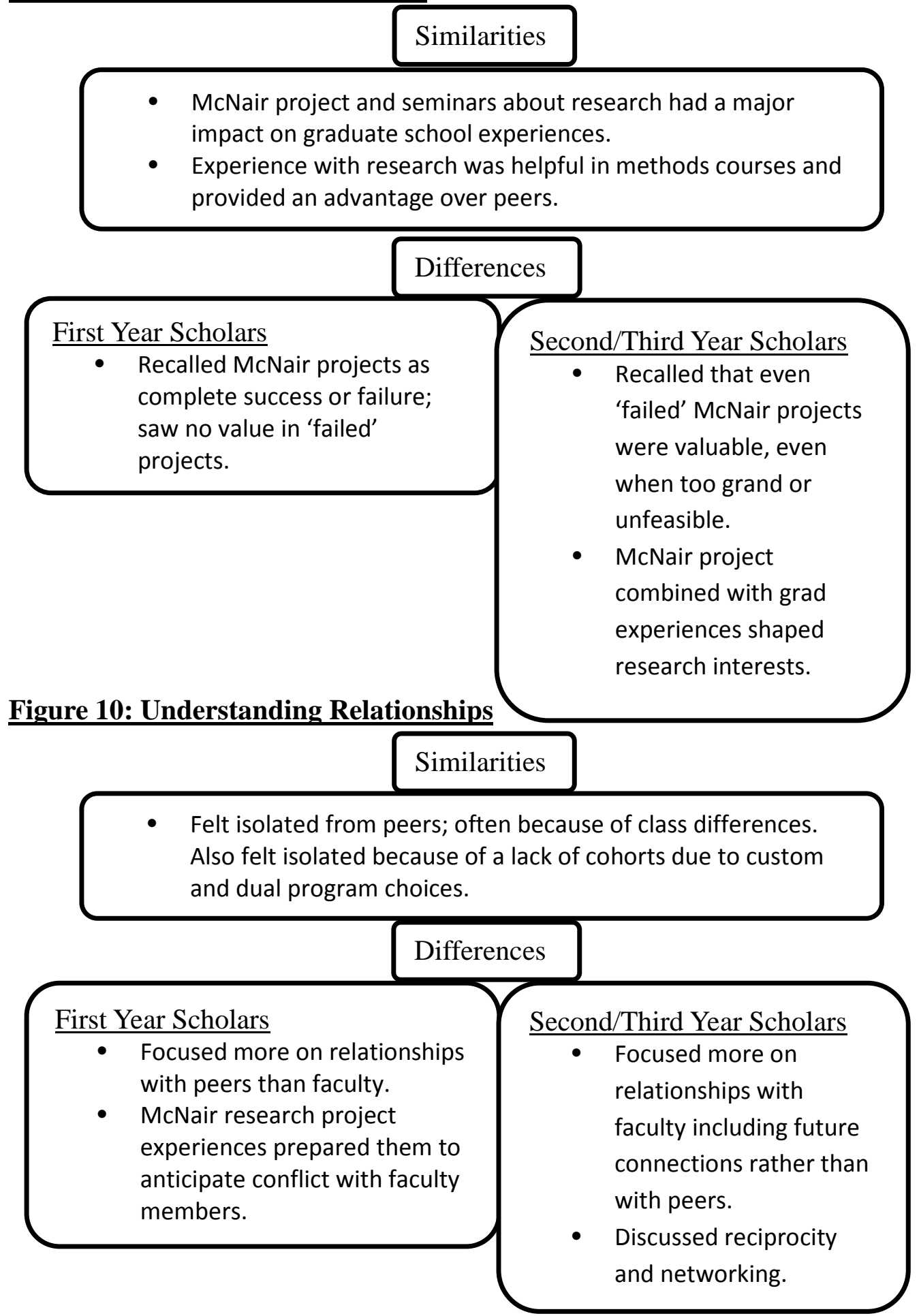


Figure 11: Understanding Programs

Similarities

- Expected graduate program to be more challenging

- Expected to have a heavy reading load

- Faced administrative challenges in custom programs.

\section{Differences}

First Year Scholars

- $\quad$ Frustrated that the grad program is not as challenging as McNair

- Generally haven't developed strategies and study habits

Figure 12: Understanding Culture

\section{Similarities}

Second/Third Year Scholars

- No longer frustrated about level of rigor; could recognize an appropriate level of effort. Now using "extra" time to focus on preparing for life after graduate school.

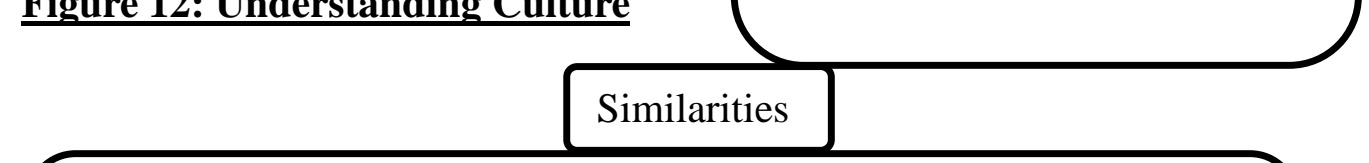

- Mentioned value of McNair presentations about "impostor syndrome"

- Discussed awareness of differences in finances and student loan debt compared to affluent peers. Noted these differences led to their increased stress levels and created practical challenges in professional development.

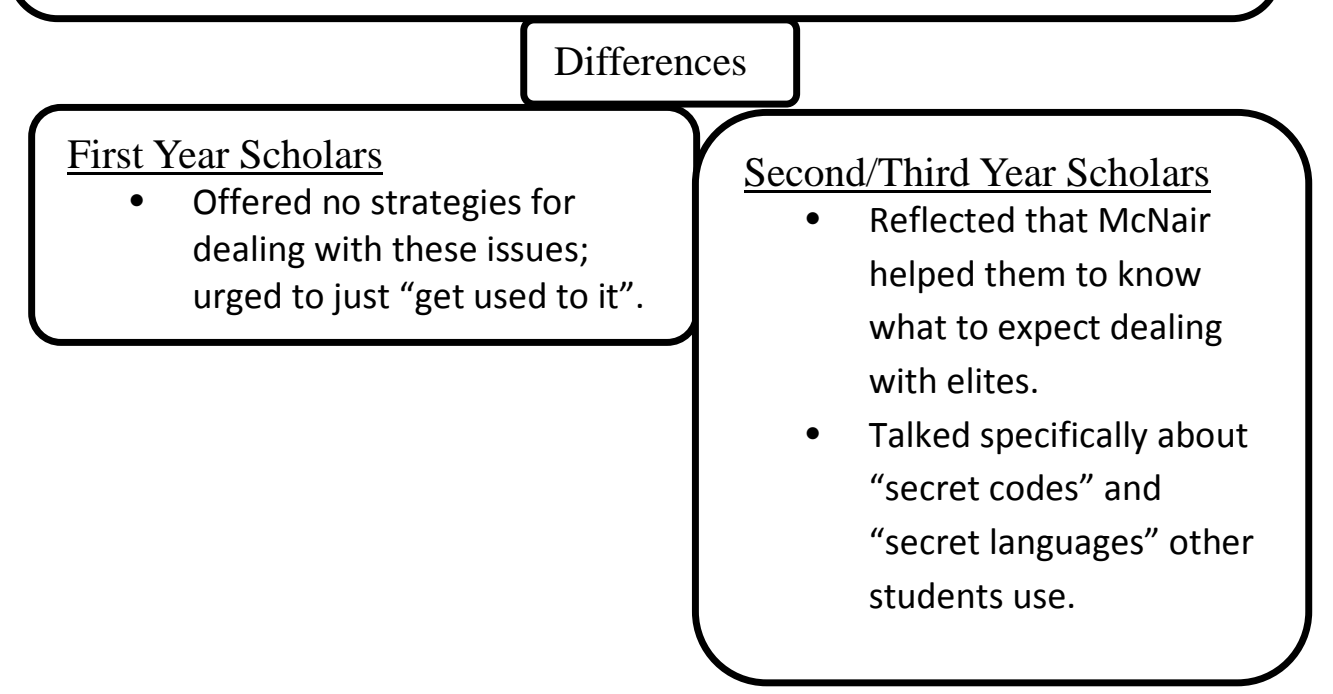




\section{Figure 13: Understanding being a grad student}

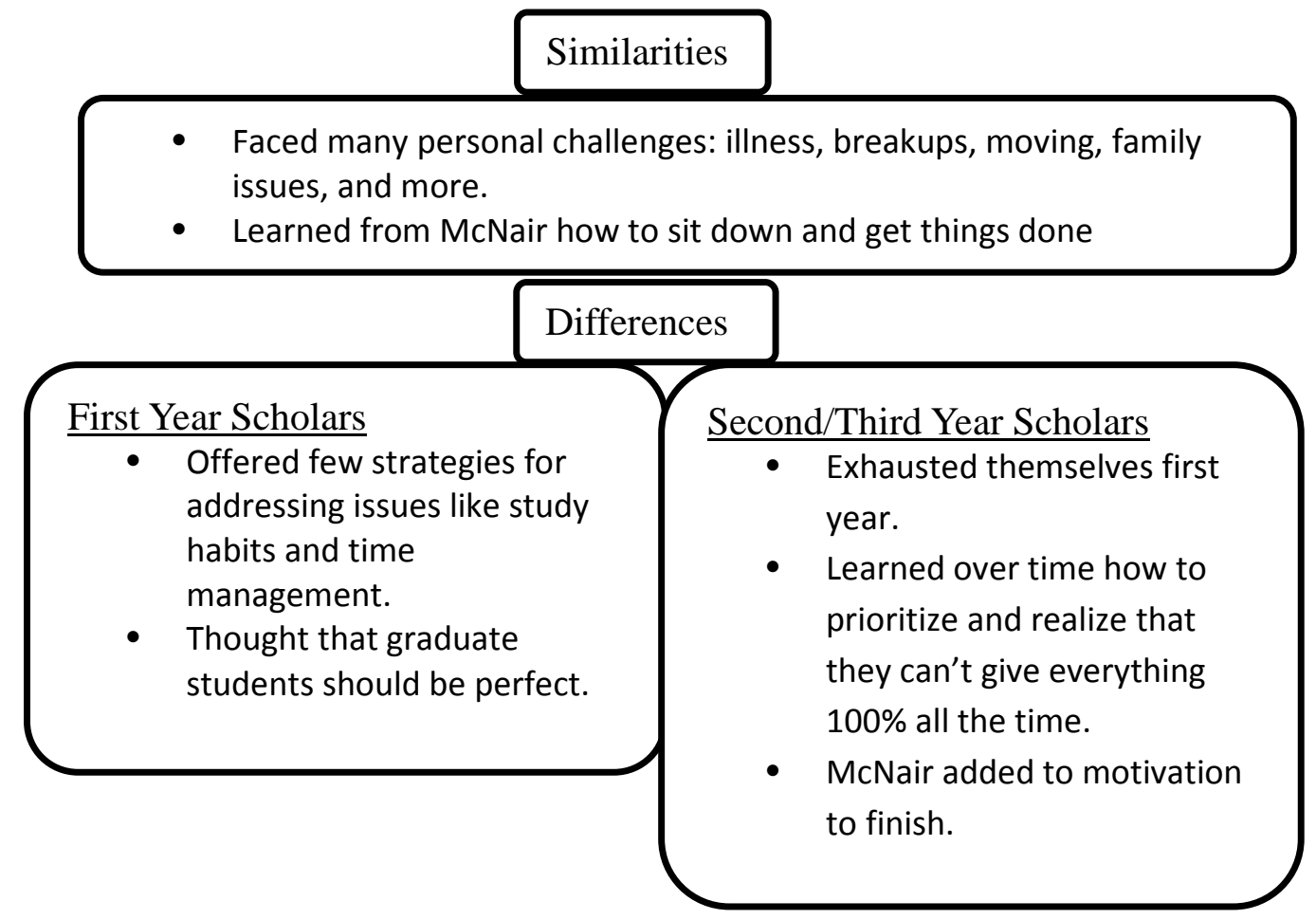

Figure 14: Reflecting Now

Similarities

- Desired to "pay it forward" to students and community members like themselves.

- Unhappy with lack of connection to peers.

\section{Differences}

\section{First Year Scholars}

- Mostly were happy with their programs so far. Still

frustrated that programs did not meet expectations. $\underline{\text { Second/Third Year Scholars }}$

- All were graduated or about to graduate at the time of the interviews.

- Mixed feelings about their program-choice decisions. 
Figure 15: Reflecting on trajectories

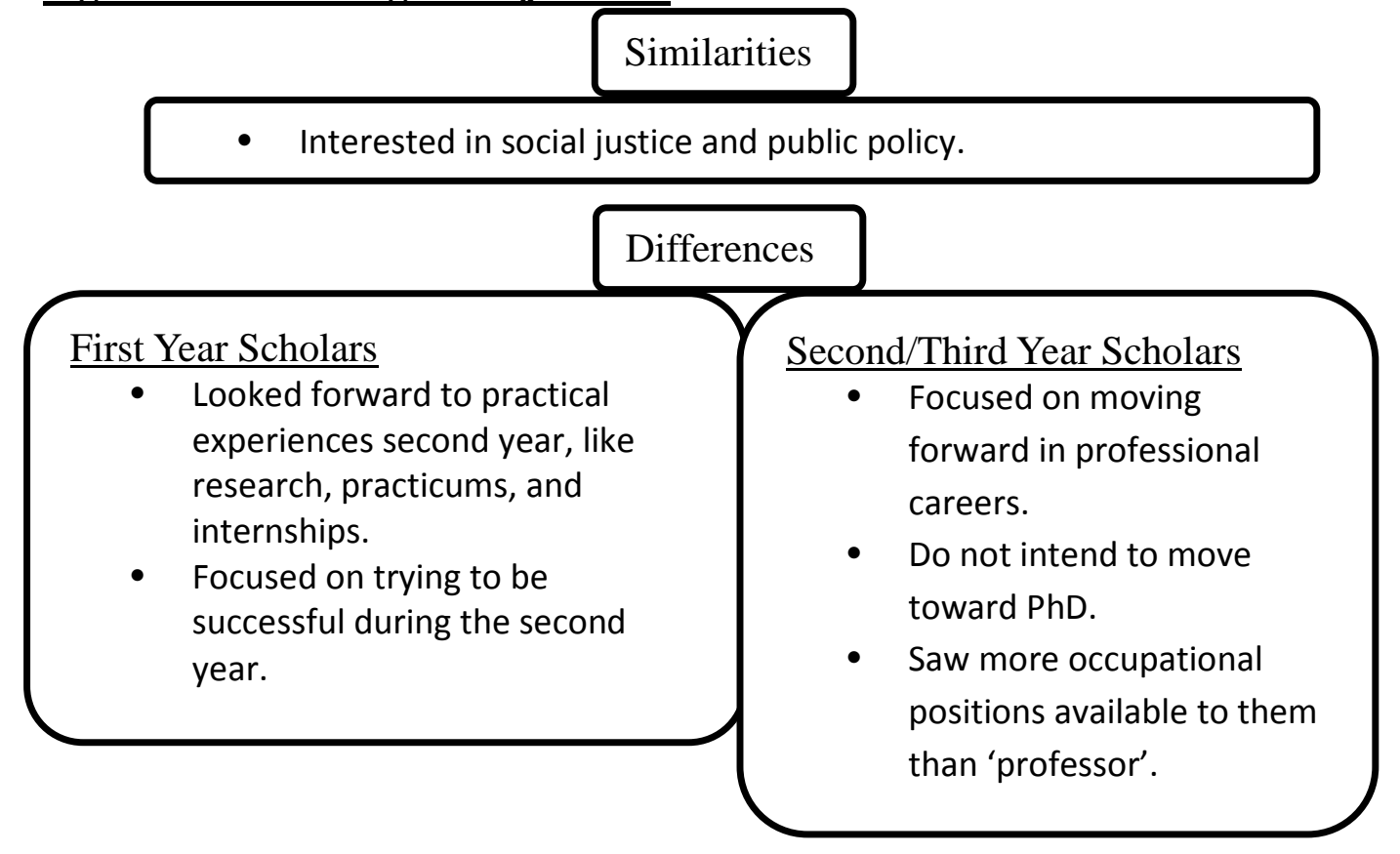

\section{Part one: role expertise at different points in time}

Chapter three of this thesis introduced the conceptual device of using lower-case and upper-cases alphabets to represent McNair Scholars' understanding of and experience enacting both undergraduate student and graduate student roles. The lowercase alphabet (Figure 11) represents Scholars' understandings of the undergraduate student role after participating in the McNair Program and before enrolling in graduate school. 


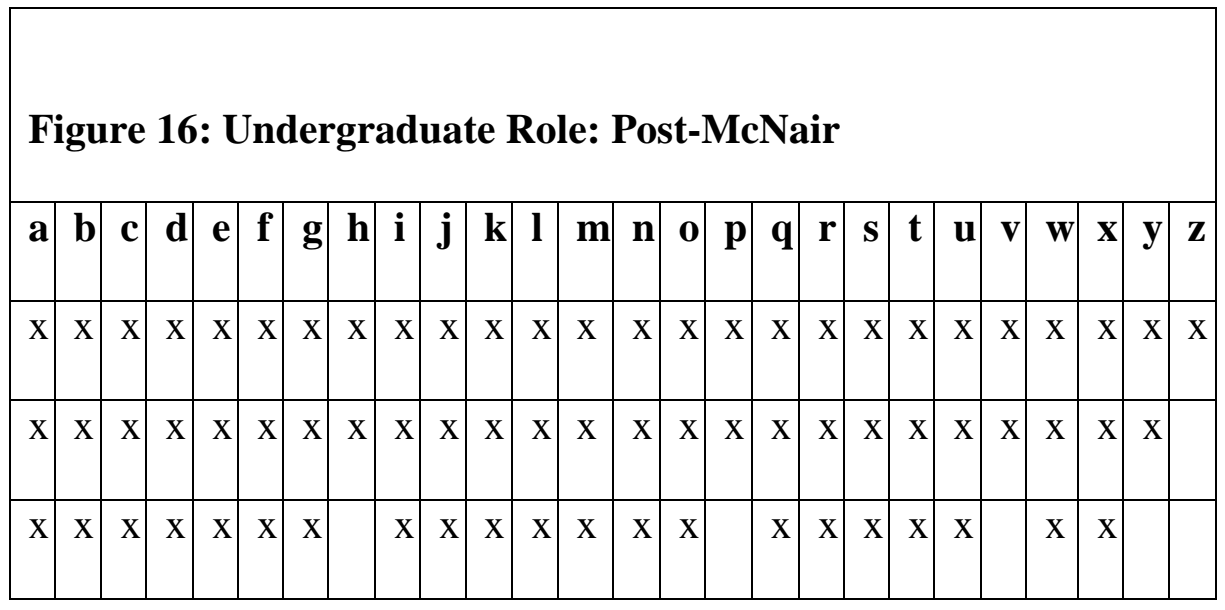

The role mastery (Turner, 1978; Baker and Faulkner 1991; Callero 1994; Collier 2001; Collier \& Morgan, 2007) and expertise (Dreyfus \& Dreyfus, 1980; Benner, 2004; Collier, Morgan, \& Fellows, 2007) theories discussed in chapter three suggest that students at this point would possess fairly extensive knowledge about the undergraduate student role. Their participation in the McNair program increased their relative levels of cultural capital elements by helping them learn how to maximize undergraduate experiences to prepare for graduate school. At the same, their relative expertise levels also increased due to richer McNair-associated undergraduate experiences. These students became experts in understanding the undergraduate role, how to enact this role effectively, and when it was appropriate to enact the role. Because these students had already demonstrated strong academic potential, McNair participation filled in the gaps in Scholars' knowledge about being undergraduate students aspiring to graduate school. The results of this study confirm this point. Both groups of scholars felt better prepared for getting into graduate school through the experience of applying to the McNair Program and specific Program assignments like designing an "education plan”. Studies reviewed 
in chapter two also confirm this point (Greene, 2007; Grimmett et al, 1999; Ishiyama, 2007; Willison \& Gibson, 2011). Scholars are generally satisfied with their McNair Program experiences and feel better prepared for some aspects of graduate school.

Scholars' responses also indicated that McNair participation might have also brought about slight changes in habitus. Scholars discussed how, after McNair program participation, they experienced increases in confidence and feelings like "graduate school might be something that is possible for students like me." This was especially true for the Scholar who realized that she was in the same Program as students she thought of as highly successful, only to find they were also experiencing the "imposter syndrome" in the same way as she was. This is not a complete change in habitus because some Scholars spoke specifically about needing the support of the McNair Program and their mentors to be able to feel like they were graduate school material. Scholars' responses indicated that they had not all necessarily internalized these feelings.

This finding provides support for the contention that McNair participation was associated with positive graduate-school associated outcomes. The McNair program was more successful in providing Scholars with cultural capital in the form of role knowledge that would help them to be successful in graduate school enrollment than in changing Scholars' habitus, which is slower to change because it must be internalized. This finding is consistent with Bourdieu's theoretical argument that capital levels tend to change faster than habitus.

As students participated in the McNair program and completed their undergraduate programs, they were also gaining higher levels of Differentiated Role Mastery. Because all of the McNair-scholars-to-be came from families that had little or 
no experience with higher education, the McNair program was one of the first places where these students were introduced to an additional student role: graduate student. While students still had a lot to learn, the McNair program introduced them to certain "early in the alphabet" aspects of the graduate student role, such as how to choose a program, apply, and get in. In addition, the program provided Scholars with opportunities to do "similar to graduate school" activities like working with faculty and conducting research. An example of this McNair-related graduate student role knowledge was Scholars' recognition of a heavier reading load in graduate school and how that load is different from what is typically expected of undergraduate students. While knowledge of this specific aspect of the role is important, this introduction may be problematic as Scholars jumped to unintended conclusions. In this case, Scholars seemed to draw the conclusion that the certain limited aspects of the graduate student role, introduced to them in the McNair program, actually represented a complete picture of what a graduate student is. The assumption seems to be that if a heavier reading load indicates how a graduate program is harder than an undergraduate one, then all aspects of graduate school must require the student to be busier and do more than she did as an undergraduate. This became a problem for Scholars who burned themselves out during the first year or two of graduate school by taking on multiple tasks at the same time. 
Figure 17: Graduate Student Role: Post-McNair

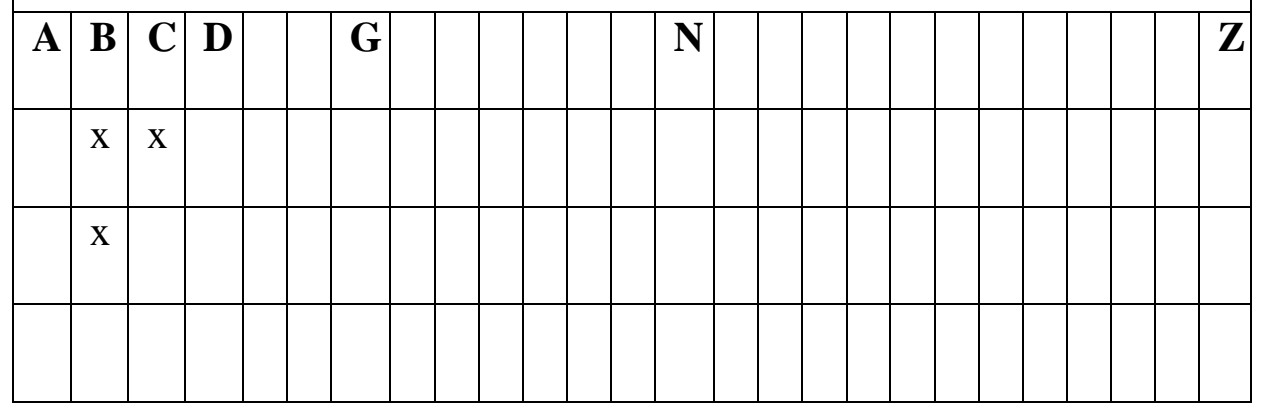

Above is a representation of Scholars' role knowledge after McNair participation and before graduate school enrollment (Figure 12). Scholars had some vague idea about some elements of the first two or three years of graduate school with the eventual goal of Ph.D. attainment "Z," but little experience with almost all of steps in the role-alphabet. In the McNair program, Scholars had gained some experiences in research and working with faculty (represented by the x's below the "B" and "C") but they had few experiences beyond that. They were novices at the graduate student role.

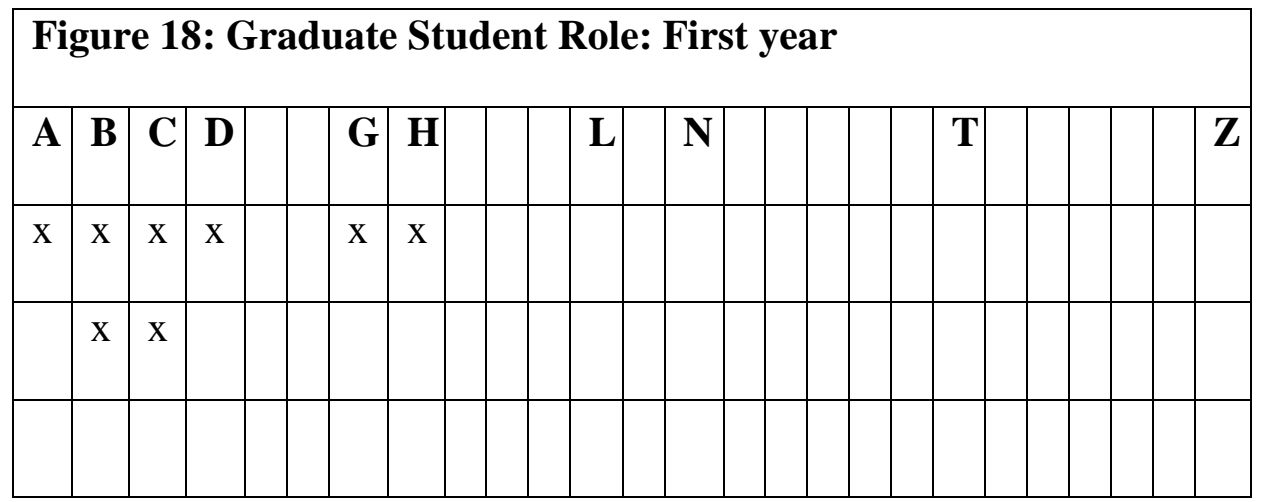

Scholars built upon the knowledge they gained in McNair about graduate school and, by the end of the first year of graduate school, their version of the role-alphabet had changed. They had filled in aspects of the role of graduate student that they were not 
previously aware of, and had deepened their understandings of aspects they were aware of through graduate school experiences. However their versions of the role-alphabet were incomplete, as they still had a lot to learn about the graduate student role.

First-year Scholars demonstrated a novice level of graduate student role expertise most clearly in the ways they discussed graduate school and themselves as graduate students. Scholars expressed very rigid opinions about the value their McNair project. Projects were either "successes" or "failures". First-year Scholars also reported entering graduate programs anticipating conflict with faculty members. These Scholars had only developed limited strategies in dealing with the challenges they faced in the first year of graduate school. Further evidence of first-year Scholars' novice level of role expertise can be found in their frustration that their graduate programs were not as academically rigorous as they expected. These Scholars, who had become experts at the undergraduate student role, seemed to be frustrated that they had to "start over" as graduate students when they had been so successful as undergraduate students.

First-year Scholars' responses suggested that they dealt with their relative low lack of graduate student role expertise by continuing to enact the undergraduate student role they had already mastered. First-year Scholars were confused as to why this strategy did not work for them. These Scholars were still frustrated and struggling in their programs, even though they came to realize they had advantages over their peers with regards to understanding research methods and actually having undergraduate experience conducting research. First-year Scholars responses that they felt that being a graduate student meant being perfect confirmed their relative low levels of graduate student role knowledge. These Scholars' enactment of an inappropriate role standard is most evident 
in their choices of programs. As undergraduates in the McNair program, they learned that "better students work harder". First-year Scholars attempted to continue using this strategy by choosing dual major or custom-designed programs because they "wanted a challenge", when a more nuanced understanding of the graduate student role might have led them to different program-choice decisions, as some second/third-year Scholars wished they had made. Their lack of graduate student role expertise meant they did not recognize the value in selecting established programs where they could benefit from the support of cohorts of other students in those programs. During their first year in graduate school, these Scholars both increased their breadth of understanding of graduate student role knowledge as well as increasing their depth of expertise through graduate program experiences, but they were not using that new knowledge to better enact the graduate student role. Instead, first-year Scholars continued to enact the undergraduate student role they had already mastered without realizing until later the consequences of these actions.

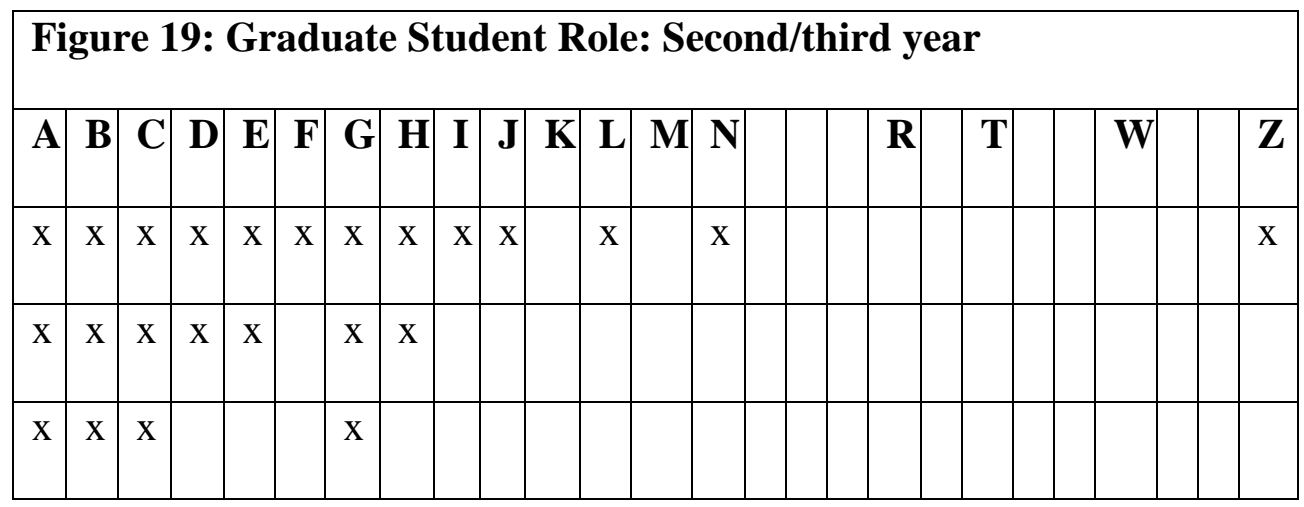

Second/third-year Scholars continued to build upon the knowledge they had

gained in McNair as well as from their experiences during the first two or three years of graduate school. Their graduate student role-alphabets were filling in over time. 
Second/third year Scholars clearly had a more sophisticated understanding and awareness of the graduate student role than first-year Scholars. Second/third year Scholars' responses demonstrated a more nuanced understanding of the impact of the McNair Program participation on their graduate school experiences. Most importantly, these Scholars seemed to be enacting a more appropriate version of the graduate student role instead of trying to enact the mastered role of undergraduate student. These scholars were not as frustrated as first-year scholars about unexpected graduate program aspects such as a perceived lack of academic rigor and were more focused on increasing their graduate student experiences.

These differences in levels of graduate student role knowledge are clear in first and second/third-year Scholars' discussions of the impact of the McNair Program on their current experiences. As opposed to first-year Scholars, second/third-year Scholars did not focus on the immediate impact of the McNair Program on increasing their competitiveness in getting into graduate school or the ways that specific assignments gave them an advantage. Instead, these Scholars had a deeper understanding of McNair's impact and focused on the ways that the Program had shaped their interests and directions of their research, as well as the changes in those interests over time since they enrolled in graduate school. Second/third-year Scholars were able to reflect about the relative value of even "failed" projects and "unsuccessful" relationships with their faculty mentors.

There is also evidence of the second/third-year Scholars' more sophisticated understanding of what it means to be a graduate student in their responses with regards to the "understanding culture" theme. Second/third-year Scholars were able to discuss the specific ways that the language and affluence of elite students gives those students 
practical advantages in graduate school. These Scholars reflected on the impact of the McNair Program in helping them prepare to deal with elite advantages in ways that first years did not. This is evidence of the ways that McNair was able to import cultural capital to these students by educating them about class-related differences in graduate school and how to navigate those differences. These findings suggest that the McNair Program impact is not fully realized until Scholars gain knowledge and expertise about being graduate students and begin enacting the appropriate role, which seems to happen after the first year of their programs.

As students became more aware of how to successfully enact the graduate student role and to be able to more accurately forecast future consequences of their role enactment, the more likely that they would be to have internalized changes of "what might be possible" in graduate school and future occupations. It is clear that second/thirdyear Scholars had begun to experience changes in their habitus. Not only were they better able to see more positions in the field of higher education, they were also able to more accurately calculate the cost-benefit of pursuing these positions and the steps that they would have to take to do so.

Second/third-year scholars explained that they were now concentrating more on networking and creating reciprocal relationships with faculty than they had been during their first year. This is evidence of increased role mastery and changes in habitus. These Scholars had a clearer vision of the path to alternative occupational positions in the field of higher education other than attaining a Ph.D. For example, Scholars at the second/third year level were aware of many more positions in the higher education field besides "professor". These positions included "policy and research analyst", "academic advisor" 
and other positions that fulfilled their desires to affect policy, help their communities and students like them, and utilize their Master's and Professional degrees in a variety of ways that they found to be more personally appropriate than continuing to $\mathrm{Ph}$. D. level. This was more personally appropriate because, whether financially or personally, pursuing alternative positions to Ph.D. fit their lifestyles or goals better. For example, the second-year scholar who saw a mismatch between her goals and pursuing a tenure-track faculty position saw opening a community center as a better fit in her life.

\section{Part two: scholars' inaccurate expectations}

First-year scholars had inaccurate expectations of themselves and of their graduate programs. Scholars in their first year created challenges for themselves and missed out on opportunities that impacted their graduate careers and potentially their occupational positions. By focusing on very particular aspects of unmet expectations, (i.e. "I'm upset that my instructors don't have Ph.D.'s" and "I'm bored in my program") and by carrying forward only isolated specific lessons from McNair (“better students work harder" and "grad students are perfect"), the students faced unintended consequences.

It is clear that second /third-year Scholars had more nuanced understandings of the ways their choice of program impacted their futures. They could see how networking and creating reciprocal relationships with faculty impacted their abilities to get internships and future employment. Second/third-year Scholars discussed ways that what they initially perceived to be a lack of academic rigor in their programs compared to McNair actually had to do with learning what constitutes an appropriate level of effort in course work for a graduate student. Second/third-year Scholars related how this "extra" time actually allowed them to gain work experience and to participate in research projects 
that provided them with marketable skills. In other words, they were now aware of additional aspects of what it takes to be a successful graduate student and what opportunities were available to them. This is evidence of a substantial increase in role knowledge and a considerable change in habitus from what was demonstrated by firstyear Scholars.

One important finding of this study is that Scholars make program choice decisions that have real and lasting consequences on their subsequent graduate school experiences well before they have developed much graduate student role expertise. Scholars are being asked to make educational and career path choices before their habitus has developed to the point where they can clearly understand their relative locations in graduate school along with what might be possible for them to accomplish in school and after graduation. This finding makes a strong case that Scholars require mentorship in the period between when they complete the McNair Program but before they have developed the kind of extensive relationships with faculty members in their new programs that lead to graduate student mentoring.

The expertise development model suggests that until these Scholars have gained substantial experience as graduate students, there is no way for them to understand the multitude of factors that should be impacting their decisions and they are not yet aware of the potential consequences of those decisions. Just as a driver cannot understand the rule for negotiating a manual transmission (e.g. "shift at 10mph"), before ever driving a car, first-year Scholars cannot understand the consequences of applying the McNair-learned rule that "working harder indicates you are a better student" when choosing whether to enroll in an established program or to design challenging dual-major or custom programs. 
While they might have made the same decisions and enrolled in the same programs, these Scholars clearly lack critical information about what those kinds of decisions mean for them as graduate students. For example, they don't yet realize that some of the consequences of designing their own programs will be a lack a cohort, so it is harder to make connections with their peers, or the administrative challenges that don't occur in established programs. First-year Scholars also don't realize that by applying this same rule to all graduate school situations they will likely burn out and exhaust themselves. This issue connects to another McNair-learned rule that first-year Scholars follow due to lack of graduate student role knowledge: graduate students must be perfect and do everything at $100 \%$ effort. It is not until the second/third year that Scholars realize that being perfect isn't a possibility and they begin to prioritize tasks.

A mentor who would be aware of these students' issues could help Scholars understand the consequences of these program-choice decisions and avoid these common mistakes. Mentors could act as personal trainers would in a gym: They provide instruction and motivation for the athlete/scholar to continue their workout/graduate school program. Just as importantly, trainers/mentors prevent their clients/students from hurting themselves. In this study, first year Scholars reported becoming frustrated with the instruction they were getting based on what they were led to expect from graduate school. At this point in their graduate school careers, first-year Scholars haven't yet begun to realize how their own decisions impacted their current circumstances. First-year Scholars have not progressed to the competent level of graduate student role expertise, where they would be able to recognize and prioritize multiple factors and internalize the consequences of their decisions. 
Differences in first-year and second/third-year Scholars' problem-solving strategies provide an excellent example of the differences between competent and novice levels of graduate student role expertise. The third year Scholar's strategy of cutting back on non-program completion related activities in response to the issue of feeling overwhelmed is an example of competence, whereas first year Scholars demonstrate their novice levels of expertise when their proposed strategies for the same issue are "just get used to it" and "do better next year." It is crucial for Scholars to have continued guidance in graduate school beyond context-free rules they acquired in McNair until they at least progress to the competent stage of the Dreyfus model. At that stage, they would able to judge which factors in a situation are most important, and would be able to take responsibility for their own decision-making and learn from their mistakes.

Scholars who continued to work with or at least stayed in contact with their McNair mentors in graduate school reported that this relationship was particularly helpful for them. These Scholars already had some experience navigating the relationship with their mentors. One consequence of being in established mentoring relationships is that these Scholars likely moved toward competence level more quickly than Scholars who had no mentors or who had to "start over" with new mentors. The already established mentors may have been able to help their Scholars correctly interpret their initial graduate school experiences, which would help Scholars deal with situations they might not know to expect or situations they might misinterpret due to novice level expertise.

\section{Part three: the McNair Paradox}

The term "McNair Paradox" was introduced in the literature review to explain the apparent contradictions in McNair Program outcomes. McNair is effective at getting 
historically disadvantaged groups enrolled in graduate programs. However, McNair seems to be relatively ineffective at realizing the program goal of improving social mobility for students from these groups by creating a more supportive atmosphere in higher education. McNair attempts to do this by diversifying the professoriate in the US through increasing Ph.D. attainment among non-dominant group students.

On the one hand, McNair Scholars are enrolling in graduate programs and obtaining financial aid at higher rates than other students with the same demographic characteristics. However, McNair Scholars are not persisting to Ph.D. level and they are not becoming professors at the rates anticipated. Often, they are not even enrolling in Ph.D. degree-granting institutions. Does this mean the McNair program is not realizing its goal of improving social mobility for historically disadvantaged group students by creating a more supportive atmosphere in higher education? The results of this study suggest this may not be so.

The PSU McNair Program is clearly successful in helping Scholars apply to and be accepted to graduate programs as well as helping Scholars to be successful in certain aspects of graduate school. Scholars were provided with valuable cultural capital in the form of increased role knowledge, especially of the role of undergraduate-studentaspiring-to-graduate-school. The Program accomplished this through specific elements, such as the application process to get into the McNair program and seminars discussing important aspects of graduate school, like recognizing feelings of the impostor syndrome and understanding different research methods. The Program also tried to provide some knowledge of the graduate student role through specific elements such as the education plan and other assignments, the opportunity for Scholars to conduct research with a 
faculty mentor and to present that research in different venues, and discussions in the seminars about attending school with elite students and faculty. Scholars also mentioned the McNair Program as one of the driving forces in their ability to stay motivated in the face of major personal and academic challenges.

The concept of habitus can help us understand why Scholars are not persisting to Ph.D. As their cultural capital increases in the form of increased graduate student role knowledge, Scholars' habitus also begins to change, although at a slower rate. Around the end of the second or third year of graduate programs, Scholars become aware of "more possibilities for me" (i.e. more positions in the field of higher education) where they can still realize their personal goals of helping subsequent students similar to themselves succeed at college and promote social justice. Not only do these positions become visible, but Scholars' are able to more accurately calculate their likelihood of success in pursuing each position, as well as the potential consequences of achieving each position. As knowledge of the field increased, Scholars were able to re-compute the cost-benefit of obtaining a Ph.D. they had initially figure out as undergraduates in the McNair program, and this outcome was no longer as desirable to them. Second/third year Scholars discussed the cost of Ph.D., the poor working conditions of professors, and the mismatch between their life goals and pursuing tenure-track positions. Reports about the changes in the academic workforce and faculty working conditions support these perceptions ${ }^{4}$.

\footnotetext{
${ }^{4}$ In "The Changing Academic Workforce" (2013), Kazer \& Maxey outline dramatic drops in the proportion of tenure-track faculty and a growing reliance on non-tenure track part-time faculty in public and private colleges and universities in the U.S. since the 1960's. These instructors face poor hiring practices, limited job security, inequitable salaries and access to benefits, lack of professional development and orientation, little involvement in curriculum development and faculty meetings, and limited office space, clerical support, and instructional materials. For more information, see this report and the book The American Faculty, published in 2006 by Jack H. Schuster and Martin J. Finkelstein (Johns Hopkins University Press).
} 
While some first year Scholars might have briefly mentioned this, second/third year Scholars discussed specific reasons for this change in path and particular strategies for pursuing new positions such as obtaining internships or taking specific research courses. These positions included working in research, policy, administrative higher education (e.g. advising), and other impactful positions within disadvantaged communities. This awareness of so many more positions available to them is evidence of increased role knowledge and substantial changes in habitus.

Second/third year Scholars were more likely to discuss a desire to "pay it forward" to other students or "give back" to the McNair Program in practical ways. This demonstrates a sophisticated understanding of the skills they gained from McNair. This also clearly shows that these Scholars, while not pursuing Ph.D.'s, still strive to impact students like themselves and to diversify degree holders by using the skills they learned in McNair to help non-traditional students succeed in higher education.

The contradiction in outcomes (enrollment and satisfaction vs. Ph.D. attainment) seems to have more to do with the program's operationalization of successfully meeting its stated goals by measuring the number of Ph.D.'s obtained. This study suggests that the McNair goal of increasing social mobility of historically disadvantaged groups and increasing non-traditional student degree attainment by creating a supportive atmosphere in higher education is being met. Scholars are seeking out McNair programs and underrepresented students and utilizing the skills they have learned and the credentials they have earned, due in part to McNair Program participation, to help those students succeed. However, given their perceptions of the current negative occupational realities of obtaining a Ph.D., Scholars are finding alternative ways to accomplish these goals. 
Scholars have become aware of more positions in the field of higher education where they can affect change and fulfill their passions for social justice. The false conclusion that McNair goals are not being met is due to the inaccurate indicator of success by only measuring Ph.D. attainment. The impact of program participation on the social mobility of disadvantaged students must be measured in more accurate ways to accurately reflect that there is no McNair Paradox: the goals of the program are being met.

The findings of this study suggest there is not really a McNair Paradox at all. Second/third year Scholars become aware of multiple positions in the field of higher education where they can affect change for historically disadvantaged students. Scholars express a strong desire to give back to the McNair Program by helping students like themselves and by providing a supportive and effective educational atmosphere for historically disadvantaged students, using the skills and credentials they have acquired in the program and in graduate school.

These findings support Beal's (2007) conclusion that McNair should expand the definition of scholar to include participants who work outside the academy. However, that study finds that Scholars do not connect culturally to the academy, while the findings here suggest a different reason why the paradox may not exist. The shift away from pursuit of Ph.D. may be due to Scholars' increased expertise and role mastery, along with changes in habitus, where Scholars recognize "better" opportunities with higher likelihoods of success in higher education field-associated positions that still allow them to realize their own goals as well as the goals of the McNair program.

This chapter began by recalling the four research questions and presenting the themes from the findings, highlighting similarities and differences between the two 105 
groups of Scholars. Next, a three part theoretically-informed discussion was provided to understand the ways Scholars reflect on the impact of the McNair Program on their graduate school experiences. The next chapter will summarize the major contributions of this study and the significance for knowledge and practice. Then it will address the limitations of the current research as well as making recommendations for future research. 


\section{Conclusions}

This chapter is organized into four major sections. First, the five major themes identified in this study will be summarized one by one. Second, the significance of this study will be discussed. Third, limitations of the study will be addressed. Finally, recommendations for future research will be suggested.

1. McNair does a good job of getting students enrolled in graduate programs and helping them to be successful in specific aspects of graduate school such as dealing with confidence issues, being prepared for graduate school research experiences, and staying motivated.

McNair Program participants gained real and valuable benefits from the program. Scholars reported that they gained confidence that they were graduate school material and felt prepared for interacting with elite peers and faculty in their graduate programs. They also noted that going through the McNair application process and discussing successful application strategies during the seminars were particularly useful for when students actually had to apply to different graduate programs. Once enrolled, Scholars acknowledged that their McNair experiences contributed to them feeling better prepared with regards to understanding research methods, conducting research, handling a heavy reading load, and staying motivated in the face of personal challenges.

2. McNair Scholars have inaccurate expectations of graduate school. They often use the wrong role standard to try to accomplish their goals, which can leave them frustrated, burnt out, and confused after the first year.

Scholars seem to be drawing incorrect conclusions about why specific McNair program elements are included in the program. Scholars are taking limited aspects of the 
McNair Program and using them to shape their whole idea about what graduate school should be like. This seems to happen due to their habitus and relative lack of cultural capital. Specific Program components, which were meant to mimic certain limited aspects of graduate work, are mistakenly thought to represent the "big picture" of graduate school by Scholars.

One example has to do with Scholars' understandings of the value of their McNair research projects. First-year Scholars believed that the goal of the research project in the McNair Program was to have accomplished a successful research project from beginning to end. Yet, from the program's perspective, the more valuable graduateschool-related McNair research project experiences may have been learning the process of doing research, gaining exposure to more than one kind of research in seminars where methods are taught, or getting to hear Scholars from different disciplines discuss different research methods in their projects.

Another example can be found in Scholars' understandings of what their McNair experiences of working with faculty mentors on undergraduate research projects were intended to help them learn about future relationships with graduate school faculty members. Scholars may have believed that their experiences working with faculty mentors on their McNair projects represented everything that their relationship with a faculty member in a graduate program should be. In reality, working on a project is only one important aspect of graduate student/faculty relationships. It is often just as valuable for graduate students to understand the importance of reciprocity and making multiple connections among faculty members, which many Scholars only recognized sometime in their second or third year of graduate school. 
Scholars may also be misinterpreting their relative levels of graduate student role expertise when they begin their programs. These Scholars were all high-achievers as undergraduate students. Yet they found out there was a lot they could learn in the McNair program. After participating in the McNair Program, Scholars felt that they were experts at being undergraduates, and they expected to carry that expertise with them into graduate school. However, because these Scholars really had a limited graduate student rolealphabet, they continued to use the already mastered undergraduate role alphabet in their graduate programs, which led to real and lasting negative consequences for these students.

3. Continued McNair-like mentorship could significantly help students, especially in regard to designing their programs and managing their expectations during the first year of graduate school. Scholars found it to be particularly beneficial when they were able to stay connected with their McNair mentors. Another example of Scholars misunderstanding their relative levels of graduate student expertise is when they used context-free rules learned during the McNair Program in order to understand their graduate programs with little guidance from more experienced players. The clearest example of this is the McNair-learned rule "work harder to be more successful."

When first-year Scholars used this rule to design dual and custom programs in order to feel "challenged," one unexpected consequence was that they missed out on key experiences like internships and networking opportunities. First-year Scholars didn't realize that applying this McNair-learned rule to all graduate school situations would likely leave them burnt out and exhausted. 
Another effect of misapplying this rule was captured in how first-year Scholars reported feeling frustrated when their graduate programs were not as academically rigorous as the final terms of their undergraduate programs, when they were also participating in the McNair Program. Scholars did not realize until the second or third year of study that trying to maintain that frantic, "almost -done-with undergraduate-about to apply to graduate school" level of academic activity and rigor was not appropriate for new graduate students in the first years of their programs. They did not realize that there were other important aspects of their programs (e.g. networking, internships) that they also needed to focus on during their first years in graduate school in order to make the most of subsequent opportunities. Scholars were causing themselves stress and missing out on important opportunities for professional development by attempting to remain the kind of experts they were as undergraduate students.

First-year Scholars who maintained contact with their original McNair mentors reported that these relationships were particularly helpful for them. This suggests that continuing McNair-like Mentorship in graduate school could be helpful for Scholars, especially during their first year of graduate school when they had to choose schools, choose whether to enroll in established or custom designed programs, and faced a range of issues related to appropriately enacting the graduate student role. Graduate-school mentoring could help Scholars make the most of McNair-provided cultural capital in the period before Scholars' habitus changes enough that they are able to see more appropriate lines of action to be successful graduate students. Continuing mentoring could also help Scholars avoid unforeseen problems by helping them more accurately understand the consequences of their decisions. For example, mentors could warn Scholars about the 110 
hidden consequences of designing custom programs, such as a lack of a cohort and having to face administrative challenges associated with non-established programs.

Continued mentorship could also help Scholars to achieve better levels of work/life balance. Scholars in this study reported that they were surprised that they faced so many personal challenges while they were in their graduate programs. These challenges included illnesses, breakups and divorces, moving, family problems, and much more. While participating in the McNair Program and completing their undergraduate degrees, Scholars had to maintain a high level of academic performance for up to three terms. This may not have been enough time for Scholars to experience as many personal challenges as they had to deal with in two or three years of graduate school. Mentors might help Scholars balance their workloads and build contingency plans in case emergencies happen, things they did not have time to learn to do during the McNair Program itself.

4. Over time, Scholars came to use more appropriate graduate student role standards as they developed more sophisticated understandings of what it means to be a successful graduate student. Second/third year Scholars habitus seem to have also changed as evidenced by the fact that they were more aware of what can be accomplished in graduate school and beyond.

By the end of the second or third year, Scholars seemed to be aware of and enact the appropriate role standard of graduate student. There is evidence that these Scholars developed a higher level of Differentiated Role Mastery. Their responses demonstrated a greater awareness of the difference between undergraduate and graduate student role standards than the first-year scholars' responses. Second and third year Scholars were no 
longer attempting to enact the undergraduate student role in trying to address graduate student issues.

Second/third year scholars also exhibited relatively higher levels of graduate student expertise. They shared effective strategies for dealing with different graduate student issues that first year Scholars had not yet realized. Second/third year Scholars reported they were now able to employ effective strategies in regard to studying effectively managing time, and prioritizing workloads, issues that first years reported they had no real ideas about how to address. Second/third years also noted that they now realized they needed to balance academic coursework and high levels of rigor with other important aspects of graduate school, such as networking and self-care.

Second/third year Scholars indirectly indicated that their habitus may have changed as well, based on their reports that greater numbers of goal-relevant positions in the higher education field had become visible to them. Second and third year scholars were much more reflexive about their school and program-choice decisions than first year Scholars, and they were more likely to connect those choices to their interests and future occupational goals. These Scholars were also more likely than their first-year Scholar peers to see value in unsuccessful McNair research projects and not-entirely-positive relationships with faculty mentors, and to be able to connect those experiences from McNair to their greater success as graduate students. Further evidence can be found in the different reactions of second/ third year and first year Scholars to the fact that their graduate programs were not as academically rigorous as Scholars had anticipated. First-year Scholars expressed frustration about unmet expectations. Second and third year Scholars reported discovering that other aspects of the graduate student 
role, such as working with faculty in their department or internships, were also important for future success, and that they had shifted their current focus to increasing their experiences in these areas. These Scholars reported they now realized more possibilities for themselves based on their understanding of the field of higher education and their reflections about McNair Program impact.

5. There is no McNair Paradox. McNair does an excellent job of helping underrepresented group students successfully apply to and enroll in graduate programs. While Scholars do not pursue Ph.D.'s at the rate the program initially expected, they are still realizing the goals of the McNair Program. Second/third year Scholars' more sophisticated understanding of what can be accomplished with advanced degrees led many of them to aspire to other positions within the field of higher education. Scholars cared about social justice and paying it forward to students from similar backgrounds in other ways that still helped those students stay in school and complete degrees.

Due to changes in habitus, second and third year Scholars reported that they were aware of more positions available to them in the field of higher education and different ways that they could utilize advanced degrees besides earning Ph.D.'s and becoming professors. They also noted they were now better able to calculate the cost-benefit of earning Ph.D.'s. A doctorate degree became relatively less desirable than they initially thought while in the McNair program as a result of habitus changes and increases in their knowledge of the field. There is a push-pull effect. On one hand, Scholars were being pushed away from Ph.D. attainment based on their "new" knowledge of the dismal numbers relating to Ph.D. employment opportunities, negative reports about the condition 
of the professoriate, and the stressful working conditions of those in tenure-track positions. At the same time, Scholars were pulled in other directions as they became aware of many more occupational opportunities available to them based on their interests and degrees earned.

These Scholars expressed interest in promoting social justice, affecting public policy and "paying it forward" to students and communities like themselves. It seemed that Scholars were finding their own ways to reach McNair Program goals of increasing the social mobility of disadvantaged groups, without having to earn Ph.D.'s to do so. They expressed their desires to work in major policy areas such as energy and education, and to have more direct impacts on their communities, such as opening a community center or working in urban planning, Scholars in this study explicitly stated that they were using the skills they learned in the McNair Program to help other students.

\section{Significance of this Study}

Recent studies of the McNair Scholars Program (Cole \& Barber, 2003; Greene, 2007; Grimmett et al., 1998; Williams, 2004) call for more qualitative information about how first-generation, low-income, and underrepresented students experience McNair Programs and graduate school in order to elicit more in-depth responses from participants. This study, then, will increase the limited qualitative research on this subject.

There are a number of recent studies on the impact of the McNair Program on students at the undergraduate level (Beal 2007, Derk 2007, Greene 2007, Ishiyama 2002, and Lam 2003). Most are from schools of education and are focused on practical solutions for program elements that are seen as requiring improvement. In her interview 
and observation study, Beal (2007) adopted Bourdieu's concept of social reproduction to better understand the ways that McNair Scholars adopt the identity of 'scholar'.

However, the results are analyzed through an educational lens. The current study adds to the larger discussion of the impacts of the McNair Program by employing a theoretical model from Sociology that can better explain identity acquisition through role-asresource theory.

This study also sheds light on what is referred to here as the "McNair Paradox". This apparent contradiction, most clearly noted in Norfles \& Mortenson (2002) as a perplexing increase in graduate enrollment and financial aid attainment but a lack of persistence to Ph.D., may not be such a contradiction at all. There are reasons outside of the McNair Program that may explain why Scholars are getting into graduate programs but are not persisting to Ph.D. In this study, Scholars discussed the ways that McNair was successful in helping them to get into and be successful in graduate programs, and eventually to learn to calculate the relative value of different options available to them beyond school. Scholars in this study reported seeking out ways to use their degrees and the knowledge they've gained to improve their lives and help others like themselves succeed in higher education.

Results from this study could be useful for the McNair Program in understanding the experiences of their students. The results could also be useful to university and student intervention programs regarding student success and increasing student enrollment and retention. It is important for the McNair Scholars Program and intervention programs like it to understand the ways that participants are experiencing and reflecting on their experiences in those programs. 
The vocabulary of role expertise, elaborated in this study, can also be useful for understanding students who are making other higher education transitions. This study identified ways that students mistakenly enacted inappropriate role standards to navigate new educational environments. This frame of reference could be useful for understanding similar issues for students in different types of educational transitions, such as from community college to the university, or from high school to college. As administrators come to better understand that transitioning students' challenges may not be solely based on relatively low levels of ability or confidence, interventions could be implemented that encourage these students to recognize and understand how to more appropriately enact new versions of the appropriate college student role. This study also identified mentorship as a key vehicle for helping students to understand new expectations and avoid critical yet avoidable mistakes in navigating their educational paths.

On a larger scale, this study identified a critical flaw in the fundamental assumptions of the McNair Program goals as well as in the ways that McNair goals are operationalized and measured. The results of this study indicate that the underlying goal of the McNair program, to help under-represented students persist in higher education and complete degrees by creating a supportive academic environment, is being met though not necessarily in the way the McNair Program developers initially thought it would be accomplished. Operationalizing McNair program success as the percentage of Scholars who earn Ph.D.'s is such a narrow focus that it ignores multiple other indicators of how program participation promotes student success. By limiting evaluation to simple measures of graduate program enrollment and degree attainment, the current evaluation approach misses the greater impacts that the Program is having on communities of 
disadvantage. McNair evaluation needs to include measures of the skills that McNair Scholars are learning in the Program, and the way that Scholars are using those skills in graduate school. There also should be measures of the ways Scholars are using their Bachelor's, Master's, and Professional degrees to give back to other students in their communities and to positively impact public policy and issues around social justice.

Using a more inclusive operationalization of McNair success and a broader range of evaluation measures would allow the McNair Program to demonstrate that it really is meeting the underlying goal of increasing the social mobility of college students from historically disadvantaged groups. In addition, future program evaluation efforts should consider trying to capture the intergenerational effects of McNair participation. Current program evaluation does not consider or measure the ways that these Scholars' children are affected by their parents' exposure to higher education or the future social mobility of McNair Scholars' families.

\section{Limitations}

The major limitations of this study are possible sample-bias and the particular academic context in which the research was conducted. With regards to the issue of potential sample-bias, the possibility of self-selection by McNair alumni should be taken into account when considering the findings of this study. Scholars' decisions about whether or not to participate in this study may have been impacted by several different factors. It could be the case that students who choose not to respond to the email request for participation had a different experience in the McNair Program and in their graduate programs than do students who responded. Also, not all McNair Scholars go on to graduate school. It is likely that students who did not apply or who were not accepted to 
graduate programs might have had different understandings of their experiences in the program than those shared by the participants in this study.

The study's particular academic context also should be considered. PSU is a large university with an urban campus. Incoming PSU students are generally older than traditional students, and transfer students outnumber new freshmen by approximately a two to one ratio. These campus demographics may have impacted the characteristics and experiences of the McNair Scholars studied in this research. It is possible that a McNair Program participant from a more traditional campus might have a different experience than a PSU McNair Scholar. McNair Programs at different institutions also vary in duration and level of Scholar funding. The PSU McNair Program for the 2007-2012 funding cycle consisted of a three-term seminar sequence and a culminating facultymentored research project. There have been major changes to the PSU Program since 2012, including STEM initiative that reserves $60 \%$ of McNair "slots" for applicants from those majors and a reduction in funding. With regards to variations in duration, McNair Programs at some other schools are just one term long, while others last as long as two years. While there are universal goals and practices outlined by the Department of Education, because of differences in length and design of the programs, it is possible that scholars in different programs may have different experiences.

\section{Recommendations for Future Research}

There are several suggestions for future research based on the findings, discussions of significance and limitations, and the review of existing literature exploring the McNair Program. These suggestions discuss methods, participants, and outcomes of interest. 
First, more national long-term studies must be conducted. There are only three major national studies of the McNair Program (McCoy et al, 2008; Seburn et al 2005; Norfles \& Mortenson, 2002) and only one of them allowed more than five years for Scholars to achieve Ph.Ds. after bachelor's degree attainment. That study measured Scholars' academic achievements 10 years after degree attainment (McCoy, et all, 2008) and overestimated degree attainment because of low response rate and selection bias of those Scholars located for the study (email correspondence with Russell Jackson, 2013; see chapter two).

Second, longer duration longitudinal studies should be considered. As noted in the literature review, Attawell \& Lavin (2007) found that, when given more time than most Department of Education studies allowed, a larger proportion of women from similarly disadvantaged backgrounds as those of McNair Scholars completed advanced degrees than any previous studies would suggest. It is important to obtain an accurate picture of the real degree attainment of populations that are more likely to have breaks in their educations due to financial burden and outside demands such as needing to care for children or parents and life disruptions such as marital breaks.

Each of the national studies used a quantitative approach while this study used only a qualitative one. Given the insights provided here about the impact of the McNair Program on Scholars over time and Scholars' reported understandings of the decisions they make in higher education, it is clear that qualitative data is important for understanding the lived experiences of participants. However, quantitative studies provide insight about Scholars nationally. Because there are so few studies on the 
Program, a mixed methods approach would be particularly useful in adding to understanding of program impact.

Out of necessity, this study utilized a two-similar-groups-at-two-different-pointsin-time design to understand similarities and differences in Scholars understanding of how McNair participation impacted their graduate school experiences. However an ideal design would be a longitudinal panel study beginning before McNair enrollment that then follows the same Scholars over time as they experience the McNair program, complete their Bachelors' degrees, enter and eventually complete graduate school. This design could provide more information about acquisition of cultural capital, increases in role expertise, and changes in habitus.

Finally, given that the overall goals of McNair have to do with social mobility and providing opportunities to historically disadvantaged groups, a study exploring the children of McNair Scholars could be useful for understanding the intergenerational impact of the Program. This study could mimic Attawell \& Lavin (2007) study, that followed women from disadvantaged backgrounds who enrolled in college under New York's open admissions policies in the 1970's over their lives for up to 30 years. The research included analysis of these women's parenting practices and children's educational outcomes and compared them with a demographically similar sample who had not attended college. This design could be replicated using McNair and a demographically similar comparison group of non-McNair students. This kind of study could be important for understanding the impact of McNair program participation, separate from the impact of college attendance and degree attainment, on historically disadvantaged groups. 


\section{Conclusion}

This study provides insights into one group of McNair Scholars' acquisition of cultural capital through role expertise, and how their habitus is clearly different at different points in time. Scholars increase their breadth and depth of knowledge and experience in the graduate student role over time. These Scholars acquired cultural capital throughout their McNair and graduate school experiences and appear to have learned to enact appropriate graduate student roles around their second or third year of graduate study. As Scholars' knowledge of the field of higher education increased, more positions in the field became visible to them. Their abilities to calculate the path to reach these alternative positions and potential cost-benefit ratios associated with each of these positions also became more accurate. In other words, Scholars' ideas of "what is possible for students like me" and then "what is possible for professionals like me" changed as they learned more and gained experience, indicating a significant change in habitus.

The McNair Program's presumptions about the impact of the McNair Program on participants and future students seem to be based on incomplete information about students' development and knowledge as well as the current realities of these students earning Ph.D.'s and working as professors. There is little to no understanding in studies of the McNair Program of the ways that scholars build a breadth and depth of knowledge and experience from program participation through graduate school or how they build on what they have learned to act appropriately and to be successful after leaving the McNair program. It is important to understand how scholars view their occupational options and opportunities to help other students and how they make decisions based on their calculations of cost-benefit ratios associated with specific paths to future success. 
McNair's assumption that creating professors is the only way to provide a supportive environment and increase the success of underrepresented students in higher education is flawed. There are multiple ways that Scholars can be successful after McNair participation, just as there are many ways these Scholars plan to impact the field of higher education and provide support to future students like themselves.

The scholars in the current study clearly plan to pursue occupations that will have positive influence on their communities. They also desire to help the McNair program and to assist other FLU students. However, these scholars do not intend to earn Ph.D.'s to do so. They perceive the fit between their lives and tenure-track professors as a mismatch and they do not see greater benefit than cost in pursuing Ph.D.'s. The PSU McNair program was certainly instrumental in helping these students enroll and be successful in graduate school. In addition, the program provided a foundation for scholars to do well in graduate school until they became aware of many positions in the field of higher education where they might succeed and help students like themselves. Subsequently, they were able to recalculate their likelihood of success in pursuing each position.

While variation in the rigor of programs is not the focus of this study, this may be a key factor in the differences between the findings of the current study and other studies on the McNair Program. As noted in the review of the McNair Program (see chapter two), there are uneven levels of rigor in McNair programs at different schools, and the PSU McNair program is highly rigorous. Beal (2007) found that scholars in her program struggled in graduate school and eventually pursued non-academic jobs due to poor academic background, problems dealing with level of rigor in research, and cultural 
estrangement. The scholars in the current study did not struggle with academics or research and were able to build enough cultural capital to overcome cultural differences between themselves, their peers, and faculty. This allowed for their habitus to change to the point where they subsequently were able to see additional positions in the field of higher education and to calculate their likelihood of success in pursuing each position. The deficits that Beal's participants faced were actually strengths of PSU McNair scholars because they were able to build upon the cultural capital imported to them by the McNair program to succeed in graduate school. The PSU McNair program is highly competitive and students are already high-achieving undergraduates when they begin the program. This, combined with the opportunities in the program for scholars to build their capital through completing a research project with a mentor, writing and presenting it, and potentially publishing it, provided a solid foundation for scholars to build their role expertise in graduate school. By the end of the second or third year, there were clear differences in Scholars' habitus compared to first-year Scholars. Second and third year Scholars could clearly see and calculate the odds of "what is possible for a professional like me."

While scholars eventually recognized the appropriate graduate student role and their habitus allowed them to see positions in higher education that were not previously visible to them, these scholars would have greatly benefited from receiving more information about the difference between the McNair Program and graduate school. McNair-like mentorship while making school and program-choice decisions and during the first year of graduate study would have been particularly helpful to Scholars. These resources would have provided scholars with a more accurate understanding of their 
relative levels of expertise in the new graduate student role. Some scholars' awareness of occupational options and chances for success may have increased if they had made more informed decisions about graduate school based on information and guidance from McNair-like mentors. Even without additional mentoring, by the second or third year of their graduate programs, scholars built up their knowledge and expertise substantially and had clear views of their career trajectories in pursuit of social justice through avenues other than Ph.D. attainment.

Based on cultural mismatch between scholars and the academy, Beal (2007) recommended that the program expand definitions of "scholar" to include those who seek work in non-academic environments. The current study partially supports this recommendation but does so based on a different theoretical argument. The findings in this study suggest that, with enough cultural capital to build upon, scholars experience changes in habitus that make more positions in higher education visible to them. This suggests that additional outcomes should be measured to gauge actual program impact on the social mobility of disadvantaged groups and the benefit of the program for students and the decisions they make in their career trajectories. The success of the McNair program appears to be grossly misrepresented based on inaccurate indicators that measure only graduate school enrollment and degree attainment. Until program evaluations expand the existing operationalization of program impact to include outcomes in addition to enrollment and Ph.D. attainment, the real impact of the McNair Program will continue to be misunderstood. 


\section{REFERENCES}

Akerheilm. K., J. Berger, M. Hooker, and D. Wise. 1998. "Factors Related to College Enrollment: Final Report." Princeton, N.J.: Final Report to the Office of Planning and Evaluation Services, U.S. Department of Education.

Attawell, Paul, and David Lavin. 2007. Passing the Torch. New York: Sage.

Autor, Katz, \& Kearney. 2008. "Trends in U.S. Wage Inequality: Revising the Revisionists”. Review of Economics and Statistics. 90: 2. p300-323.

Baker, W \& Faulkner, R. 1991. Role as resource in the Hollywood film industry. American Journal of Sociology 97: 279-309.

Beal, Ramona Yvette. 2007. “"You Mean They'll Pay Me to Think?": How Low-Income, First-Generation and Underrepresented Minority McNair Students Construct an Academic Identity as a Scholar.” Dissertation Abstracts International. 68-07. Thesis (Ph.D.)--University of Colorado at Boulder.

Bourdieu, P. 1973. Cultural Reproduction and Social Reproduction. In R. Brown (Ed.). Knowledge, Education, and Cultural Change. London: Tavistock: 71-112.

Bourdieu, P. 1977. Reproduction in Education, Society, and Culture. Thousand Oaks, CA: Sage Publications.

Bourdieu, P. 1984. Distinction: A Social Critique of the Judgment of Taste. (R. Nice, trans). Cambridge, MA: Harvard university Press.

Bradbury \& Mather. 2009. "The Integration of First-year, first-generation college students from Ohio, Appalachia. Journal of Student Affairs Research and Practice $46(2)$.

Calhoun, C. 1993. Habitus, field, and capital: The question of historical specificity. Bourdieu: critical perspectives, 1 .

Callero, Peter. 1994. "From role-play to role-using: Understanding roles as resources." Social Psychology Quarterly 57:228-243.

Campbell, T. A., \& Campbell, D. E. 1997. Faculty/student mentor program: Effects on academic performance and retention. Research in Higher Education, 38(6), 727742. 
Carrera, S. 2002. An Evaluation of the Mentoring Component in the Ronald E. McNair Postbaccalaureate Achievement Program: A National Sample. Doctoral Dissertation.

Cole, S. \& Barber, E. 2003. Increasing Faculty Diversity: The Occupational Choices of High-Achieving Minority Students. Cambridge, MA: Harvard University Press.

Collier, P. J. (2001). "The differentiated model of role identity acquisition." Symbolic Interaction, 24(2), pp. 217-235.

Collier \& Morgan. 2007. “'Is That Paper Really Due Today?': differences in firstgeneration and traditional college students' understandings of faculty expectations." Higher Education

Collier, Morgan, \& Fellows. 2007. "Mentoring as Imported Cultural Capital: A Program to Facilitate First-Generation Students' Transition to the University". Paper prepared for the 102nd Annual American Sociological Association Meetings. New York City, New York.

Crisp, G. 2009. Mentoring College Students: A Critical Review of the Literature Between 1990 and 2007. Research In Higher Education, 50(6), 525-545.

Crowe, M. \& Brakke, D. 2008. Assessing the Impact of Undergraduate Research Experiences: An Overview of the Current Literature. Council on Undergraduate Research. 20(4): 43-50.

Derk, Angela Marie. 2007. Highlighting Hope: An Exploration of the Experiences of West Virginia University McNair Scholars. Doctoral Dissertation. Morgantown, W. Va: [West Virginia University Libraries].

Dixon Rayle, Andrea, Sharon E. Robinson Kurpius, and Patricia Arredondo. 2007. "Relationship of Self-Beliefs, Social Support, and University Comfort with the Academic Success of Freshman College Women." Journal of College Student Retention: Research, Theory \& Practice 8(3):325-43.

Dreyfus, S.E. \& Dreyfus, H. 1982. Mind over machine. New York: Free Press.

Dreyfus, S.E. \& Dreyfus, H. 2005. "Peripheral Vision". Organization studies (01708406), 26 (5), p. 779.

Dumais, S. 2002. Cultural Capital, Gender, and School Success: The Role of Habitus. Sociology of Education, 75(1): 44-68. 
Engstrom, Cathy, and Vincent Tinto. 2008. "Access without Support Is Not Opportunity." Change: The Magazine of Higher Learning 40(1):46-50.

Esler, A. K. (1998). A Texas-wide evaluation of the Ronald E. McNair postbaccalaureate achievement program. Doctoral dissertation, Texas Tech University.

Fischer, Mary Jane. (2007). "Settling into Campus Life: Differences by Race/Ethnicity in College Involvement and Outcomes". The Journal of higher education (Columbus) (0022-1546), 78 (2), p. 125.

Ford, Lunaire. 2011. A Phenomenological Study Exploring the Undergraduate McNair Program Experience of Program Alumni Currently Serving as College Faculty. Dissertation-Loyola University, Chicago.

Greene, Kathleen. 2007. "Alumni Perceptions of the McNair Scholars Program at Kansas Universities.” Doctoral Dissertation. Manhattan, Kan: Kansas State University.

Grimmett, Muriel, James Bliss, Diane Davis, and Louis Ray. 1998. “Assessing Federal TRIO McNair Program Participants' Expectations and Satisfaction with Project Services: A Preliminary Study.” Journal of Negro Education 67 (4):404-415

Hadjioannou, X., Shelton, N.R., Fu, D., Dhanarattigannon, J. 2007. “The Road to a Doctoral Degree: Co-travelers through a perilous passage. College Student Journal 4(1): 160-177.

Hakim, T. (1998). Soft assessment of undergraduate research: Reactions and student perceptions. CUR Quarterly, 18, 189-192.

Hallock, Virginia. 2003. "Perceptions of the professoriate: Anticipatory socialization of undergraduate students from underrepresented groups". Cultural Foundations of Education - Dissertations. Paper 21.

Hathaway, R. S, Nagda, B. R., \& Gregerman, S. R. 2002. The relationship of undergraduate research participation to graduate and professional education pursuit: An empirical study. Journal of College Student Development, 43, 614631.

Hout, Michael. 2012. "Social and Economic Returns to College Education in the United States". Annual review of sociology (0360-0572), 38 (1), p. 379.

Horvat, Erin McNamara. 2001. Understanding Equity and Access in Higher Education: The Potential Contribution of Pierre Bordieu. In Higher Education Handbook Of 
Theory and Research, William G. Tierney, Ed. New York: Agathon Press pp. 195-238.

Hune, Shirley. 2002. "Demographics and Diversity of Asian American College Students". New Directions for Student Services 2002(97).

Hurtado, Sylvia. 2005. "The Next Generation of Diversity and Intergroup Relations Research". Journal of Social Issues 61(3): 595-610

Ishiyama, John. 2007. Expectations and Perceptions of Undergraduate Research Mentoring: Comparing First-Generation, Low-Income White/Caucasion and African American Students. College Student Journal. 41(3): 510-520.

Ishiyama, John and Valerie Hopkins. 2002. "Assessing the Impact of a Graduate School Preparation Program on First-Generation, Low-Income College Students at a Public Liberal Arts University." Journal of College Student Retention: Research, Theory, and Practice 4 (4):393-405.

Jacobi, M. (1991). Mentoring and undergraduate academic success: A literature review. Review of Educational Research, 61, 505-532

Kardash, C. M. 2000. Evaluation of an undergraduate research experience: Perceptions of undergraduate interns and their faculty mentors. Journal of Educational Psychology, 9, 191-201.

Kazey, Adrianna \& Maxey, Daniel. 2013. "Changes in the Academic Workforce”. Trusteeship magazine 3(21).

Lam, Paul C, Okechukwu Ugweje, Ruby P. Mawasha, Tirumalai Srivatsan. 2003 “An Assessment of the Effectiveness of the McNair Program at the University of Akron." Journal of Women and Minorities in Science and Engineering 9(1):70.

Lareau, A. \& Horvat, E. 1999. Moments of Social Inclusion and Exclusion Race, Class, and Cultural Capital in Family-School Relationships. Sociology of Education 72(1): 37-53.

Leichnitz, R. 2006. Self-identification of non-cognitive factors that lead to educational success. Doctoral dissertation, University of the Incarnate Word.

Lopatto, D. (2004). Survey of undergraduate research experiences (SURE): First findings . Cell Biology Education, 3, 270-277.

Loppatto, D. 2007.Undergraduate research experiences support science career decisions and active learning. CBE-Life Sciences Education, 6(4), 297-306. 
McCormick, A.C., Nuñez, A., Shah, V., and Choy, S.P. (1999). Life After College: A Descriptive Summary of 1992-93 Bachelor's Degree Recipients in 1997, With an Essay on Participation in Graduate and First-Professional Education (NCES 1999155). U.S. Department of Education. Washington, DC: National Center for Education Statistics.

McCoy, Wilkinson \& Jackson. 2008. Education and Employment Outcomes of the Ronald E. McNair Post baccalaureate achievement program alumni. Washington DC. US Department of Education.

National Center for Education Statistics. 2011. Integrated Postsecondary Education Data System (IPEDS) Spring 2011, Enrollment component.

National Center for Education Statistics. 2013. Digest of Education Statistics: 2012. NCES 2014-15. U.S. Department of Education. Table 502.30.

Neville \& Chen. 2007. The Path Through Graduate School: A Longitudinal Examination 10 Years After Bachelor's Degree. US Department of Education.

Nnadozie, E., J. Ishiyama, J. Chon. 2001. Undergraduate Research Internships and Graduate School Success. Journal of College Student Development. 42(2): 145156.

Norfles, N \& Mortenson, T. 2002. Financing the First Year of Graduate School: A Study of TRIO Ronald E. McNair Post-baccalaureate Achievement Alumni. Washington DC: The Pell Institute for the Study of Opportunity in Higher Education.

Parker, Keith D. 2003. Achieving Diversity in Graduate Education: Impact of the Ronald E. McNair Postbaccalaureate Achievement Program.” Negro Educational Review 54: 47-50.

Pascarella, E. T., \& Terenzini, P. T. (2005). How college affects students: Findings and insights from 20 years of research. San Francisco, CA: Jossey-Bass.

Perna, Laura W. (2005). "The Benefits of Higher Education: Sex, Racial/Ethnic, and Socioeconomic Group Differences". Review of higher education (0162-5748), 29 (1), p. 23.

Perry, G., Moore, H., Edwards, C., Acosta, K, \& Frey, C. 2009. Maintaining Credibility and Authority as an Instructor of Color in Diversity-Education Classrooms: A Qualitative Inquiry. The Journal of Higher Education, 80(1): 80-105. 
Portland State University. 2008. Ronald E. McNair Scholars Program: PSU Scholars Home. Retrieved February 5, 2013.

(https://sites.google.com/site/psumcnairscholars/home/).

Rendon, Laura. 1994. Validating Culturally Diverse Students: Toward a New Model of Learning and Student Development. Innovative Higher Education 19(1).

Ross, Catherine, and John Mirowsky. 1999. "Refining the Association between Education and Health: The Effects of Quantity, Credential, and Selectivity." Demography 36:445-60.

Russel, S., M. Hancock, J. McCullough. 2007. The Pipeline: Benefits of Undergraduate Research Experiences. Science Magazine. 316(5824): 548-549.

Seburn, Chan \& Kirshstein. 2005. A Profile of the Ronald E. McNair Postbaccalaureate Achievement Program: 1997-1998 through 2001-2002. Washington DC: US Department of Education.

Schuster \& Finkelstein. 2006. The American Faculty. Johns Hopkins University Press.

Thayer, Paul. 2000. Retention of Students from First-Generation and Low-Income Backgrounds. Department of Education, Washington DC: TRIO Clearinghouse. Retrieved from http://files.eric.ed.gov/fulltext/ED446633.pdf on October 26, 2013.

Tinto, V. 1975. Dropout from higher education: a theoretical synthesis of recent research. Review of Educational Research 45: 89-125.

Torche, Florencia. 2011. Is a College Degree Still the Great Equalizer? Intergenerational Mobility across Levels of Schooling in the United States. American Journal of Sociology. Vol. 117 (3): 763-807

TRIO McNair Postbaccalaureate Achievement Assessment. 2006. Washington, DC: U.S. Department of Education.

Turner, R. 1956. Role-Taking, Role Standpoint, and Reference-Group Behavior. American Journal of Scoiology 61(4): 316-328.

Umbach, Paul D. 2006. "The Contribution of Faculty of Color to Undergraduate Education". Research in higher education (0361-0365), 47 (3)

US Census Bureau. 2010. Overview of Race and Hispanic Origin: 2010.

U.S. Department of Education. (2011). Ronald E. McNair Postbaccalaureate Achievement Program.http://www2.ed.gov/programs/triomcnair/index.html. 
US Department of Education. 2013. RONALD E. MCNAIR POSTBACCALAUREATE ACHIEVEMENT PROGRAM.. Retrieved July 17, 2013 at http://www2.ed.gov/programs/triomcnair/index.html

US Department of Health and Services. 2007. HHS Poverty Guidelines. Retrieved August 16, 2013 at http://aspe.hhs.gov/poverty/07poverty.shtml

US Department of Health and Services. 2012. HHS Poverty Guidelines. Retrieved August 16, 2013 at http://aspe.hhs.gov/poverty/12poverty.shtml

Vance, M. L. 1993. A study of perceptual changes on the part of students with respect to their decisions to pursue graduate studies. Doctoral dissertation, Michigan State University, Ann Arbor, Michigan.

Williams, E. G. 2004. Academic, research, and social self-efficacy among African American pre-McNair Scholar participants and African American post-McNair Scholar participants. Ph.D. dissertation, Virginia Polytechnic Institute and State University.

Willison, S. \& Gibson, E. 2011. "Graduate School Learning Curves: McNair Scholars' Postbaccalaureate Transitions". Equity \& excellence in education. 44 (2). 


\section{Appendix: Interview Guide}

Follow-up/probe questions were used for clarification and elaboration.

1. Tell me about your current program.

2. Tell me about how you ended up in this program.

- Once you started, was the program what you expected?

- (for second year) Have your expectations of the program changed from the first to the second year?

- (for second year) Have your expectations of yourself changed in the second year?

3. How do you feel about your graduate experience so far?

- How do you feel about yourself as a student now?

- (for second/third year) has this changed since the first year?

4. Tell me about issues you encountered in the first year of your program? (list)

for each issue:

- How did you deal with this issue?

- how did you resolve this problem;

- what did you do? Is this still an issue?

- Did you try any other ways to deal with this issue?

- Would you have done things differently then, knowing what you know now?

4a. Were your McNair experiences helpful in dealing with this issue?

4b. (for second and third year students) What issues have you encountered in the second/third year of your program? (list)

for each issue:

- How did you deal with this issue?

- how did you resolve this problem;

- what did you do? Is this still an issue?

- Did you try any other ways to deal with this issue?

- Would you have done things differently then, knowing what you know now?

4c. Were your McNair experiences helpful in dealing with this issue?

5. What do you think it takes to be a good student in your current graduate program? 
- How do you know? How did you find out about this?

- Did any of your McNair experiences help you to reach that understanding?

- (for second/third year) Has your understanding of this changed since your first year? How?

Now I want to talk about your undergraduate experiences...

6. So think back before McNair, tell me about what you remember your goals were.

- Had you considered going to graduate school? (if so) what kind of program?

- What were your expectations about grad school?

- What job did you want after graduation?

- How did you feel about yourself as a student?

7. Thinking back on what you told me, how have your goals changed?

- Tell me how your McNair experiences impacted your goals.

Now think about when you started McNair...

8. Tell me about how you found out about McNair

9. Tell me about your McNair project

10. In what ways did the McNair Program prepare you for the first year only of your graduate study?

(probes, if not specifically mentioned)

- getting in / filling out the forms/applying for things

- conducting research

- working with faculty in grad student role / equal partner in research

- presenting at professional meetings

- is there anything else?

10a. (for second year) In what ways did the McNair Program prepared you for the second/third year of your graduate study?

(probes, if not specifically mentioned)

- getting in / filling out the forms/applying for things 
- conducting research

- working with faculty in grad student role / equal partner in research

- presenting at professional meetings

- is there anything else?

11. How do you feel about your McNair experience?

12. Imagine that you are talking to a new McNair Scholar who is like you. You can give them any advice about how to take advantage of the McNair Program to prepare for grad school. What would you tell them?

- (if multiple) What is the most important piece of advice?

13. Now imagine that you get to sit down with Jolina and help make the program better to prepare students for grad school. If you could make any recommendations to the McNair Program about how to better prepare students for graduate school, what would you tell them?

- (if multiple) What is the most important recommendation?

14. Would it be okay with you if I contact you to follow up with any other questions?

15. Do you know any PSU McNair Scholars who are in grad school who might want to participate in this study? 